\title{
Errol Bouchette
}

(1903)

\section{Mémoires de \\ Robert-S.-M. Bouchette (1805-1840)}

Un document produit en version numérique par Mme Marcelle Bergeron, bénévole Professeure à la retraite de l’École Dominique-Racine de Chicoutimi, Québec et collaboratrice bénévole

Courriel : $\underline{\text { mailto: mabergeron@videotron.ca }}$

Dans le cadre de la collection : "Les classiques des sciences sociales" dirigée et fondée par Jean-Marie Tremblay, professeur de sociologie au Cégep de Chicoutimi

Site web : http://classiques.uqac.ca/

Une collection développée en collaboration avec la Bibliothèque Paul-Émile-Boulet de l'Université du Québec à Chicoutimi

Site web : http://classiques.uqac.ca 
Un document produit en version numérique par Mme Marcelle Bergeron, bénévole, professeure à la retraite de l'École Dominique-Racine de Chicoutimi, Québec courriel : mailto:mabergeron@videotron.ca

Une édition électronique réalisée à partir

\section{Robert-S.-M. Bouchette}

\section{Mémoires de Robert-S.-M. Bouchette (1804-1840) recueillis par son fils Errol Bouchette, et annotés par A.-D. Decelles, Docteur ès lettres, membre de la Société Royale du Cananda, Conservateur de la Bibliothèque du Parlement.}

Montréal, La Cie de publication de la Revue canadienne. 1903, 129 pp.

Polices de caractères utilisés :

Pour le texte : Times, 12 points.

Pour les citations : Times 10 points.

Pour les notes de bas de page : Times, 10 points.

Édition électronique réalisée avec le traitement de textes Microsoft Word 2004 pour Macintosh.

Mise en page sur papier format

LETTRE (US letter), 8.5’’ x 11’’)

Édition complétée le 30 juillet, 2006 à Chicoutimi, Québec. 


\section{Robert-S.-M. Bouchette}

\section{MEMOIRES DE \\ ROBERT-S.-II. BOUCHETTE}

$1805-1840$

Recueillis par son fils ERROL BOUCHETTE

$-\mathrm{Er}-$

Annotés par A.-D. DECELLES

Doeteur is lettres, membre de is Sockub Royale da Canals, Coaservateur de is Bibliothicye da Parkement.

LA CIE DE PUBLICATION DE LA REVUE CANADIENNE Montréal, Canada 


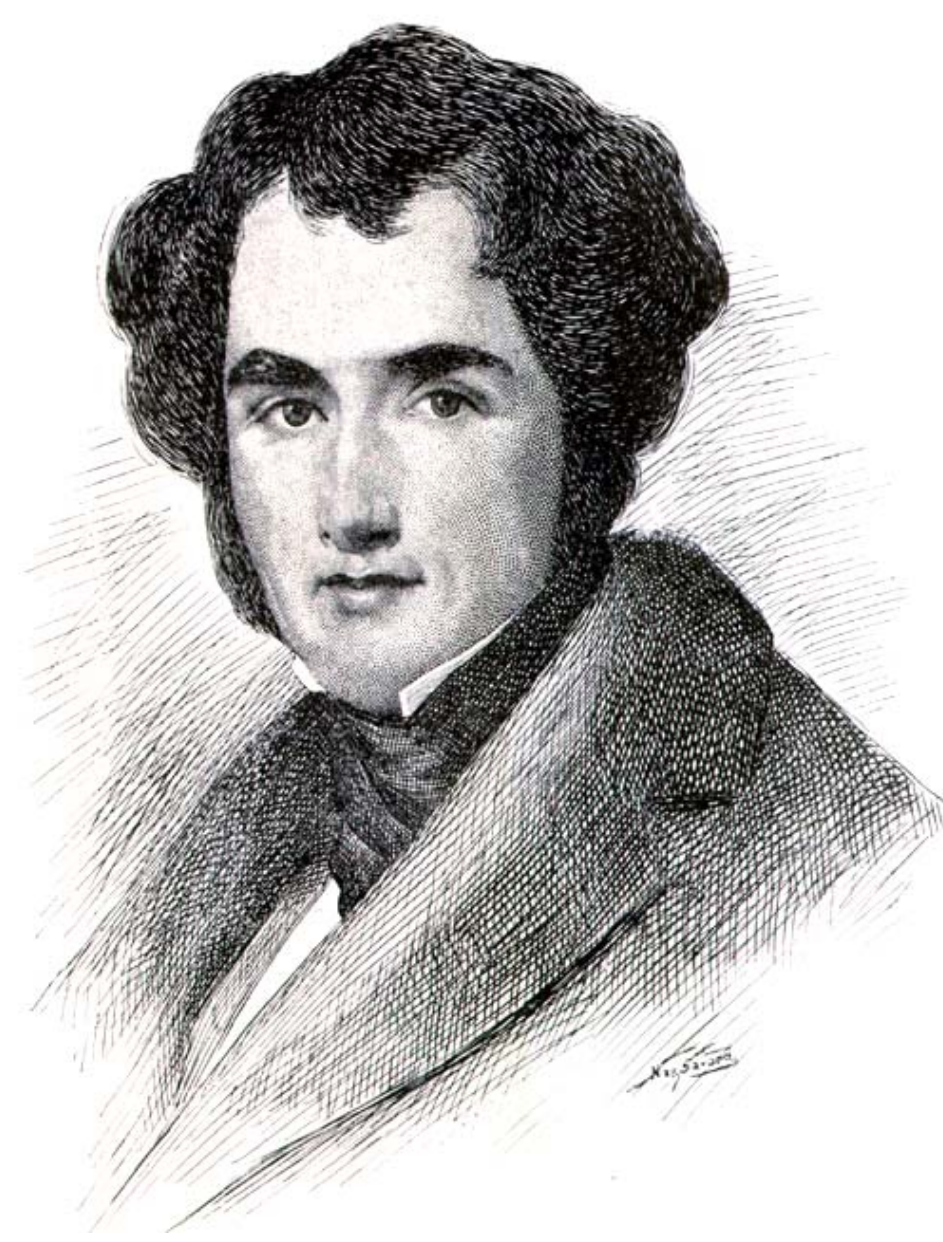

\section{ROBERT S. M. BOUCHETTE}

D’APRÈS UN PORTRAIT PEINT PAR ARMINIUS MEYER, EN 1830 


\section{Table des matières}

Esquisse biographique, par A.-D. De Celles.

Chapitre I: $\quad$ Ma famille - mes débuts.

Chapitre II : Un incident.

Chapitre III : $\quad$ Voyage à Londres - publication des œuvres géographiques de Bouchette - présentation au roi à la duchesse de Kent et à la princesse Victoria.

Chapitre IV : $\quad$ La société de Londres en 1830 - lord Sidmouth - le salon de Madame Skinner - tournoi avec le Prince LouisNapoléon - une lettre de Lord Harrington.

Chapitre V: Obsèques de George IV - couronnement de Guillaume IV - coup d'œil général sur cette époque.

Chapitre VI: $\quad$ Un voyage en Italie - mariage à Douvres - un événement tragique.

Chapitre VII : Quelques mots sur l'agitation politique antérieure au mouvement insurrectionnel.

Chapitre VIII : $\quad$ Le district de Montréal en novembre et décembre 1837.

Chapitre IX: Combat de Moore's Corner.

Chapitre X: $\quad$ Observation de ce qui précède.

Chapitre XI : Les prisonniers transportés à l'Île au Noix, puis à Montréal - contraste entre les volontaires et les troupes régulières les prisons de Montréal - pauvre Dick.

Chapitre XII : $\quad$ Une correspondance qui a une valeur historique.

Chapitre XIII: Négociations entamées par lord Durham - attitude de 8 prisonniers - ils consentent à l'exil pour procurer la libération des autres prisonniers.

Chapitre XIV : Départ pour l'exil.

Chapitre XV: $\quad$ Le voyage sur la Vestal.

Chapitre XVI: L'arrivée.

Chapitre XVII : Document rédigé à bord de la « Vestale ».

Chapitre XVIII : Séjour aux Bermudes - retour.

Chapitre XIX: Quelques détails sur la carrière subséquente de l'auteur.

Chapitre XX: Le gouvernement responsable est l'œuvre des Canadiens. 
Enregistré conformément à l'acte du Parlement du Canada en l'année mil neuf cent trois, par M. Errol Bouchette au ministère de l'Agriculture. 


\title{
MÉMOIRES DE ROBERT-S.-M. BOUCHETTE 1805-1840
}

\author{
RECUEILLIS PAR SON FILS ET ANNOTÉS PAR A.-D. DECELLES \\ Docteur ès lettres, membre de la Société Royale du Canada, \\ Conservateur de la Bibliothèque du Parlement.
}

OTTAWA, 15 mai, 1903.

\begin{abstract}
À Monsieur A.-D. DECELLES, Docteur ès lettres,

Membre de la Société Royale du Canada et Conservateur de la Bibliothèque du Parlement.
\end{abstract}

Mon cher monsieur DeCelles,

Pendant de longues années les mémoires de mon père sont restés inédits. Cela tient à plusieurs causes.

En Premier lieu, ils sont incomplets. Des notes assez suivies permettent bien de reconstituer le récit aux endroits où l'auteur lui-même n'en a pas terminé la rédaction; mais cela exige un travail considérable et une connaissance intime du sujet.

Puis, ces mémoires, rédigés partie en français, partie en anglais, exigent le travail de la traduction dans quelque langue qu'on les publie. Mon père avait l'intention de les publier dans les deux langues, qui lui étaient également familières.

Malgré toutes ces difficultés, vous avez bien voulu parcourir le manuscrit, et vous me confirmez dans l'opinion qu'il est d'une valeur historique incontestable. 
En ce moment où les relations du Canada avec la métropole, sont de nouveau discutées, il ne sera pas inutile de mettre sous les yeux du lecteur quelques pages de la genèse du gouvernement responsable colonial; sans parler de la rareté extrême de mémoires en Canada, et de l'attrait qu'offre tout écrit racontant en détail ce qui se passait il y a trois quarts de siècles.

Je me suis donc mis à l'œuvre, j'ai transcrit et j'ai traduit. J'ai même dû, en certains endroits, prendre la parole, mais en le faisant, je crois être resté fidèle aux idées et, aux sentiments de l'auteur, lequel se plaisait, pendant mon enfance, à m'instruire par le récit des incidents de sa vie si mouvementée, si pleine et si honorable.

Le résultat de mon travail est devant vous. L'œuvre de piété filiale est accomplie, en autant que mes faibles moyens me permettent de l'accomplir. J'ose espérer que vous voudrez bien y ajouter les éclaircissements et les réflexions que vos études et votre connaissance profonde des hommes et des choses de ce temps pourront vous suggérer.

Veuillez agréer par avance l'expression de ma reconnaissance et de mon dévouement. 


\section{ESQUISSE BIOGRAPHIQUE}

«La révolte de 1837, dirigée non contre
l'Angleterre, mais contre la mauvaise
administration coloniale, était parfaitement
justifiable. »

LORD STRATHCONA \& MOUNTROYAL.

\section{$\underline{\text { Retour à la table des matières }}$}

Robert-S.-M. Bouchette, dont la Revue Canadienne publie les Mémoires, était fils du colonel Joseph Bouchette, qui a laissé un nom célèbre dans notre histoire. Après avoir servi dans les guerres de 1775 et de 1812 avec une distinction qui lui valut les éloges et l'amitié de lord Dorchester, du duc de Kent et de sir George Prévost, il consacra son temps à des ouvrages de topographie et de géographie, monuments impérissables de science. On peut regarder comme le premier des géographes canadiens l'auteur de la Description typographique du Bas-Canada (dont il existe aussi une édition anglaise), et de British Dominions in North America, que la bienveillance du roi Guillaume IV contribua à faire publier. Sir George-Étienne Cartier, parlant un jour à la Chambre d'Assemblée, à Québec, lui rendit ce témoignage d'estime : «Un homme éminemment distingué, $\mathrm{M}$. Joseph Bouchette, avait tout fait pour la topographie et la géographie du pays. Cet homme devançait véritablement son siècle, chez nous. Il fournit au public une masse d'informations, qui sont demeurées la base des connaissances géographiques en Canada.

«Cet homme de grands talents, qui était à la gêne, s'adressa à la législature ; mais il ne put obtenir d'aide. Il avait fait la connaissance du duc de Kent. Celui-ci le dirigea vers l'Angleterre et grâce à sa protection, il put publier ses trois volumes, dont on reconnaît aujourd'hui le prix infini et qui ont été le signal du développement des ressources du pays. »

M. Bouchette devint l'ami de tous les gouverneurs de son temps, et lorsque l'auteur des Mémoires que l'on va lire, vint au monde, le gouverneur sir RobertShore Milnes consentit à être son parrain et il lui donna au baptême ses noms et prénoms. Comme son père, Bouchette fut très répandu dans la société anglaise dont il partageait les goûts et les aspirations. À ce titre, nous pouvons dire qu'il était plutôt Anglais que Canadien. Il convient, ce semble, de souligner cette attitude spéciale de l'auteur des Mémoires pour donner plus de 
force à la position qu'il prit plus tard à côté de Papineau. Dans une lettre qui constitue un des documents les plus probants à l'appui de la justification de la réclamation des Canadiens, il explique pourquoi il quitta soudain le camp des bureaucrates pour passer (1834) à celui des Canadiens. Assez indifférent jusqu'alors à la politique, il fut pris d'indignation en voyant que le gouvernement anglais nous enlevait, au moyen des fameuses résolutions de lord John Russell, les derniers vestiges d'autorité au Parlement. On le vit dès lors se jeter, corps et âme, au milieu des agitations qui trouvent leur point culminant dans les mauvais jours de novembre et décembre 1837.

Au moment où $\mathrm{W}$. Nelson organisait la résistance, il se mit à la disposition de ce dernier, qui lui confia la mission de passer aux États-Unis pour organiser un corps de troupes destinées à opérer sur la frontière. Bouchette exécuta cet ordre, revint au Canada et rencontra l'ennemi à Moore's Corners, où il tomba aux mains des soldats de Colborne. Il passa quelques mois dans la prison de Montréal, avant d'être exilé aux Bermudes avec W. Nelson, Masson, Viger, Gauvin, DesRivières, Goddu et Marchessault. Après le désaveu de l'ordonnance de Durham qui l'avait frappé, ainsi que ses compagnons, Bouchette rentra au Canada où il exerça pendant quelques années sa profession d'avocat à Montréal et à Toronto, en société avec M. de Salaberry. Plus tard il accepta la charge de directeur du département des Douanes, qu'il occupa jusqu'à sa mort. Ce ministère lui doit son organisation. En 1867, il eut l'honneur de représenter, avec J.-C. Taché, le Canada à l'exposition universelle de Paris. Il lut dans un des congrès tenus dans cette ville à ce moment, un Mémoire fort remarqué sur l'unification des monnaies et aussi des poids et des mesures basée sur le système métrique.

Il a laissé à Ottawa et à Québec le souvenir d'un homme de talent, ayant conservé de son origine française une grande vivacité et une élégance de manières qui le faisaient rechercher dans la société. Les souvenirs personnels sur les événements de «37 » ne sont pas nombreux; c’est cette rareté qui ajoutera un intérêt de plus aux Mémoires de M. Bouchette.

A.-D. DE CELLES. 


\section{MÉMOIRES DE R.-S.-M. BOUCHETTE}

\section{$\underline{\text { Retour à la table des matières }}$}

Ce ne sont pas à proprement parler, des mémoires que je me propose d'écrire. Cependant, ma carrière a été accidentée, et s'il est vrai, comme l'a dit un auteur dont j'oublie le nom, qu'il n'est pas d'existence humaine si vide qu'on n'en puisse tirer quelque enseignement, la mienne ne sera pas dépourvue d'intérêt. J'esquisserai donc, brièvement, dans les pages qui vont suivre, les principaux événements de ma vie, espérant qu'ils pourront servir à l'instruction future de mes chers enfants, qui sont tous encore en bas âge ${ }^{1}$. 


\section{CHAPITRE I.}

\section{MA FAMILLE - MES DÉBUTS.}

$\underline{\text { Retour à la table des matières }}$

Mon grand-père, Jean-Baptiste Bouchette, commandait l'escadre sur les grands lacs ou les mers intérieures du Canada. Officier consciencieux et intrépide, le seul Canadien, depuis d’Iberville, qui ait commandé en chef une flotte de guerre, l'histoire et les romains historiques nous ont conservé le souvenir de quelques-uns de ses exploits ${ }^{1}$. Il mourut avant ma naissance.

Mon père est bien connu pour ses travaux géographiques, scientifiques et littéraires. On a publié sur lui, depuis sa mort, de nombreuses notices biographiques ${ }^{2}$. Il était d'un caractère chevaleresque et l'honneur incarné.

Quoique très occupé par ses travaux, il n'avait pas les impatiences des hommes absorbés ; il se montrait toujours, au contraire, doux et charitable dans sa vie de tous les jours.

1 a. Voyages du duc de La Rochefoucault-Liancour en Amérique, 1787.

b. Les Bastonnais, J. Lespérance.

c. La note suivante adressée par S. A. R. le duc de Kent au commodore Bouchette fera voir quel cas on faisait de ses services.

« Kensington Palace, March $9^{\text {th }}, 1802$.

Captain Dodd, Military Secretary and Aide-de-Camp to the Duke of Kent, is commanded by His Royal Highness to inform Captain Bouchette that conceiving it might be an object of great convenience to him to retire from his present laborious situation, provided he could be permitted to retain his whole pay, as his retreat ; the Duke has taken an opportunity of sounding the Lords of the Treasury upon the subject, and has reason from their answers to think that if a Memorial were presented from Captain Bouchette, stating his long and faithful services and advanced age, and praying leave to retire upon his full pay, it would be attended with success.

« His Royal Highness has therefore instructed Captain Dodd to make the circurnstance known to Captain Bouchette and to acquaint him that if he feels disposed to solicit his retreat on these terms and to memorialize the Lords of the Treasury to that effect, it will only be necessary for him to transmit his Memorial to His Royal Highness, under cover to the Secretary at War, and he may depend upon its being presented with every recommendation and meeting with every support which the Duke can give it.

« Captain BOUCHETTE,

« Commanding His Majesty's armed vessels on Lake Ontario,

« Kingston, U. Canada. »

2 Portraits de Canadiens célèbres, W. Notman, partie VIII. - Notice biographique écrite par Fennings Taylor, Lovell, Montréal, 1865.

Voir aussi Bibliotheca Canadensis et autres compilations de M. Henry J. Morgan. 
Ma mère bien-aimée était la seconde des quatre filles de Charles Chaboillez, un des associés de la fameuse compagnie du Nord-Ouest. L'aînée, Marguerite, épousa Simon McTavish, le chef de cette même compagnie ; la seconde, Marie-Louise-Adélaïde, mon père ; la troisième, Rachel, l'honorable Roderick MacKenzie, seigneur de Terrebonne et membre du Conseil Législatif du Bas-Canada ; la quatrième, Charlotte, entra dans la vie religieuse et mourut au couvent de l'Hôtel-Dieu, à Montréal.

Ma mère avait lu beaucoup et bien, tant en anglais qu'en français. Ses lettres étaient des modèles du style épistolaire familier. Elle chantait avec beaucoup d'expression et d'une riche voix de mezzo-soprano. Petite plutôt que grande, sa taille était d'une symétrie parfaite. Ses cheveux noirs et abondants étaient toujours très soignés, ses yeux noirs et expressifs, frangés de longs cils sous des sourcils bien marqués, éclairaient un visage intelligent, aux traits très fins et au teint clair et délicat. Telle était ma mère, et je parle d'elle le cœur débordant d'amour et de reconnaissance à la pensée de sa tendresse et de son dévouement sans bornes pour ses enfants. Elle est morte à Montréal, à l'âge de 67 ans, en 1848. Ses cendres vénérées reposent à côté de celles de mon père dans l'église Notre-Dame, à Montréal. Leurs enfants ont érigé à leur mémoire un monument dans le cimetière de la Côte-des-Neiges.

Je suis né jeudi, le douze mars, 1805, dans la maison qui forme l'angle occidental des rues St-Louis et du Parloir, à Québec. Mon père occupait alors la charge d'arpenteur-général du Bas-Canada. Il jouissait de la confiance officielle et de l'amitié personnelle du lieutenant-gouverneur, sir Robert-Shore Milnes ; c'est probablement à cette circonstance que je dois d'avoir eu celui-ci pour parrain et de porter son nom. Je fis mes études sous la direction du révérend docteur Wilkie, un lettré et un excellent professeur. Avant seize ans j'avais commencé l'étude du droit en qualité de clerc dans le bureau de $\mathrm{M}$. Andrew Stuart, un ami de mon père et un des hommes les plus remarquables du barreau canadien. Mes cinq années de cléricature sous un directeur aussi éclairé, ne furent pas perdues. Outre le droit, auquel je m'appliquai avec ardeur, j'étudiai l'histoire, les lettres et les mathématiques ; cette dernière étude surtout était pour moi une récréation. Je cultivai aussi l'italien; avant la fin de ma cléricature, je pouvais lire dans le texte Consolato del mare. Mon patron, $\mathrm{M}$. Stuart, ainsi que son associé, M. Henry Black, plus tard juge de la cour de viceamirauté du Canada, un homme supérieur aussi, s'occupaient surtout du droit maritime. Je partageais leur goût pour cette branche du droit; aussi est-ce devant la cour de vice-amirauté que j'ai peut-être plaidé le plus souvent. Je fus admis à la pratique du droit le 15 mars 1826. J'avais vingt et un ans. 


\title{
CHAPITRE II
}

\author{
UN INCIDENT.
}

Retour à la table des matières

Un incident inattendu était venu interrompre pendant quelque temps mes études. Par une froide après-midi de décembre 1823, mon excellent père en revenant de son bureau, m'annonça que le gouverneur-général, le comte de Dalhousie, m'avait choisi, en qualité d'assistant du capitaine Pears, du Royal staff corps, pour copier les cartes de la frontière entre les États-Unis et le Canada, sous les articles quatrième et cinquième du traité de Gand. Ces cartes étaient entre les mains des Commissaires réunis à New-York ; c'était là qu'il fallait les copier. Cette nouvelle me remplit de joie. Outre mon goût naturel pour le dessin et la cartographie, j'étais tourmenté, comme la plupart des jeunes gens, par le désir des voyages. Aussi me sembla-t-il qu'une ère nouvelle allait s'ouvrir pour moi.

La diligence me transporta jusqu'à Montréal où je rencontrai le capitaine Pears à l'hôtel Rasco. Nous ne nous connaissions pas. J'étais porteur de nos instructions et des lettres de créance que nous devions présenter à notre arrivée à New-York. Je remis ces dépêches à mon chef avec toute la solennité d'un ambassadeur, et quarante-huit heures après nous étions en route pour la métropole commerciale des États-Unis. Le capitaine Pears pouvait avoir trentecinq ans, il était de taille moyenne et blond, d'un abord courtois, mais froid, il n'offrait pas sa main, il se la laissait prendre. Ce trait indique presque toujours un caractère prudent ; aussi, malgré ma jeunesse, j'en conclus que je serais un second Télémaque entre les mains d'un sage Mentor.

De notre trajet jusqu'à New-York je ne dirai rien, si ce n’est que, voyageur inexpérimenté, je m'étais encombré d'un bagage inutile. Si nous avions été au temps d'Alfred-le-Grand où même les bourses d'or jetées sur les routes ne tentaient pas les passants, j'aurais pu retracer mes pas en suivant les objets que j'avais semés sur notre parcours. Mais le chemin de fer et le télégraphe ont maintenant changé tout cela. 
Washington Hall, Broadway, était alors l'hôtel par excellence. Nous y descendîmes. Après que nous eûmes présenté nos lettres de créance au colonel Barclay, le commissaire britannique et à M. Buchanan, le consul d'Angleterre, on nous remit les cartes que nous devions copier, et nous comprîmes en les examinant que notre travail nous occuperait pendant une bonne partie de l'hiver. Ayant retenu à l'hôtel un local convenable, nous nous mîmes harmonieusement à l'œuvre. Les cartes, grandes et petites, étaient au nombre de vingt-cinq. En travaillant consciencieusement six heures par jour (nous ne pouvions dessiner après le coucher du soleil, à cette époque où l'éclairage était difficile et dispendieux), nous terminâmes notre tâche en un peu moins de trois mois. Notre travail ne nous absorbait pas au point de nous faire négliger nos devoirs sociaux, et les distractions ne nous manquaient pas. Il arrivait souvent que nous assistions dans une même soirée à un dîner, à un concert et à un bal. Je pourrais ici raconter plus d'un épisode intéressant, mais je me suis déjà trop écarté de l’ordre chronologique de mon récit. 


\title{
CHAPITRE III
}

\author{
VOYAGE À LONDRES - PUBLICATION DES EUVRES \\ GÉOGRAPHIQUES DE BOUCHETTE - PRÉSENTATION AU ROI, À LA \\ DUCHESSE DE KENT ET À LA PRINCESSE VICTORIA.
}

\section{$\underline{\text { Retour à la table des matières }}$}

Pendant les deux années qui suivirent mon admission à 1a pratique du droit, je me consacrai avec ardeur à ma profession et je pus me convaincre que je ne m'étais pas trompé sur ma vocation. Je remportai des succès dans deux causes importantes devant la cour de vice-amirauté et j'adressai plusieurs fois la parole au jury dans des procès au criminel.

Cependant mon père travaillait sans relâche à la réalisation de son grand projet de doter son pays d'une édition nouvelle et beaucoup plus considérable de son œuvre géographique. Il me demanda de lui aider à recueillir les matériaux dont il avait besoin. Comme il tenait à puiser chaque renseignement à sa source même, nous eûmes à visiter tous les établissements des deux Canadas, les nouveaux comme les anciens, les colonies lointaines comme les centres plus rapprochés. Nous collectionnions des cartes locales pour les compiler à loisir, nous prenions en note de nombreuses et de précieuses statistiques. Partout où nous allions nous trouvions les gens non seulement pleins de bonne volonté, mais préparés à nous renseigner, car mon père annonçait ses tournées d'avance par la voie des journaux, en priant les personnes qui pouvaient le renseigner de lui procurer certaines données qu'il spécifiait. Il avait aussi distribué dans tous le pays des circulaires imprimées dans le même but. Cette méthode, parait-il, était celle que mon père avait adoptée pour son premier ouvrage publié en 1815, sous les auspices de l'Assemblée législative du Bas-Canada. L'Assemblée s'était engagée, par une résolution adoptée à l'unanimité, à solder les frais de publication de cette œuvre nationale, jusqu'à concurrence de la somme de £1,500. Pourtant, un tiers seulement de cette somme fut payée, quoique, par une singulière contradiction, 
la légitimité de la réclamation ait été maintes fois et à différentes époques reconnue dans l'enceinte du Parlement ${ }^{1}$.

La dette était claire et incontestable. Malheureusement la demande de paiement fut faite dans un moment de violente agitation politique. Mon père, en sa qualité d'arpenteur-général, appartenait à la classe des bureaucrates, que la majorité de l'Assemblée tenait en aversion. L'auteur des cartes et de la description géographique du Canada était cité en toute occasion comme un puits de science et un prodige de persévérance et d'application ; on vantait l'excellence, l'importance et la beauté artistique de son ouvrage. Mais les $£ 1,500$ votés par toute la Chambre et sur lesquels il avait compté pour rencontrer les dépenses de son entreprise ne lui furent jamais entièrement payés.

Mais c'est là une digression. J'étais sur le point de dire un mot de notre départ pour l'Angleterre où mon père devait publier son second ouvrage sur l'Amérique Britannique. Le 29 septembre 1829, par une radieuse journée, nous nous embarquâmes sur un très beau navire, le General Wolfe, commandé par un homme compétent et bien élevé, le capitaine Stamworth. Mon père, ma mère et moi étions les seuls passagers de cabine. Pendant qu'on appareillait, je m'installai sur la poupe du vaisseau et je dessinai la vue de Québec qui est reproduite dans le premier volume de l'ouvrage de mon père. Pendant la traversée, le temps fut presque constamment beau et le vent favorable ; aussi le voyage fut-il charmant. Le 24 octobre nous entrions dans la Mersey et nous débarquions dans l'opulente ville de Liverpool.

Nous nous trouvions à Liverpool, au moment où l'on inaugurait avec pompe le tunnel du chemin de fer Liverpool et Manchester. Sur l'invitation des directeurs, nous assistâmes à la cérémonie. Je ne puis oublier l'impression singulière et nouvelle que me causa le mouvement rapide de ces wagons remplis de monde se précipitant sur un plan incliné et s'engouffrant sous terre.

Pendant notre séjour à Liverpool, nous nous retirâmes à l'hôtel Eagle. Après avoir visité les endroits les plus intéressants, nous nous rendîmes à Londres par la diligence, en passant par Birmingham. Je ne dirai rien de ce voyage pourtant rempli d'incidents qui composeraient un chapitre. Nous entrâmes à Londres par Tyburn. La soirée était déjà avancée lorsque nous remontâmes Oxford Street entre deux rangées interminables de réverbères. À mesure que nous avancions, les magasins devenaient plus grands et plus brillants, les voitures plus nombreuses, la foule plus dense et la rumeur plus

Ce dénis de justice causa pendant quelque temps au colonel Bouchette des embarras d'argent et retarda la publication de son second ouvrage qui est la plus considérable de toutes ses œuvres. La balance de sa réclamation $(\$ 1,000)$, fut payée à ses héritier, en 1875 seulement, et sans intérêt. 
assourdissante. Ces spectacles si extraordinaire et si nouveau pour moi, me causa un véritable éblouissement. Je ne pus que contempler sans analyser et me former quelque idée de la grandeur de la métropole où j'entrais, par la pensée que ce que je voyais n'était que le seuil d'une capitale contenant à cette époque près de 2,500,000 êtres humains, soit trois fois plus de monde que n'en contenaient alors les provinces canadiennes !

Nous descendîmes à l'hôtel Bedford, Covent Garden, où nous trouvâmes à la fois l'élégance et le confort. Cet hôtel était situé à proximité des principaux théâtres seulement le voisinage immédiat du marché de Covent Garden, lui enlevait quelque chose de sa vogue. Nous y serions demeurés cependant si nous avions voyagé en simples touristes. Mais nous avions traversé l'Océan pour parachever une œuvre géographique et littéraire longue et laborieuse ; il nous fallait donc un appartement de plusieurs pièces, le calme et le silence de la retraite. Nous occupâmes en conséquence une maison garnie dans Baker Street, Portman Square, où nous commençâmes sur-le-champ à préparer pour le graveur et pour l'imprimeur les trois grandes cartes du Canada et des autres provinces de l'Amérique Britannique, ainsi que la description historique et topographique de ces pays, c'est-à-dire l'ouvrage qui a paru en 1831. Les cartes furent gravées par Walker, Bedford Street, Russell Square, et publiées par Wyld, géographe du roi, Charing-Cross. Le livre fut imprimé par Davidson, et publié par Longman \& Rees, Paternoster Row, Il était en trois volumes ornés de nombreuses gravures et comprenait, outre la description géographique, un dictionnaire topographique.

Mon père s'était rendu à Londres, pour la publication de cet ouvrage, sous les auspices du gouvernement du Canada.

Il était accrédité auprès de lord Goderich, le secrétaire des colonies. Celuici le reçut avec courtoisie, prit connaissance du prospectus de l'ouvrage et fut très encourageant. Après dix-huit mois de travail incessant, consacré à la préparation des cartes manuscrites et à l'examen minutieux que faisait mon père lui-même des épreuves que nous envoyait le graveur, nous pûmes enfin passer de la partie topographique à la partie littéraire. Nous possédions une masse énorme de matériaux. L'étendue et le plan général de l'ouvrage étaient depuis longtemps déterminés, mais il restait encore beaucoup à faire avant de pouvoir remettre le manuscrit entre les mains de l'imprimeur. Nous savions avec quelle rapidité les grands établissements comme celui de Davidson composent, et l'impatience des imprimeurs lorsqu'il leur faut attendre la « copie ». Nous nous consacrâmes donc entièrement à cette tâche et plus de la moitié de l'ouvrage était écrite avant l'envol des premières feuilles à l'imprimerie. Cependant, malgré ces précautions, dès que l'impression fut en marche, les épreuves et les revises s’accumulaient sur nos tables au point qu'il m'est arrivé souvent, durant les derniers six mois, de travailler jusqu'à deux et trois heures du matin avant de pouvoir expédier ce qui se trouvait devant moi. 
On peut s'imaginer avec quelle satisfaction mon excellent et infatigable père put contempler un matin sur sa table de travail, dans une reliure provisoire, un exemplaire complet des British Dominions in North America et du Topographical Dictionary of Lower Canada. Je partageais sa joie. Une série complète des cartes était déjà tirée, de sorte que nous nous trouvions en possession du résultat complet de nos deux années de travail ardu. Nous éprouvions quelque chose des sensations du marin qui après un long et périlleux voyage rentre enfin sain et sauf au port.

Un exemplaire de l'ouvrage, convenablement relié, fut présenté au roi Guillaume IV, dans une audience (spéciale, à Brighton. Un recueil des gravures de scènes canadiennes, dans une reliure élégante, velours et or, fut présenté à la duchesse de Kent. Mon père eût l'honneur de lui présenter les gravures en personne, au palais de Kensington. En cette occasion j'accompagnai mon père. On nous reçut avec beaucoup de grâce et de bienveillance. Après une conversation prolongée, au cours de laquelle mon père parla des nombreuses faveurs et de la protection dont il était redevable à feu le duc de Kent, Son Altesse Royale nous demanda si nous avions été présentés à la princesse Victoria. Mon père ayant répondu que nous n'avions pas encore eu cet honneur, Son Altesse se leva du sofa où elle était assise, sonna la dame de service et lui demanda de prier la princesse de venir.

La future reine d'Angleterre entra quelques instants plus tard. Nous vîmes une belle jeune fille de quatorze ans dont le maintien indiquait une heureuse combinaison de dignité, de candeur et de grâce. Et c'est ainsi que nous eûmes, par la faveur spéciale de son auguste mère, le remarquable honneur d'une audience particulière, de celle qui devait être une des plus grandes souveraines du monde.

Je n'oublierai jamais la bonté et la condescendance que la duchesse de Kent témoigna à mon père, et à moi-même incidemment, pendant cette audience que Son Altesse daigna prolonger pendant près d'une demi-heure.

Écrivant aujourd'hui dans la trente-cinquième année du règne glorieux et prospère de la reine Victoria, une reine qui vit dans le cœur de ses sujets et qui commande l'admiration de toutes les cours étrangères, c'est avec un sentiment de satisfaction et de sincère loyauté que je me rappelle cette audience à Kensington Palace en l'année 1832. 


\title{
CHAPITRE IV
}

\author{
LA SOCIÉTÉ DE LONDRES EN 1830 - LORD SIDMOUTH \\ - LE SALON DE MADAME SKINNER - TOURNOI AVEC LE PRINCE \\ LOUIS-NAPOLÉON - UNE LETTRE DE LORD HARRINGTON.
}

$\underline{\text { Retour à la table des matières }}$

Mon séjour en Angleterre s'était déjà prolongé au delà de deux ans. Ce temps avait été employé à aider mon père dans la publication de son grand ouvrage géographique. Cependant ce travail ne m'absorbait pas au point de me faire renoncer à toute distraction et aux plaisirs de la société.

La position officielle de mon père au Canada, le but littéraire et scientifique de son séjour dans la métropole, le bon souvenir que conservaient de lui les hommes distingués de la régence de 1814 et 1815, lors de la publication à Londres de ses premières œuvres ${ }^{1}$, me procurèrent l'honneur de rencontrer quelques-uns des personnages les plus distingués de l'époque. Parmi ceux-ci, je mentionnerai le comte de Sidmouth, le contemporain et l'ami de William Pitt. Il avait été deux fois premier ministre de George III et avait été en outre l'ami de son souverain, dans la mesure qu'un sujet peut l'être. La présentation eut lieu à Richmond Lodge, lord Sidmouth étant alors à la retraite et occupant la charge de Ranger of Richmond Park, magnifique domaine royal dont il savait faire les honneurs avec dignité et distinction. Cet homme inspirait un profond respect ; au physique, il ressemblait au général Washington, si j'en puis juger par les portraits que j'ai vus du premier président des États-Unis. 1 À cette époque, mon père avait été traité avec beaucoup de bonté par S. A. R. le duc de
Kent. - NOTE DE L'AUTEUR. 
Lord Sidmouth était le contemporain et l'ami personnel de l'amiral Nelson. Il avait recueilli de la bouche même de ce célèbre marin une description détaillée de la bataille du Nil ou d'Aboukir. Un jour, en nous parlant de cet engagement, il dessina sur une petite table qui se trouvait près de lui, la position des deux escadres et nous expliqua que le vaisseau anglais Culloden, tenant la tête de l'escadre anglaise, s'étant échoué accidentellement à l'entrée même de la rade, devint un point de repère, ce qui permit à tous les autres vaisseaux de passer dans la rade en évitant des bas-fonds dangereux où ils auraient pu se perdre ; c'est ainsi qu'il leur devint possible de prendre à revers la ligne française.

Mon père me présenta aussi à un autre de ses amis, le très honorable Edward Ellice, qui était propriétaire de la seigneurie de Beauharnois, dans le district de Montréal. Sa longue carrière parlementaire et sa parenté avec le comte Grey, qui était son beau-frère, ajoutaient à peine à l'influence que lui assuraient sa grande fortune et ses talents incontestés ${ }^{1}$. Sa maison est la seule en Angleterre où je vis en entrant un de nos gros poêles carrés du Canada. C'était sans doute pendant un de ses voyages dans notre pays, qu'il avait fait l'acquisition de cet objet utile sinon élégant, que nous vîmes avec plaisir, parce qu'il nous rappelait notre patrie ${ }^{2}$.

En retraçant ici quelques-uns des souvenirs les plus agréables de ma résidence dans la métropole de l'Angleterre, je dois mentionner spécialement et avec reconnaissance le juge et madame Samuel Skinner, de Portland Place. J'étais toujours le bienvenu dans leur maison élégante et hospitalière. Madame Skinner était d'une rare beauté. C'était à elle que Byron avait, disait-on, adressé une de ses premières odes, et elle était digne d'un tel hommage. Dans ses brillants salons on rencontrait, outre le grand monde, les principaux poètes, romanciers et artistes de l'époque. Grâce à elle, je pus faire la connaissance d'un grand nombre d'écrivains dont j'avais lu les œuvres en Canada, mais que je ne croyais guère rencontrer un jour. Parmi ceux-ci se trouvait le plus grand romancier du jour, je dirais du siècle, en Angleterre, si l'auteur de Waverley n'appartenait pas au dix-neuvième siècle, sir Edward Bulwer Lytton, maintenant lord Lytton. Je causais aussi dans les salons de madame Skinner avec Tom Moore, Hogg, le capitaine Marriott, Mlle Landon, Mlle Edgeworth,

Mon père m'a toujours dit qu'il était fort redevable à M. Ellice pour ses bons procédés en 1815, lors de la publication de son premier ouvrage. Il s'intéressa beaucoup pour nous à l'époque dont je parle. - NOTE DE L'AUTEUR.

2 Ellice fut l'ennemi des Canadiens-Français. C'est lui qui suggérait au ministère anglais en 1812, d'unir en une seule province le Haut et le Bas-Canada. Une mesure présentée à cet effet, fut retirée à la demande de Papineau et Neilson, députés en Angleterre pour la combattre. - D. 
Jane et Maria Porter, Basil Hall, Mme Trollope, Rosetti l'impresario, et plusieurs autres ${ }^{1}$.

Que de souvenirs me reviennent de ces trois années de résidence à Londres ! J'aurais beaucoup de plaisir à les retracer ici ; cependant, je dois me borner aux incidents qui ne sont pas d'occurrence journalière et qui sont de nature à intéresser mes enfants lorsqu'ils liront cette esquisse des événements de ma vie. Dans cette dernière catégorie je dois placer ma rencontre avec le prince Louis Bonaparte, auquel je fus présenté à un dîner chez le colonel Leicester Stanhope, (plus tard, lord Harrington), en 1833. Par une lettre que j'ai maintenant devant moi, je trouve la date précise de l'incident, le dix-huit janvier de cette même année. Le prince était accompagné d'un seigneur toscan, dont je ne me rappelle pas le nom. Parmi les personnes présentes se trouvait monsieur Aaron Vail, chargé d'affaires des États-Unis, en l'absence de monsieur McLane, l'ambassadeur de la république, à Londres. Lorsque nous rentrâmes au salon pour rejoindre les dames, la conversation devint assez générale. Le prince, qui y prenait la principale part, ayant préalablement obtenu l'assentiment de notre gracieuse hôtesse, proposa une espèce de joute ou de tournoi. Il invitait lui-même certains des messieurs présents à lutter contre lui. Voici comment la chose se passait. Le prince et son adversaire se tenaient visà-vis l'un de l'autre, le pied droit en avant, le coude droit appuyé sur la hanche, la main droite saisissant celle de l'adversaire. La victoire consistait à faire baisser la main de l'adversaire en lui faisant plier le poignet en dehors. Le prince ayant assez facilement fait céder son premier adversaire, celui-ci fut aussitôt remplacé par un second lutteur dans cette lice improvisée, et le second par un troisième, avec le même résultat. Je me tenais à côté de M. Vail, parmi

\footnotetext{
Bulwer Lytton et Marriott, tous deux romanciers célèbres, Tom Moore, ce merveilleux poète, qui, comme Botrel et Nadeau, chantait lui-même ses vers, sont trop connus pour qu'il soit nécessaire d'en faire une mention spéciale.

James Hogg, poète écossais. Sa fille, Mme Garland, a publié ses mémoires, qui sont d'un vif intérêt.

Létitia Landon, poète anglais de talent. Elle naquit en 1802. En 1838 elle épousa M. Maclean, gouverneur de Cape Coast Castle, et mourut la même année, victime du climat de ce pays.

Maria Edgeworth, écrivain de grand mérite, romancier, philosophe, économiste, était d'origine irlandaise. Son père était aussi un écrivain renommé.

Jane Porter, écrivain écossais. Il reste d'elle plusieurs romans de la vie écossaise. Elle eut le grand mérite de comprendre et d'encourager le talent de Walter Scott.

Basil Hall, voyageur et écrivain, fils de sir James Hall, qui le premier appliqua la méthode expérimentale à la géologie.

Frances Trollope, auteur de plusieurs romans, mère de Anthony Trollope, le célèbre romancier.

Gabriele Rosetti, poète, critique et musicien, naquit à Vasto, Italie, en 1783, et mourut à Londres en 1854, où il s'était réfugié à la suite de difficultés politiques. Sa mémoire est révérée au lieu de sa naissance, où on lui a élevé une statue.
} 
les spectateurs, lorsque madame Stanhope, avec cette grâce qui la distinguait, m'invita à lutter contre le prince ; celui-ci ayant appuyé cette invitation avec beaucoup de politesse, je me plaçai vis-à-vis de lui en lui assurant, en français, que je me regardais déjà comme vaincu. Cependant, je n'étais pas tout à fait sans expérience à ce jeu, qui est bien connu au Canada. Sans être d'une aussi grande force musculaire que le prince, j'étais de taille plus élevée; nous luttions donc à conditions égales. Nous nous serrâmes la main et la joute commença. Elle se maintint pendant quelque temps sans avantage appréciable d'un côté ou de l'autre. Le prince y mit fin en me disant en, souriant : «Vous avez le tour ».

Vingt ans après, la France ayant, dans l'intervalle, de révolution en révolution, passé de la monarchie à la république et de la république à l'empire, par la volonté unanime du peuple français, un Bonaparte occupait de nouveau le trône impérial. Je me demandai alors si l'empereur Napoléon III ne serait pas le prince Louis Bonaparte contre lequel j'avais lutté dans le salon de Madame Stanhope. J'étais convaincu que ce ne pouvait être que lui. Désirant cependant confirmer cette impression, je m'adressai, non sans quelque hésitation, car l'objet de ma lettre pouvait paraître assez trivial, à mon ancien et aimable hôte, le comte de Harrington. Celui-ci me répondit avec la même courtoisie qui distinguait le colonel Stanhope pendant mon séjour à Londres. Je transcris ici cette lettre, surtout à cause des idées justes et libérales qu'exprime cet homme d'État éclairé quant aux destinées à venir de notre pays.

«Elvaston Castle, 12 mars 1853.

« Mon cher monsieur,

« Acceptez mes remerciements pour votre aimable lettre. J'ai conservé de vous un agréable souvenir et je suis bien aise d'apprendre qu'il en est de même de votre côté. Je ne me souviens plus du tournoi en question, mais il est certain que c'est sur l'empereur des Français que vous avez triomphé en cette circonstance. Il était souvent chez moi. Lucien aussi était un de nos habitués, mais vous le connaissiez, ainsi que d'autres membres de la famille Bonaparte.

« J'espère sincèrement que le lien qui nous unit au Canada se maintiendra longtemps, et que lorsque vous aurez obtenu votre indépendance, nous serons encore unis par l'affection et par nos intérêts, qui sont identiques. Je crois cependant qu'il est de notre avantage de part et d'autre de continuer comme 
nous sommes, vous n'étant pas dépendants, mais formant partie de l'empire britannique, qui, malgré tous ses défauts, n'eut jamais d'égal quant aux lumières, à la liberté et au bonheur social.

« Croyez-moi, très sincèrement,

« HARRINGTON ${ }^{1}$.

1 Voici l'original de cette lettre :

My dear Sir,

Elvaston Castle, $12^{\text {th }}$ March 1853.

Accept my cordial thanks for your kind letter. I have a pleasing recollection of you and am much gratified to find that it is mutual. I do not recollect the tournament you allude to. I have no doubt the present Emperor of the French is the person you triumphed over, as he was frequently at our house. So was Lucien, but with him you were acquainted as also with other members of the Bonaparte family.

I sincerely hope that our connection with Canada may long continue, and that when you gain your independence we may still be bound together by the ties of affection and interest. I consider it our mutual interest to continue as we are, you not dependent, but a part of the British Empire, which with all its faults has never been equalled as regards enlightenment, liberty and social happiness.

Believe me, most sincerely,

HARRINGTON. 


\section{CHAPITRE V}

\section{OBSÈQUES DE GEORGE IV - COURONNEMENT DE GUILLAUME IV - COUP D’EIL GÉNÉRAL SUR CETTE ÉPOQUE.}

$\underline{\text { Retour à la table des matières }}$

Je m'aperçois que j'ai un peu trop précipité mon récit, et que j'ai négligé de parler de deux événements importants dans les annales de l'empire britannique : la mort de George IV, qui eut lieu le 26 juin 1830, et l'accession au trône de son frère le duc de Clarence, sous le nom de Guillaume IV. Celuici fut couronné en septembre 1831 à l'abbaye de Westminster.

Il était naturel qu'un jeune homme nouvellement débarqué d'une contrée lointaine où de tels spectacles ne se voient jamais, fût désireux d'en être témoin. Je résolus donc d'assister à la cérémonie des obsèques du monarque défunt, ainsi qu'au brillant spectacle du couronnement de son successeur. J'eus l'heur de réussir dans ces deux entreprises, grâce à l'influence dont disposait mon père. Sir George Naylor, qui était alors, je crois, Garter King at Arms ou chef des hérauts officiels d'Angleterre, eut la bonté de me présenter une carte d'admission à la chapelle royale de Windsor, où devaient avoir lieu les funérailles solennelles du roi George IV, le 15 juillet 1830.

Le matin donc de ce jour je me mis en route pour Windsor, imposante, résidence royale dont les origines remontent à Guillaume le Conquérant. J'étais seul dans ma voiture et le temps était pluvieux. Cependant je ne m'ennuyais pas. La campagne était si verte, l'air si parfumé des senteurs du foin nouveau, que c'était une jouissance de regarder et de respirer. Sur la grande route, une longue suite d'équipages de toutes sortes, les uns imposants, les autres grotesques, se dirigeaient tous du même côté que moi. Vers neuf heures, je descendis pour déjeuner dans un petit village très vieux, se groupant autour 
d'une petite église plus vieille encore et toute recouverte de mousse. On me servit à déjeuner dans une très ancienne mais excellente auberge appelée the swan (le cygne). C'était le village de Stanwell. Les gens y semblaient polis et obligeants, plusieurs s'offrirent d'aller quérir la clef de l'église afin que je pusse la visiter à l'intérieur. Je ne saurais dire si cette politesse de simples villageois envers un étranger est exceptionnelle dans le pays de John Bull. Il est certain que la population anglaise de la classe inférieure semble d'un abord difficile dans les villes, tandis que les paysans que j'ai rencontrés m'ont toujours paru hospitaliers et désireux de plaire, bien que souvent très timides.

Après déjeuner, je me remis en route. Je me rapprochais maintenant de Windsor. Le temps était devenu beau et clair. La masse imposante du château s'élevait majestueuse au-dessus de la verdure qui l'entoure de toutes parts; la foule des équipages devenait plus dense, les détonations du canon funèbre plus distinctement perceptibles.

Rien ne saurait donner une idée du bruit et de la confusion qui régnaient dans la ville de Windsor au moment où j'y entrai. Naturellement, les hôtels et les auberges, étaient depuis longtemps remplis. On voyait dans les rues de longues rangées de voitures et de chevaux dont les conducteurs se disposaient à passer la nuit en plein air, puisqu'il leur était impossible de se trouver un abri. On n'apercevait sur les visages aucun signe de tristesse ou de deuil. Les arrivages constants piquaient la curiosité publique, on acclamait souvent quelque personnage connu. La ville était remplie de soldats; de jeunes et joyeux officiers portant le brillant uniforme des gardes du corps (Life Guards) et des Blues ou Horse Guards, paraissaient à toutes, les fenêtres et sur tous les balcons, d'où ils regardaient la fourmilière grouillant à leurs pieds. Dans cette cohue circulaient des revendeurs et des colporteurs annonçant leurs marchandises d'une voix qui s'efforçait de dominer le tumulte. Seuls les magasins fermés et les détonations espacées du canon remplissant l'air de ses vibrations mélancoliques, pouvaient indiquer la cause funèbre de ce rassemblement.

Je déposai mon sac de voyage dans une auberge peu attrayante, j'y trouvai même un coin pour changer ma toilette, puis je me dirigeai vers le château, afin de contempler les restes du souverain défunt sur son lit de parade, hommage auquel tous les sujets britanniques sont conviés. La barrière de l'avenue conduisant au palais était gardée par deux sentinelles des Life Guards à cheval, et par deux huissiers qui me laissèrent passer après avoir examiné ma carte d'admission. En suivant l'avenue sur une distance d'environ douze cents pieds, j'arrivai à la barrière extérieure du château. Ici l'on traverse une autre allée appelée, the long walk. Cette allée, s'étend en ligne droite sur une distance considérable. On voyait tout au bout à la droite une foule considérable réunie autour des canons qui tiraient la salve funèbre. 
La chambre ardente, assez vaste, était toute drapée de noir. De nombreux lustres éclairaient la pièce et autour de la bière royale, déjà fermée, d'innombrables bougies brûlaient dans de magnifiques candélabres d'or et d'argent. De chaque côté de cette bière se tenaient immobiles des chevaliers et des hérauts d'armes chacun dans le costume de son grade ou de son emploi. Le silence était profond, bien que la foule ne cessât pas un instant de défiler devant la bière.

C'était à neuf heures du soir que le cortège funèbre devait faire son entrée dans la chapelle Saint-Georges, pour déposer dans leur dernière demeure les restes du souverain décédé. Longtemps avant cette heure, les portes de la chapelle étaient assiégées par la foule des dames et des messieurs ayant des cartes d'admission à la nef ou aux galeries. J'arrivai moi-même à cinq heures, et bien que les portes ne dussent s'ouvrir qu'à huit heures, je me trouvai dans la troisième rangée d'invités déjà groupés devant le portique. Accoudé assez commodément contre un arc-boutant, je m'amusai à regarder grossir la foule des porteurs de cartes se déployant en demi-cercle autour du groupe central dont je faisais partie. Un certain nombre de personnes avaient apporté des chaises ou des pliants et je ne tardai pas à comprendre la sagesse de cette précaution, car au bout d'une heure d'attente la fatigue commençait déjà de m'envahir. La faim se mit aussi de la partie et d'autant plus agaçante que je voyais autour de moi des dames et des messieurs qui soupaient gaiement d'un sandwich et d'un verre de vin.

Enfin les portes s'ouvrirent et je me trouvai bientôt commodément installé dans la galerie du nord, d'où je pus très bien voir défiler le cortège, et suivre la cérémonie dans le chœur. La chapelle du château de Windsor passe pour un modèle du genre gothique fleuri. En cette occasion elle était éclairée par d'innombrables bougies, mais de pesantes et riches draperies, des centaines de bannières héraldiques projetant des murs, dont les plus belles se trouvaient dans le chœur, en masquaient les beautés architecturales. À neuf heures le cortège entra dans la chapelle. Derrière le cercueil marchait le roi Guillaume IV, frère du roi défunt. La cérémonie de l'inhumation eut lieu dans l'angle oriental de la chapelle. À dix heures, tout était terminé et je sortis fortement impressionné par tout ce que j'avais vu.

Le brocart du droit français «le mort saisit le vif», est strictement applicable aux monarchies héréditaires. Au dernier soupir de George IV, son frère, le duc de Clarence, devint le souverain des îles Britanniques. Ce n'est cependant qu'un an après, le 8 septembre 1831, qu'il fut couronné sous le titre de Guillaume IV dans l'abbaye de Westminster. La reine Adélaïde fut couronnée en même temps. J'assistai à cette solennité, mais je ne la décrirai pas. Tous les détails furent publiés dans les journaux du temps et l'événement était revêtu d'un intérêt d'autant plus considérable que pareille solennité n'avait pas eu lieu depuis le couronnement de George III, en septembre 1761. Le roi et 
la reine tinrent une cour plénière ou un drawing room, comme on dit à Londres. Presque tous les pairs du royaume et leurs femmes y assistaient revêtus de leurs manteaux d'hermine et portant leurs couronnes ou leurs tortils soit sur la tête, soit à la main. Je n'avais jamais vu de réunion aussi brillante.

J’avais précédemment en l'honneur d'être présenté à la cour, lors de la première cour plénière tenue par Leurs Majestés Guillaume IV et la reine Adélaïde, après la mort de George IV ; mais la cour était alors bien moins brillante, à cause du deuil récent.

Ici $^{1}$ il y a interruption dans le manuscrit. Je puis, cependant, suppléer presque en entier à ce qui manque par le souvenir que j'ai conservé des récits de mon père, et surtout en me servant des notes volumineuses qu'il m'a laissées et qui sont maintenant devant moi. Je serai obligé de procéder de même dans certains autres endroits. Presque toujours les matériaux sont complets et toujours le récit ainsi continué est basé sur les notes mêmes de l'auteur. Leur valeur historique reste donc intacte.

L'auteur des mémoires aimait à raconter le détail suivant. Lorsqu'il fut question pour lui d'être presented at court, il apprit que, la cour étant en deuil, il lui faudrait endosser un costume spécial assez embarrassant à porter pour qui n'a pas l'habitude de la pompe des cours. Il allait se résoudre à ce travestissement, lorsqu'il se souvint qu'il était lieutenant dans l'artillerie canadienne. Or les officiers militaires étant admis à cette présentation dans l'uniforme de leur grade, il se fit aussitôt confectionner un uniforme d'artilleur et c'est en sa qualité d'officier qu'il fut présenté aux souverains. J'ajouterai que ses connaissances militaires aussi bien que sa commission lui donnaient le droit de porter l'uniforme d'artilleur. Je possède, écrites de sa main, les notes complètes d'un cours intitulé : Tactique de l'artillerie de campagne. Ces notes contiennent des détails fort curieux sur le maniement des canons de campagne pendant les guerres du premier empire et sur la portée des différentes armes de l'époque. Je ne puis cependant entrer dans ces détails sans interrompre trop longtemps le fil du récit.

Au moment où mon père séjourna à Londres, la grandeur et la puissance anglaises étaient près de leur apogée. Wellington et Waterloo, Nelson et Trafalgar, Castelreagh et l'unité administrative des Îles Britanniques se détachaient tout frais dans ses annales ${ }^{2}$. Un immense empire fondé aux Indes,

Rédaction de M. Errol Bouchette.

Cette unité administrative au prix du sacrifice de l'autonomie de l'Irlande, devait être une source de faiblesse pour l'empire, car l'Irlande mécontente n'a cessé depuis de s'agiter et sa population d'émigrer pour créer aux États-Unis un parti nombreux et puissant hostile aux aspirations britanniques. 
les Américains repoussés du Canada, faisaient oublier la perte de la NouvelleAngleterre et le suicide du parlement d'Irlande. Les mœurs affectaient une grande élégance. Tout noble Anglais se piquait surtout du titre de gentleman. Ceux de baron, de marquis ou de comte n'étaient pas alors les plus estimés. Dans les demeures seigneuriales, dont alors comme aujourd'hui, rien n'égalait le luxe et l'élégance, l'étranger régulièrement présenté était sûr de trouver la plus large hospitalité. On y rencontrait des représentants de l'aristocratie de toute l'Europe, mais surtout de celle de France, charmée de pouvoir enfin occuper son rang d'antan auprès de ceux auxquels elle avait, quelques années auparavant et dans le dénûment de l'exil, dû demander protection et même souvent servir en qualité de professeurs de français, de musique ou de danse. La roue du temps avait tourné. Les Bonaparte maintenant étaient les exilés. Nous avons vu Louis-Napoléon, le futur empereur des Français, faisant à Londres des connaissances qu'il devait retrouver après Sédan. Walter Scott avait terminé son œuvre, Bulwer Lytton terminait la sienne, Tom Moore chantait ses vers et ses mélodies immortelles. Mon père m'a souvent parlé de ce temps. Dans cette atmosphère de prospérité et de gloire tout était séduisant, à l'exception peut-être des toilettes féminines, dont Cruikshanks, le célèbre caricaturiste, que l'auteur connaissait personnellement, nous a conservé le souvenir. Le bon goût de cet artiste lui faisait détester ces monstruosités, comme il les appelait, et il se plaisait à les ridiculiser. Figurez-vous de véritables chapeaux haut-de-forme autour desquels s'enroulaient de nombreuses courroies, surmontés d'un panache comme le couvre-chef d'un sagamo indien, et d'où retombaient en cascade des mèches de cheveux roulés en tire-bouchon. Les douairières pouvaient peut-être se consoler de se trouver ainsi affublées, mais quel cadre pour un visage jeune et frais ! Et plus bas, une taille déformée par un corset qui ramenait violemment le buste en avant, en rejetant les hanches en arrière... Mais je m'arrête. N'ai-je pas vu quelque chose de semblable tout récemment dans les rues de Montréal ? Et malgré l'appareil qui les comprime, ces dames ne réussissent pas à se faire laides. Il en était sans doute de même pour les belles du temps passé. Jamais le corset ni la crinoline ne servirent de cuirasse contre l'amour. Mon père, alors en visite chez une dame de ses parents, madame Plenderheath, à Douvres, rencontra mademoiselle Marianne Gardner, fille de l'honorable Herbert Gardner et petitefille de l'amiral comte Gardner, pair d'Angleterre. Il l'aima, il en fut aimé. Trois semaines après les jeunes gens étaient fiancés du consentement de leurs parents. C'était en octobre 1832. Il fut décidé cependant que le mariage n'aurait pas lieu immédiatement, et mon père s’embarqua pour le Canada en mai 1833. Il devait retourner en Angleterre en décembre, alors qu'aurait lieu le mariage. 


\section{CHAPITRE VI}

\section{UN VOYAGE EN ITALIE - MARIAGE À DOUVRES - UN ÉVÉNEMENT TRAGIQUE.}

\section{$\underline{\text { Retour à la table des matières }}$}

Au moment de l'incident remarquable que j'ai raconté à la fin du dernier chapitre, mon père revenait d'un voyage assez prolongé à travers la France et l'Italie. Il était parti avec un ami, M. Fricker, autant que je puis déchiffrer le nom dans le manuscrit qui était porteur de dépêches du roi d'Angleterre pour l'Italie, et qui lui avait offert une place dans sa briska. Il fait une description de cette excellente voiture de voyage si vaste et si confortable et contenant tout ce qu'il fallait pour la toilette et pour la table. Vraiment nos pères n'étaient pas si arriérés qu'on veut le dire. Les voyageurs d'alors voyaient au moins le pays qu'ils traversaient et c'est à cette époque qu'on pouvait dire avec vérité que les voyages forment la jeunesse.

Leur itinéraire sur le continent fut celui des courriers ordinaires de l'époque et pourra par conséquent intéresser ceux qui veulent lire avec une intelligence plus complète des détails l'histoire si attachante du commencement du dixneuvième siècle, Débarquant à Calais, ils se rendirent à Paris. Après un séjour peu prolongé dans cette capitale, ils prirent le chemin de l'Italie en passant par Mélun, Auxerre, Macon, Port-Beauvoisin, Chambéry, la vallée de l'Isère, le Mont-Cénis, Suze, Turin, Alexandrie, Marengo, Pise, Florence, Sienne, jusqu'à Rome où ils demeurèrent trois semaines. Puis, après une excursion jusqu'à Naples et Pompéi, ils revinrent, mais en passant cette fois par la Suisse et le Jura. La plupart des cahiers de ce voyage étant détruits, je me contenterai de donner quelques extraits de l'unique cahier qui me reste.

« Je n'oublierai jamais, dit l'auteur des Mémoires les passes terribles de l'Apennin. Même au sortir des paysages grandioses des Alpes, elles me causèrent une impression durable. Nous sortîmes de Montefiascone à la nuit 
tombante, mais par un magnifique clair de lune. De Montefiascone, à Viterbe, la route étroite longe d'un côté des hauteurs escarpées, de l'autre le fleuve qui coule au fond d'un second précipice. Elle est coupée de temps à autre par de profondes coulées sur lesquelles on a jeté des ponts de bois. Rien de tout cela n'arrêtait nos postillons qui descendaient, malgré qu'il fût nuit, au grand galop.

«Au moment où nous approchions de Viterbe, une troupe de taureaux sauvages nous dépassa comme une avalanche; nous crûmes un instant que nous étions perdus. Ils étaient poursuivis de très près par plusieurs cavaliers. C'étaient des bouviers de l'Apennin qui cherchaient à dépasser les bêtes pour leur faire rebrousser chemin. Nous les voyions à la lumière de la lune avec leurs longues lances en arrêt, courir ventre à terre et en poussant de grands cris sur l'étroit ruban de verdure entre la route et la rive élevée. Toute la troupe passa comme un éclair, mais nous entendîmes pendant quelque temps encore le bruit de leur course vertigineuse réveillant les échos dans les profondeurs des ravins. Ces bouviers de l'Apennin sont de « beaux et hardis cavaliers. Ils me rappellent les picatoros d'Espagne ».

«C'est des hauteurs de Baccano, dit-il un peu plus loin, à environ neuf milles de Rome, que nous vîmes pour la première fois le dôme de Saint-Pierre. Un sentiment de vénération et de bonheur inexprimables me saisit à ce premier regard jeté sur la Ville-Éternelle. Rome ! autrefois la maîtresse du monde. Rome ! où naquirent les héros antiques. Rome ! la mère des orateurs et des poètes. Rome le siège des arts, le centre de toutes les grandeurs, dont les vestiges grandioses sont encore aujourd'hui les modèles des modernes, dont le génie législatif, littéraire, artistique est de nos jours encore la merveille par excellence de l'univers ! Rome, dis-je, était là devant mes yeux. Dans un transport irrésistible je me dressai dans la voiture, et soulevant mon chapeau je saluai de loin la capitale de l'occident ».

Je terminerai ces extraits par la description d'une cérémonie pontificale d'il y a trois quarts de siècle.

«Samedi, le 8 septembre (1832) à neuf heures du matin, nous nous rendîmes à l'église de Santa Maria del Popolo pour assister à la célébration de la Nativité de la Vierge. Le Pape assistait à cette cérémonie ; il était entouré de toute la pompe pontificale et suivi d'un grand nombre de cardinaux. Une garde d'honneur faisait haie depuis le portique jusqu'au chœur. Les rues par lesquelles Sa Sainteté devait passer pour se rendre de son palais, qui est situé à l'autre extrémité de la ville, jusqu'à l'église, étaient soigneusement étendues de sable fin, et sur la, piazza del popolo, vis-à-vis l'église s'étendait un immense auvent. Nous attendions dans l'église depuis près d'une heure lorsque le Pape parut précédé d'une vingtaine de cardinaux. Il se tenait sur un trône magnifique, la sedia gestatoria, portée sur les épaules de quatre officiers en brillants uniformes. Le Pape portait de somptueux vêtements de satin blanc, 
deux cardinaux soutenaient la longue queue de sa robe. Ceux-ci, ainsi que les autres cardinaux, portaient la robe de pourpre dont la queue était soutenue par des prélats en soutane violette. Le pontife fit son entrée tiare en tête, il remonta la nef en distribuant des bénédictions à droite et à gauche sur la foule agenouillée, puis arrivé au chœur, il quitta la sédia pour occuper un trône encore plus magnifique. Autour de lui se rangèrent les cardinaux par ordre d'ancienneté, et aux pieds de ceux-ci, sur des tabourets, les camériers et les caudataires. Derrière les cardinaux se rangèrent les évêques et le haut clergé parmi lesquels deux dignitaires grecs étaient remarquables par leur longue barbe blanche et la solennité de leur maintien. La messe fut chantée par un évêque et la cérémonie ne fut pas trop longue. La musique était bonne, mais entièrement vocale ; il me sembla que l'orgue en aurait rehaussé l'éclat.

«Après la messe, le Pape se retira avec le même cérémonial, et nous nous hâtâmes de sortir pour être témoins du départ. La grande place del popolo offrait un spectacle très brillant. Le carrosse du Pape, un carrosse immense de forme antique, mais richement orné de mitres et de tiares et couvert de dorures, était traîné par six magnifiques chevaux noirs somptueusement harnachés et guidés par trois postillons. Venait ensuite une seconde voiture, moins riche, mais de même forme et de même dimension et traînée aussi par six chevaux, c'était la voiture de la famille du Pape. Les carrosses des cardinaux sont rouges, ainsi que les harnais de leurs chevaux. Quelques-uns de ces équipages sont plus beaux que les autres, mais à l'arrière de chaque carrosse on voit au moins trois laquais en livrée. L'effet général est fort impressionnant, il combine la pompe de la royauté avec la solennité de la religion, et en recevant la bénédiction papale je ressentis quelque chose de ces deux influences, qui donnent au pape un avantage considérable sur les autres souverains de l'Europe. En revenant nous trouvâmes le Corso encombré d'une foule immense, mais rien dans les costumes n'était remarquable, rien ne nous rappelait que nous nous trouvions dans la Rome moderne, si ce n'est le langage de cette foule et son empressement extraordinaire à se courber sous la main bénissante du pontife-roi ».

C'est, comme je l'ai dit, au retour de ce voyage que mon père rencontra Marianne Gardner, obtint la promesse de sa main et s'embarqua quelque temps après pour le Canada. En décembre il se rembarqua à New-York pour l'Angleterre sur le navire Caledonia. Ce voilier arriva à Liverpool après une traversée de seize jours seulement. De Liverpool, mon père se rendit à Douvres où résidait sa fiancée. C'est là qu'il rencontra, entre autres personnes, le colonel Dundas, un noble et généreux cœur, dont il sera question plus tard au cours de ce récit. Là se trouvait aussi le capitaine Surgison Smith, des dragons de la garde, qui devait épouser Georgiana, la sœur de Marianne Gardner. Il fut décidé que les deux mariages seraient célébrés le même jour. 
Le double mariage eut lieu en effet en grande pompe, à Douvres, le 6 mars 1834. Bouchette se rendit avec sa femme au château de Deal, sur les côtes de l'Atlantique, résidence du comte de Carrington, oncle de madame Bouchette. De là, ils s'embarquèrent pour le Canada à la fin d'avril. « Le bonheur dont cet hymen me combla, dit mon père, devait, dans les décrets de la Providence, n'être que de courte durée. De retour dans mes foyers, depuis trois mois à peine, mon épouse bien-aimée devint une des premières victimes du choléra asiatique qui sévit en Canada en 1834. Elle succomba le 27 juillet à cette funeste épidémie ». 


\section{CHAPITRE VII}

\section{QUELQUES MOTS SUR L’AGITATION POLITIQUE ANTÉRIEURE AU MOUVEMENT INSURRECTIONNEL DE 1837.}

$\underline{\text { Retour à la table des matières }}$

Je me résignai difficilement à cette cruelle séparation. Je cherchais vainement à m'en distraire, en me livrant énergiquement à la pratique de ma profession, lorsque les événements politiques prirent une gravité qui rendait l'indifférentisme presque impossible. Je me rangeai sans hésitation du côté des libéraux, quoiqu'il m'en coûtât beaucoup de me séparer de ma famille et de beaucoup de mes amis personnels qui sympathisaient avec le parti qui avait pris bien à tort le titre de constitutionnel. La politique vint ainsi me distraire des angoisses dont souffrait mon cœur et je me lançai dans l'arène avec l'enthousiasme qui m'est naturel et avec toute l'ardeur que m'inspirait ma conviction profonde de la justice de la cause libérale.

En 1836 et en 1837, je pris une part active aux assemblées publiques de la capitale (Québec) et des comtés avoisinants. Je fondai un journal, le Libéral, qui paraissait trois fois la semaine dans les deux langues. Me réservant la partie française, je confiai la rédaction de la partie anglaise à mon habile ami et confrère $\mathrm{M}$. Hunter.

Quelque temps auparavant, j'avais posé ma candidature comme député à l'Assemblée dans le comté de Saguenay, (alors Northumberland). Mon adversaire, M. Drolet, était aussi un libéral. À la Baie Saint-Paul, je l'avais emporté sur lui par une majorité de six cents voix, mais à la Malbaie, M. Drolet 
combla son déficit et fut finalement élu par une majorité de soixante-quatre voix, grâce à l'influence de M. Papineau ${ }^{1}$.

Une des importantes assemblées qui eurent lieu à cette époque fut celle dite de la Garderobe, parce qu'elle fut tenue dans la grande salle du vestiaire de l'Assemblée législative, dimanche, le 28 mai 1837.

Cette assemblée avait été convoquée par nos adversaires, avec invitation au public de s'y rendre. Sachant qu'on devait y prendre en considération les résolutions odieuses passées le 8 mai à la Chambre des Communes, sur la proposition de lord John Russell, alors ministre des colonies, je me rendis à l'église de la grande et influente paroisse de Saint-Roch, au moment où allait se terminer l'office de vêpres. À la sortie, j'adressai la parole à la foule; je rappelai aux électeurs combien il était de notre devoir de nous rendre à cette assemblée, afin de nous opposer à l'adoption de toute résolution qui pourrait compromettre l'honneur ou la liberté du Canada.

Un acquiescement général suivit mon invitation, et je m'acheminai en tête de plus de huit cents hommes vers le palais de la Législature. Nous y arrivâmes avec un accroissement assez considérable de partisans qui s'étaient joints à nous à la sortie de vêpres à la cathédrale, l'office se terminant au moment où nous passions.

J'aurais voulu que l'entrée se fût faite tranquillement et sans déranger nos adversaires, dont nous supposions l'assemblée déjà organisée. Mais la foule n'étant plus sous contrôle, il était impossible de la réprimer, et elle envahit la salle du vestiaire presque en masse. Cette brusque irruption jeta l'épouvante parmi nos adversaires, qui soudain se dispersèrent. On voyait tous les préparatifs d'une assemblée, table, fauteuils, papier, encre et plumes, enfin, rien ne manquait sauf les assistants. Que faire dans les circonstances ? Je n'hésitai pas un instant. Je m'élançai sur la table et m'adressant à la foule qui comblait l'enceinte : "Messieurs, leur dis-je, nous sommes venus ici pour prendre une part paisible et légitime, en notre qualité de citoyens de Québec, à une assemblée convoquée par la voix des journaux, pour la considération de questions importantes touchant gravement nos droits et nos libertés politiques. Nous n'y trouvons personne, pas même ceux qui ont convoqué l'assemblée. Que nous reste-t-il à faire ? Nous organiser tout de suite (applaudissements). Je

Malgré cette lutte, mon père et $\mathrm{M}$. Drolet restèrent amis personnels aussi bien qu'amis politique. Cette élection, qui ne changeait rien à la force des partis, puisque les deux candidats avaient les mêmes opinions, prouve d'une façon irréfutable l'influence énorme dont jouissait alors M. Papineau. Mon père était plus influent que M. Drolet à la Malbaie, tous les chefs locaux étaient ses partisans. Cependant la région toute entière obéit à la voix du chef politique de la province. Cette influence entraînait avec elle une bien lourde responsabilité. 
propose donc que notre digne et estimé concitoyen $M$. Légaré, que je vois ici devant moi, soit appelé au fauteuil ». La proposition fut adoptée unanimement. M. Legaré ayant pris le fauteuil, un secrétaire fut élu, et l'assemblée procéda aux affaires.

Je ne donnerai pas ici un compte rendu des discours prononcés ni des résolutions adoptées en cette circonstance. Les journaux du temps qu'on peut consulter en sont remplis et le résultat général est aujourd'hui connu. Je ferai seulement remarquer la grande portée qu'eurent cet incident et ces résolutions. Une révolution soudaine semblait s'être opérée dans l'esprit des libéraux temporisateurs. Le Canadien, par exemple, journal influent qui jusqu'alors tenait le juste milieu, se déclara approbateur des résolutions ; le parti libéral se recrutait partout et nos adversaires fléchissaient devant l'énergie qu'il déployait ${ }^{1}$. M. Van Felson, représentant la basse-ville de Québec à la Chambre et partisan de l'exécutif, cédant à la force de l'opinion publique, démissionna quelques jours après.

Vint plus tard, en octobre, la fameuse assemblée dite (les cinq comtés, mais où six comtés étaient réellement représentés, dans le district de Montréal. Elle fut suivie de l'organisation de nombreux comités de consultation et de surveillance à Québec et ailleurs. Ces comités, au moins à Québec, tout en protestant énergiquement contre la violation par le Parlement anglais de nos droits constitutionnels les plus sacrés, n'ont pas, à ce que je crois, outrepassé ce qui aurait pu se dire en Angleterre en de semblables circonstances. Néanmoins, il fut émané des mandats d'arrestation contre tous les présidents de ces comités. Me trouvant dans la catégorie de ces présidents, je me disposai à subir les conséquences auxquelles m'exposaient mes convictions. Cédant cependant aux

\footnotetext{
L'épisode dont parle Bouchette est bien curieux et montre comment les choses se passent en temps de révolution. Voici un homme qui harangue une foule, l'entraîne à sa suite à une assemblée ; arrivé là, la salle de réunion est encore vide et Bouchette est tout disposé à attendre l'arrivée de ceux qui ont convoqué la réunion, mais le peuple souverain n'a pas le don de la patience, et il pousse Bouchette à s'emparer, un peu malgré lui, d'un terrain qui ne lui appartient pas et de se faire l'organe des sentiments qu'il a fait naître un instant auparavant, un peu d'après le principe : « Je suis leur chef, donc il faut que je les suive »; le Canadien, dont le jeune disciple de Papineau semble blâmer la froideur en cette circonstance, ne se gêne pas de le rendre responsable de cet esclandre et de dénoncer sa conduite. Quelques jours plus tard, le 4 juin, on retrouve Bouchette dans une autre assemblée proposant des résolutions de circonstances, en compagnie de Morin, de Narcisse-Fortunat Belleau, plus tard ministre et lieutenant-gouverneur, des députés Drolet, Bardy, Blanchet et Besserer. À cette assemblée, après avoir récapitulé tous les griefs du pays, on passa condamnation sur les résolutions de lord John Russell présentées à la Chambre des Communes au mois de février 1837, lesquelles donnaient au gouverneur le droit de se servir de l'argent public en dehors du contrôle de la Chambre d'Assemblée, et furent les causes déterminantes de l'agitation qui aboutit à l'explosion de 1837. Le Canadien, rédigé par Étienne Parent, s'était séparé quelque temps de la fraction avancée des Patriotes qui le décrétèrent de trahison.
} 
vœux de mes amis, je quittai la ville et remontant la rive sud du Saint-Laurent, je me rendis à la rivière Chambly. Me trouvant ainsi au foyer même du mouvement, je croyais pouvoir m'y rendre utile en faisant partie d'une organisation puissante dirigée par M. Papineau lui-même. 


\title{
CHAPITRE VIII
}

\author{
LE DISTRICT DE MONTRÉAL \\ EN NOVEMBRE ET DÉCEMBRE 1837.
}

\section{$\underline{\text { Retour à la table des matières }}$}

Arrivé à Saint-Denis, le vingt-trois novembre 1837, je descendis chez le colonel Deschambault. Le docteur Wolfred Nelson vint m'y rencontrer. Je l'accompagnai chez lui et je trouvai sa maison bien gardée par de braves habitants, l'arme au bras. Ils devaient s'opposer à l'arrestation dont leur bienaimé chef, le docteur Nelson était menacé. Je couchai chez le docteur. La nuit se passa sans alerte. Le lendemain continuant ma route suivant les instructions de Nelson, en remontant les bords de la rivière Chambly.

Je descendis un instant chez M. Drolet, à Saint-Marc. M. Drolet n'y était pas, mais son fils ${ }^{1}$ s'offrit à m'accompagner. À peine avions-nous fait une lieue que nous rencontrâmes deux personnes en calèche, venant à toute vitesse. Ces messieurs, dont je ne me rappelle pas les noms, reconnurent en passant $M$. Drolet, fils, et s'arrêtant, ils nous firent signe d'arrêter aussi. Ils demandèrent avec empressement où se trouvait $M$. Papineau. Ils étaient des délégués et venaient de la pointe Olivier où se tenait une grande assemblée des personnes les plus influentes de toutes les paroisses circonvoisines. On demandait avec véhémence que $\mathrm{M}$. Papineau, qu'on savait être quelque part sur les bords du Richelieu, se rendît auprès d'eux pour aviser à ce qu'il fallait faire dans la crise menaçante actuelle. $\mathrm{M}$. Drolet répondit qu'il ne pouvait dire où se trouvait $\mathrm{M}$. Papineau, qu'il n'était pas chez son père. Enfin nous nous séparâmes, les délégués toujours à la recherche de $\mathrm{M}$. Papineau, et nous continuant notre route dans la direction de Chambly.

1 C'était le père du colonel G. Drolet, de Montréal. - D. 
Rendus sur les confins du village de Chambly, nous fûmes arrêtés par une sentinelle armée d'un fusil de chasse. Nous nous rendions chez le docteur Kimber. Mon ami Drolet me servit de passeport et nous nous rendîmes à destination sous la garde d'une autre sentinelle. Après beaucoup d'hésitation, on nous permit de franchir le seuil de la porte, et nous fûmes admis dans une grande salle où se trouvait beaucoup de monde. À peine y étions-nous entrés, que nous vîmes les personnes qui occupaient le fond de la salle se diviser respectueusement pour laisser passer une dame qui s'avançait vers nous avec calme et dignité. Elle tenait dans sa main droite un pistolet dont le canon reposait sur son bras gauche. $M$. Drolet me présenta à madame Kimber. Mon nom ne lui était pas inconnu, mais ce qui sembla lui inspirer une confiance entière en l'étranger qu'elle recevait c'était ma qualité de rédacteur du Libéral, de Québec.

Madame Kimber, dont la physionomie et le maintien étaient empreints d'une noble fermeté, s'entretint avec moi de l'événement de la veille, la délivrance de Davignon et de Démaray par le vaillant Bonaventure Viger sur le chemin de Longueuil. Ces deux messieurs, le docteur Davignon et $\mathrm{M}$. Démaray, notaire, avaient été arrachés de leurs demeures, à Saint-Jean, au milieu de la nuit par un détachement de la cavalerie volontaire de Montréal. On ne se contenta pas de les charger de chaînes, de les garrotter, et de les attacher à la banquette d'une voiture, on leur mit encore, en dérision, la corde au cou pour indiquer le sort qui les attendait. On les acheminait dans cet état vers les prisons de Montréal, lorsque Bonaventure Viger attaqua l'escorte, la mit en fuite et délivra les prisonniers.

Il se faisait tard. Mon excellent guide et ami M. Drolet, me proposa d'aller passer la nuit chez un de ses intimes, un fidèle patriote dont la demeure était au milieu du village. Nous souhaitâmes le bonsoir à madame Kimber, et nous nous rendîmes chez $\mathrm{M}$. $\mathrm{X}^{1}{ }^{1} .$. , qui nous reçut avec grande cordialité. Il était bien renseigné sur ce qui se passait au dehors. Il venait d'apprendre qu'une batterie d'artillerie de deux pièces était en route pour Saint-Jean et qu'un détachement d'infanterie régulière l'accompagnait. Quant à ce qui se faisait de notre côté, il nous apprit que les patriotes s'assemblaient en nombre dans la Grande-Ligne-de-l'Acadie (Pointe-à-la-Mule). Parmi les chefs qui s'y trouvaient, on mentionnait les noms d'Édouard Rodier, Ludger Duvernay, le docteur Cote et autres.

Le docteur Boudreault, un jeune médecin de Chambly, qui se trouvait chez notre hôte, prenait comme nous un vif intérêt à la conversation. Je lui demandai s'il connaissait les routes par lesquelles on pourrait se rendre à la Grande-Ligne, en évitant les chemins les plus fréquentés. Il me répondit qu'il

Nom en blanc dans le manuscrit. 
croyait assez bien les connaître, mais qu'il y avait dans le village un de nos chauds partisans qui non seulement connaissait tous les grande chemins et toutes les routes, mais qui pourrait aussi nous procurer de bons chevaux pour nous rendre à la Grande-Ligne. Le docteur Boudreault consentait à nous accompagner. Il fut arrêté que nous nous mettrions en route le lendemain avant le jour, et je priai le docteur de faire pour moi tous les arrangements qu'il jugerait convenables.

Longtemps avant le jour — nous étions en novembre — j'entendis le bruit d'une voiture qui arrivait. Elle s'arrêta devant la porte. J'étais tout prêt. Le docteur Boudreault entre avec notre brave et vigilant cocher. Notre hôte est debout pour nous souhaiter bon voyage. Il nous fortifie au départ d'un délicieux punch au lait. Nous lui serrons la main ainsi qu'à mon ami M. Drolet, dont je prends congé ici et nous partons.

Nous éloignant des chemins les plus fréquentés autant que les circonstances nous le permettaient sans trop allonger notre route, afin d'éviter la rencontre des troupes, nous atteignîmes enfin, en dépit de la boue et des ornières, le haut ou l'extrémité de la Grande-Ligne. Il faisait déjà grand jour lorsque nous arrivâmes à la maison d'un cultivateur riche et influent de cette région où nos amis avaient établi leur quartier général. Je trouvai là Rodier, Duvernay, Cote et aussi M. Gagnon, de la Pointe-à-la-Mule. Ces messieurs nous firent immédiatement part d'un plan d'opérations arrêté d'avance. L'on se proposait d'attaquer Saint-Jean ce soir-là même.

Je crus de mon devoir de communiquer sur-le-champ à nos amis le renseignement qu'on m'avait donné à Chambly. Je leur fis remarquer que les autorités militaires étaient évidemment prémunies contre le mouvement projeté, je leur demandai de réfléchir et de décider si, dans les circonstances, il ne serait pas plus prudent d'en différer l'exécution ou même de l'abandonner. Mon opinion exprimée le matin se confirma, lorsque vers quatre ou cinq heures du soir, nos braves habitants s'assemblèrent au lieu du rendez-vous, précédés de leur chef $\mathrm{M}$. Gagnon de la Pointe-à-la-Mule, monté sur un magnifique cheval bai qu'il maniait avec tout l'aplomb et toute la grâce d'un Bayard. Il y avait là une centaine d'hommes dont pas un tiers ne portaient des armes à feu, et ces armes de simples fusils de chasse. Les autres étaient armés de fourches et de faux diversement emmanchées. Mais ce défaut d'armement ne semblait nullement faire fléchir leur courage.

Tous les chefs à cette vue se rangèrent de mon avis et jugèrent l'attaque intempestive. Nous réussîmes, mais non sans peine, à persuader à ces braves gens de retourner chez eux.

Le défaut d'armement se faisant ainsi péniblement sentir, Duvernay ou Gagnon, je ne me rappelle pas bien lequel des deux, fit remarquer que nous 
pourrions suppléer à ce défaut de l'autre côté de la frontière, qui n'était éloignée que de cinq ou six lieues. Gagnon connaissait parfaitement tous les chemins conduisant à la frontière, et ce projet étant adopté, il se chargea spontanément de la tâche difficile et périlleuse de nous transporter cette nuit-là même, soit à Swanton, soit à Highgate, villes limitrophes de l’État du Vermont. Vers minuit, sous sa direction, nous traversâmes le Richelieu armes et bagages, dans des canots. Les officiers de cette expédition étaient $M$. Gagnon, qui nous servait de chef et de guide, le docteur Malhiot, de la paroisse de Boucherville, Ludger Duvernay, Édouard Rodier, le docteur Cote, le docteur Boudreault et moimême.

Sur la rive gauche, dans Sabrevois, nous montâmes dans deux charrettes à foin qui nous attendaient, toujours par les soins de Gagnon, et nous atteignîmes la frontière sans rencontre aucune, même en traversant le village de La Baie ou Phillipsburg, dont la population nous était politiquement hostile. Avant l'aurore nous étions arrivés sains et saufs dans la jolie petite ville de Swanton. Descendant à l'auberge, nous, entrâmes dans une grande salle tout à la fois chauffée et éclairée par un brasier ardent qui remplissait un âtre énorme. Rien ne pouvait se trouver plus à point. Nous arrivions glacés par les froids de novembre et fort soucieux sur les destinées de notre cher pays. Et voilà que tout à coup une chaleur bienfaisante vient dégourdir nos membres transis et une lumière quasi éblouissante dissipe la tristesse de nos pensées.

Nous ne fûmes pas longtemps à Swanton sans nous apercevoir que nous nous trouvions dans un milieu sympathique. Le nombre de nos amis croissait tous les jours. Nous nous mîmes sans tarder à la recherche d'armes pour suppléer à ce qui nous manquait le plus dans la lutte à main armée où nos adversaires politiques nous avaient entraînés. Nous avions fait sous ce rapport des progrès satisfaisants, lorsque dans une de nos courses aux environs de Swanton, nous fîmes la rencontre de l'honorable L.-J. Papineau ${ }^{1}$ et du docteur O'Callaghan, ce qui précipita nos plans et hâta le retour des réfugiés sur le sol canadien.

M. Papineau voyageait sous le nom de M. Martin. - Note de l'auteur. 


\section{CHAPITRE IX}

\section{COMBAT DE MOORE'S CORNER ${ }^{1}$}

$\underline{\text { Retour à la table des matières }}$

Au commencement de décembre 1837, nous nous trouvions une dizaine de Canadiens à Swanton, jolie petite ville de l'État du Vermont, située à sept ou huit milles de la frontière canadienne. Au nombre de ces Canadiens étaient Ludger Duvernay, éditeur-propriétaire de La Minerve, Édouard Rodier, député à la Législature, le docteur Malhiot le docteur Boudreault, le docteur Cote et le capitaine Gagnon, de la Pointe-à-la-Mule, homme remarquable par son caractère intrépide et héroïque.

Nous n'avions pas été oisifs pendant notre séjour à Swanton. Engagés dans une lutte de principes dont dépendait l'avenir de notre cher Canada, tous jeunes et pleins d'exaltation patriotique, nous avions foi en l'avenir. Mais dans cette lutte, quand de part et d'autre les partis grossissaient, nos adversaires avaient tous les avantages d'un facile armement, tandis que nous nous trouvions contraints de repousser leurs attaques et leurs atteintes à nos libertés et à nos droits constitutionnels avec des armes improvisées, des fourches et des faux. Nous avions donc pourvu, en autant que nos ressources nous le permettaient, aux moyens de nous défendre. Nous nous trouvâmes bientôt en possession d'une centaine d'armes à feu dont plusieurs étaient des carabines, deux petites pièces de canon et des munitions convenables pour toutes armes. Tout ceci se faisait autant que possible à l'insu des autorités américaines.

Une de nos difficultés étaient de rendre ces armements à Saint-Césaire, sur la rivière Richelieu, où, nous avait dit l'honorable L. J. Papineau, nous étions attendus, un camp ayant été formé en cet endroit sous le commandement du docteur Wolfred Nelson.

1 Quelques-uns des détails de ce combat ont été communiqués par mon père à M. L. -O. David, qui les a publiés dans son ouvrage : Les Patriotes, de 1837-38. 
Nous partons de Swanton le 6 décembre 1837. Passant par Righgate, nous franchissons la ligne $45^{\mathrm{e}}$ et nous nous retrouvons sur le sol canadien. Nous sommes en tout et partout soixante-quinze à quatre-vingts hommes, dont les trois quarts sont des habitants de la Grande-Ligne (Pointe-à-la-Mule). Ils nous sont arrivés sur le haut du jour précédés de leur chef le brave, l'héroïque Gagnon. Il était passé comme un coup de foudre avec son petit corps d'élite à travers le village de Missisquoi. Il avait, par la hardiesse de cette manœuvre, paralysé les habitants et pétrifié les sentinelles, à tel point que personne n'avait osé s’opposer sérieusement à son passage. Il s'était rendu ainsi, presque sans coup férir, jusqu'à Swanton pour nous rejoindre et former la masse de la force qui devait ce soir-là même se mettre en route pour Saint-Césaire.

L'organisation de notre petite troupe se fit, si ma mémoire ne me trompe, avec un peu de précipitation et au moment même du départ. Le commandement fut décerné au docteur Malhiot, ayant sous ses ordres en qualité d'officiers, Gagnon, Duvernay, Rodier, Boudreault et moi. Je fus chargé de l'avant-garde composée d'une dizaine d'hommes.

Nous avançons dans cet ordre sur la grande route. Arrivés à l'endroit appelé Moore's Corner, un des éclaireurs vient m'avertir de l'approche d'un corps de troupes. Je commande aussitôt la halte et le corps principal nous rejoint. Je m'approche du commandant Malhiot et des autres officiers groupés autour de lui et je leur indique les hauteurs qui, à une distance de moins de deux cents pieds, sont hérissés de baïonnettes.

Presque au même instant des coups de feu partent de ces hauteurs, et nous n'avons que le temps, pour nous mettre en position de riposter, de nous déployer en tirailleurs diagonalement sur la grande route, en longeant les clôtures. Nous aurions pu nous retrancher dans la maison Moore, mais la force numérique de l'ennemi était si manifestement supérieure à la nôtre que celui-ci aurait pu nous y cerner et nous couper la retraite. Nous fûmes en effet obligés de retraiter, mais ce ne fut qu'après un feu vivement soutenu de part et d'autre que notre brave petite cohorte laissa la victoire à nos adversaires. Ce résultat était inévitable. Nous combattions un contre quatre au moins, et l'ennemi avait l'avantage de la position et de l'armement.

Je me trouvais avec mon avant-garde au centre de la ligne. Chacun se tint courageusement à son poste sur la ligne entière, jusqu'à ce que le commandant eût donné l'ordre de la retraite. Presque tous purent regagner la frontière.

Un seul des nôtres fut tué sur place, un jeune homme nommé Patenaude, âgé de vingt ans à peine. Gagnon et Rodier dangereusement blessés, cinq ou six autres, plus ou moins gravement atteints furent transportés par leurs camarades en lieu sûr. Deux jeunes gens de la Grande-Ligne, légèrement atteints, tombèrent aux mains des soldats. Dès le commencement de l'action, je 
reçus au pied une balle de mousquet. Au moment de la retraite, on me transporta dans une remise, mais comme les balles y pleuvaient, on me reçut dans la maison de M. Moore, où les soldats me trouvèrent, après le combat. 


\section{CHAPITRE $\mathbf{X}$}

\section{OBSERVATIONS SUR CE QUI PRÉCÈDE ${ }^{1}$ •}

\section{$\underline{\text { Retour à la table des matières }}$}

Il y a ici une seconde interruption dans les mémoires de Bouchette. Comme pour la première interruption, on peut continuer le récit, se guidant sur les notes laissées par l'auteur, lesquelles sont assez complètes et suivies pour donner une connaissance des faits et même des détails. Il reste un seul point qu'il faut reconstituer par la tradition orale principalement, c'est le jugement que portait mon père sur les événements auxquels nous venons d'assister et ceux de même nature que nous savons s'être passés ailleurs à peu près simultanément. J'ai recueilli ce jugement de la bouche de l'auteur des Mémoires, à une époque éloignée des événements dont il est question. Je le donne ici exactement tel qu'il se présente à mon souvenir. Je n'avais que dixsept ans lorsque mon père mourut le 4 juin 1879, mais il m'avait déjà raconté sa vie, et en me remettant les documents que je publie aujourd'hui et dont il n'avait pu terminer la rédaction, il me donna les explications que j'essaye de résumer ici et dans un chapitre qu'on trouvera plus loin.

Une chose devient évidente à la lecture des événements qui ont précédé et accompagné l'insurrection de 1837, c'est que l'on n'est pas en présence d'un soulèvement voulu et préparé, mais d'une explosion provoquée par une suite d'actes injustifiables. Ce n'est qu'un épisode, l'événement, c'est la conquête du gouvernement responsable. Les contemporains, comme cela arrive presque toujours, ne croyaient pas l'œuvre aussi avancée qu'elle l'était réellement. Le pays en était pourtant à ce moment critique où, dans l'ancienne Rome, les plébéiens se préparant à la résistance, les patriciens se voyaient obligés de céder. L'oligarchie canadienne, comme jadis celle de Rome, sentait venir la fin de son règne et elle se cramponnait désespérément au pouvoir qui lui échappait. C'était là précisément la cause de l'embrasement qui se produisit

\footnotetext{
1 Rédaction de M. ERROL BOUCHETTE.
} 
simultanément dans les deux Canadas. La situation créée par le family compact ou par la domination de la caste était en effet à peu près la même dans les deux provinces, sauf sur ce point très important, que dans la province inférieure elle se compliquait d'une question de race et dans la province supérieure d'une question d'allégeance.

Les agitateurs haut-canadiens, sans renoncer à leur allégeance britannique, n'envisageaient cependant pas avec beaucoup de répugnance l'annexion à une république composée d'hommes de leur race et de leur langue.

Il en était autrement des Canadien s-Français. Pour des raisons nationales, ils ne pouvaient vouloir de l'annexion — pas plus qu'ils n'en veulent aujourd'hui. L'indépendance, qu'ils auraient pu souhaiter dans d'autres circonstances étant irréalisable, il leur restait un seul objectif, la réforme constitutionnelle qui leur procurerait une liberté politique suffisante sans changement de drapeau. Ils s'étaient organisés dans ce but, ils comprenaient tous la chose ainsi, depuis le citoyen le plus humble jusqu'au plus illustre.

Les partis dans le Bas-Canada pouvaient donc se classifier comme suit :

$1^{\circ}$ Les Canadiens-Français, voulant la liberté constitutionnelle et acceptant volontiers le lien colonial ;

$2^{\circ}$ L'Angleterre, voulant le maintien du lien colonial et la paix, ne s'objectant pas au fond à accorder des réformes constitutionnelles, mais craignant les conséquences d'une trop grande libéralité ;

$3^{\circ}$ L'oligarchie; un petit groupe d'hommes détenant le pouvoir dans la colonie, craignant de le perdre et prêt à tout tenter pour le conserver.

Il est certain que les résolutions iniques de lord John Russell lui furent inspirées par ce dernier groupe. Lord John Russell lui-même n'avait pas de parti pris. Ses actes subséquents le prouvent, puisque c'est lui qui a enfin décrété le gouvernement responsable colonial. On s'était trompé en Angleterre.

Au Canada, M. Papineau eut à résister à l'insurrection d'une caste contre l'évolution constitutionnelle. La population française ne songeait nullement à la résistance armée, mais elle était bien organisée pour la défense constitutionnelle. Dans tous les principaux centres et dans les grandes paroisses, il existait des comités de surveillance dirigés par des hommes éclairés et animés d'un excellent esprit. Toute cette organisation était entre les mains de M. Papineau qui jouissait de la confiance universelle et d'une autorité absolue. Même les modérés, M. Parent en tête, s'étaient ralliés à lui entièrement. Cette cuirasse constitutionnelle devait être invulnérable, à moins de fautes de tactique ou d'imprudences de la part de ceux qu'elle abritait. Or les 
imprudences étaient à craindre dans la région qui s'étend au sud de Montréal jusqu'à la frontière des États-Unis. Là, la population était plus dense, les esprits plus exaltés, on pouvait y provoquer, en décrétant l'arrestation des chefs de paroisses, par exemple, des manifestations inconsidérées qui permettraient de crier à la rébellion.

Mon père croyait que $M$. Papineau aurait pu tirer un grand parti de cette belle organisation nationale en provoquant simultanément, dans toutes les parties du pays, une protestation solennelle où le peuple aurait réaffirmé son intention de vivre sous l'égide de l'Angleterre, à la seule condition qu'on lui accordât la jouissance de tous les droits des sujets britanniques. On aurait supplié, en même temps, les autorités de ne pas pousser la population, en désespoir de cause, aux résolutions extrêmes. Puis se saisissant fortement de la région menacée, on y aurait organisé la résistance ; non pas la résistance inutile par les armes, mais par le moyen de grands rassemblements pacifiques qu'on aurait dérobés à la rencontre des troupes en rétrogradant vers la frontière qu'on aurait franchie au besoin. C'eût été mettre en opposition éclatante, le droit et la force.

Par cette tactique, croyait-il, on eût fait forcément entrer en scène le clergé catholique, dont l'intervention, dans ces conditions, eût sans doute mis fin à la lutte et permis peut-être à $\mathrm{M}$. Papineau de recueillir la gloire qui fut plus tard le partage de La Fontaine.

Un tel effort aurait-il pu réussir ? Sans pouvoir, à cette distance, l'affirmer positivement, il faut convenir que cette tactique eût été la continuation, dans des circonstances plus difficiles, il est vrai, du système invariablement adopté par les Canadiens-Français dans leurs revendications et qui avait donné par le passé de bons résultats. Quoi qu'il en soit, une chose reste acquise, c'est que disposant de l'immense force morale qui résulte de l'unanimité d'un peuple, le chef de ce peuple ne sut rien faire ni rien tenter.

Et le récit circonstancié de Bouchette nous fait voir le résultat inévitable de cette inaction, les chefs subalternes livrés à eux-mêmes, sans direction et sans entente, ne communiquant pas même entre eux, et dans un complet désarroi ; une population héroïque et dévouée résistant en vain à la force militaire organisée.

Faisons pourtant la part des difficultés de la situation et reconnaissons que les accusations avilissantes portées contre les hommes qui ont fait de grandes choses, contiennent presque toujours un élément d'injustice. Admirons donc sans réserve en Papineau le tribun et le chef populaire, reconnaissons la noblesse de ses services durant la première et la belle partie de sa vie. Imputons ses graves erreurs, puisqu'elles sont indéniables, à la faiblesse humaine uniquement et nous resterons dans le vrai. Plaignons-le d'être, en ce 
moment décisif, tombé dans un désordre d'esprit qui le rendit incapable de former et d'exécuter les résolutions énergiques qu'exigeaient les circonstances. Il dut lui-même en souffrir cruellement. Il disparut de la scène, on peut dire qu'il en disparut à jamais, car là, en vérité, se termine sa carrière.

Papineau disparut, mais le peuple resta debout et vraiment victorieux, même au moment où Wolfred Nelson et ses vaillants compagnons se faisaient écharper pour un principe dans des escarmouches insignifiantes dont leurs compatriotes ne perdront jamais le souvenir. 


\title{
CHAPITRE XI
}

\author{
LES PRISONNIERS TRANSPORTÉS À L'ÎLE AUX NOIX, PUIS À \\ MONTRÉAL - CONTRASTE ENTRE LES VOLONTAIRES ET \\ LES TROUPES RÉGULIÈRES - LES PRISONS DE \\ MONTRÉAL - PAUVRE DICK.
}

\section{$\underline{\text { Retour à la table des matières }}$}

Nous avons laissé l'auteur des Mémoires blessé et alité dans la maison hospitalière de M. Moore. Celui-ci se montra pour son hôte involontaire plein d'égards et de bonté. Quant à madame Moore, dit mon père, elle fut vraiment la bonne Samaritaine. Il y avait aussi dans la maison, M. Moore, fils, alors un jeune garçon, que j'ai revu plus tard lorsqu'il était déjà âgé. J'ai pu le remercier des bons procédés des siens envers mon père. Toutes les circonstances de cet événement étaient restées profondément gravés dans la mémoire de M. Moore. Il se rappelait bien que sa mère avait protégé Bouchette contre la première fureur des volontaires qui menaçaient de lui faire un mauvais parti. Cependant, elle ne put les empêcher d'amener le blessé, malgré son état, qui était sérieux.

Le 7 décembre il fut, avec les autres prisonniers, jeté dans une charrette sans ressorts et conduit à l'Île aux Noix par des chemins affreux. Le voyage dura toute la journée, les saccades de la voiture le faisant cruellement souffrir. Une des pièces de 9 ramenés par des libéraux des États-Unis, était tombée aux mains des volontaires. À la halte de midi, ceux-ci voulurent s'amuser en tirant à la cible avec ce canon, mais au premier coup il éclata, blessant deux hommes assez sérieusement. Ce détail fera juger de la qualité des armes dont disposaient les Canadiens.

La garde du fort de l'Île aux Noix était à cette époque confiée à une compagnie de vétérans sous le commandement du major Johnson. Celui-ci se montra, en autant que les circonstances le lui permettaient, bon et même généreux envers les prisonniers. Son subalterne, le capitaine Knight, fut au contraire d'une sévérité outrée. Mon père, alors très malade et souffrant de la 
fièvre, fut placé dans la salle du corps de garde, où la famille du commandant et surtout son fils un jeune clergyman, lui prodiguèrent des soins. Il en parle avec reconnaissance. On avait placé les autres prisonniers dans les cachots. Il en arrivait deux ou trois nouveaux chaque jour. Bientôt ils furent au nombre d'une vingtaine, parmi lesquels le docteur Kimber, le major Jalbert et Rodolphe des Rivières. On les traitait fort mal. Les cachots n'étaient pas chauffés et on ne leur donnait pas même de la paille pour se coucher. "Cependant, remarque l'auteur, nous n'étions pas des rebelles, nous n'avions jamais eu l'intention de renoncer à notre allégeance. Nous n'avions fait que nous défendre contre l'agression ».

Après dix jours de souffrances au fort de l'Île aux Noix, on achemina les prisonniers sur Montréal. Ils devaient voyager sous l'escorte d'un détachement de volontaires commandé par un très vilain personnage nommé Marsh. Bien qu'il fit grand froid, ce Marsh fit garrotter les prisonniers. Comme on les transportait dans des traîneaux sans abri, et qu'ils ne pouvaient faire un mouvement pour se réchauffer en activant la circulation du sang, ils étaient transis de froid. Mon père seul ne fut pas garrotté. Il était trop malade pour se mouvoir. On le coucha sur de la paille au fond d'un traîneau. Avant de mettre sa troupe en marche, Marsh donna à ses hommes des instructions tellement barbares que mon père ne put s'empêcher de protester hautement.

À la Pointe-à-la-Mule, un détachement du $66^{\mathrm{e}}$ régiment, sous le commandement du lieutenant Johnson, vint remplacer les volontaires à la garde des prisonniers. Ceux-ci s'en trouvèrent bien. Les volontaires manquaient de discipline. Ils étaient des partisans fanatiques ou des immigrants ignorants et grossiers, croyant s'attirer les faveurs du pouvoir en se montrant impitoyables. Les soldats réguliers au contraire étaient disciplinés et savaient à l'occasion se montrer humains. Ils soulagèrent autant que possible les souffrances de ceux qui étaient confiés à leur garde. À Saint-Jean, les prisonniers furent incarcérés pour la nuit. Ils furent en butte à une cruauté féroce, de la part de leurs gardiens.

Le lendemain, les prisonniers continuèrent leur voyage jusqu'à Montréal, cette fois par le chemin de fer ${ }^{1}$. Ils y arrivèrent le matin. La ville était sous le coup d'une excitation intense. Les patriotes traversèrent la ville enchaînés, sauf mon père, qui, toujours très malade, dévoré par la fièvre et incapable de se mouvoir, fut placé dans une carriole entre deux grenadiers. Un citoyen de Montréal, feu M. Peter-S. Murphy, frère de feu le sénateur Murphy, m’a décrit cette entrée des prisonniers. La foule faisait haie silencieuse mais menaçante. Elle se préoccupait surtout de protéger les prisonniers contre les insultes et les projectiles des membres du Doric Club. Ceux-ci n'osèrent pas exécuter ce

\footnotetext{
1 Le premier chemin de fer construit au Canada.
} 
projet qu'ils avaient, paraît-il, formé et qui aurait, disait M. Murphy, provoqué une émeute sanglante.

On les enferma d'abord dans l'ancienne prison, mais deux ou trois heures après on les transporta à la prison nouvelle sous une escorte de volontaires commandée par $\mathrm{M}$. de Bleury. On assigna à quelques-uns des chefs des chambres dans l'appartement du geôlier. Quant à mon père, on le logea au troisième étage dans une pièce assez vaste et dont la fenêtre n'était pas grillée. Elle le fut dans la suite mais la prison n'était pas tout à fait terminée, et l'on jugeait avec raison que dans son état de faiblesse il ne pourrait s'évader. C'est là du reste une idée à laquelle mon père et ses principaux compagnons ne se sont jamais arrêtés. On le plaça sur un lit qui se trouvait dans cette chambre et on l'enferma. La chaleur que répandait un gros poêle chauffé à blanc était intense au point que, se sentant défaillir, il parvint à enlever sa chaussure et la lança contre la fenêtre dans l'espoir de briser une vitre. Mais il n'eut pas la force d'atteindre la vitre et il tomba dans le délire. Sur les entrefaites, le geôlier, un nommé Ward, entra et ouvrit la fenêtre toute grande. C'était une froide journée du mois de décembre. Ce brusque changement de la chaleur intolérable au froid le plus vif faillit causer la mort de mon père. Pendant plusieurs semaines il souffrit d'une violente attaque de rhumatisme articulaire.

«Quelques jours après mon incarcération, continue l'auteur, le docteur Nelson, cet homme bon et héroïque, fut fait prisonnier. On l'enferma tout d'abord dans un cachot. Il demanda à être conduit auprès de moi et dès que je fus suffisamment rétabli, les autorités y consentirent. On finit même par lui donner une chambre vis-à-vis la mienne et nous pûmes nous consulter ensemble au sujet de notre défense. La loi martiale était proclamée et nous attendions tous les jours à comparaître devant un conseil de guerre ».

Ces détails font voir, comme le dit d'ailleurs Bouchette, que la discipline de la prison, d'abord très sévère, était devenue peu à peu, plus tolérable. Les prisonniers purent communiquer entre eux. Ils organisèrent même une fête assez joyeuse à l'occasion du premier janvier 1838. Il Je décorai ma chambre, continue l'auteur, au moyen de mon pinceau et en reproduisant sur les murs des paysages qui se trouvaient dans mes cartons. D'un côté, je peignis les chutes Montmorency, de l'autre la villa de M. Atkinson, au Cap-Rouge. Autour de ma fenêtre cintrée s'enlaçaient, une vigne et un chèvrefeuille. Les deux autres pans, car ma chambre affectait la forme d'un pentagone irrégulier, étaient occupés, l'un par des tablettes où j'avais placé mes livres, l'autre par ma petite batterie de cuisine, mon service de table, ma cafetière, etc., le tout autant que possible dissimulé et disposé de manière à ne pas nuire à l'harmonie générale. Dans un coin de la pièce, je plaçai mes portefeuilles, dans l'autre ma guitare. Le plafond, naturellement, devait être bleu ciel. J'étais en robe de chambre, et monté sur une échelle j'achevais de brosser le ciel de mon jardin, lorsque je reçus la visite de $\mathrm{M}$. Aaron Vail, ancien chargé d'affaires des États-Unis à 
Londres, où je l'avais rencontré en 1833, chez le colonel Stanhope. Nous causâmes longuement des choses du passé et il se mit entièrement à ma disposition, paraissant désireux de me rendre service. Le capitaine Marriott, que j'avais également rencontré à Londres, vint aussi me faire visite.

«Peu à peu nous avions organisé un système qui nous permettait de communiquer avec le dehors et d'obtenir des nouvelles. Au point de vue matériel, nous ne manquions de rien, grâce aux dames du parti libéral qui nous comblaient de mets et d'objets de luxe. On m'avait permis de prendre à mon service un jeune garçon muet, emprisonné pour quelque menu vol. Cet enfant me fut très utile. Il s'attacha à moi et me fit cadeau d'un serin appelé Dick. Bientôt Dick devint mon ami. Il perchait sur mon épaule et partageait mes repas. Son chant m'éveillait le matin. Pendant quatre mois nous fûmes inséparables. Mais un beau matin d'avril il sortit par la fenêtre ouverte, qui maintenant était grillée, et malgré mes appels, ne revint plus. 


\section{CHAPITRE XII}

\section{UNE CORRESPONDANCE QUI A UNE VALEUR HISTORIQUE.}

Retour à la table des matières

On avait fini par permettre aux prisonniers de recevoir certaines lettres et d'en écrire. Mon père avait conservé plusieurs de ces souvenirs de sa captivité. J'ai devant moi une correspondance qu'il a voulu transcrire en entier dans ses mémoires. Il écrit à ce sujet :

« Je retrouve parmi mes papiers une lettre que m’écrivit mon excellent ami le colonel Dundas, pendant que j'étais prisonnier à Montréal, en 1837. Même après tant d'années, cette lettre généreuse m’est encore d'un grand prix, et la réponse que j'y fis et dont j'ai conservé une copie, possède quelque valeur historique. Lorsqu'on la publiera on comprendra non seulement mes propres sentiments quant à ce qu'on a appelé « la rébellion », mais aussi la cause et le motif du mouvement tout entier, au fond duquel on ne trouve aucune déloyauté véritable envers la couronne anglaise. Cette lettre, jointe à la narration que je préparai à bord de la frégate Vestal, à la demande des officiers de ce vaisseau, pendant que j'étais en route pour les Bermudes, servira à rectifier l'opinion quant aux événements dont elles traitent. Un exemplaire de cette narration écrite sur la Vestal se trouve entre les mains du docteur Nelson qui l'a approuvée et signée avec moi ${ }^{1}$. Depuis longtemps déjà le gouvernement

Une copie de ce mémoire important était restée entre les mains de l'auteur. Malheureusement, il m'a été impossible de le retrouver, et je crains bien qu'il soit perdu. La copie dit docteur Nelson a été détruite par un incendie. L'historien Kingsford m'ayant dit que lord Durham l'avait insérée comme annexe à son rapport. J'ai feuilleté avec grand soin ce tome volumineux, mais sans pouvoir le retrouver. Il est donc probable que M. Kingsford était sous une fausse impression. L'auteur s'attache, dans ce document, à démontrer, comme il le fait plus succinctement dans la lettre qu'on va lire, que les Canadiens n'ont jamais eu l'intention de se révolter contre la couronne anglaise, qu'ils n'avaient rien préparé pour cela, bien qu'il leur eût été facile de se procurer des armes et d'organiser une résistance formidable. Qu'en résistant à l'arrestation inique et illégale de leurs chefs, ils ont cédé à ce sentiment naturel et spontané qui porte tout homme digne de ce nom à résister à l'agression et à défendre sa vie et sa liberté. Les Canadiens-Français ont, en effet, de hautes 
anglais a pratiquement reconnu que ceux qui participèrent à ce mouvement n'étaient pas coupables de haute trahison. L'histoire leur rendra justice encore plus entière en reconnaissant formellement qu'ils s'engagèrent dans cette lutte par patriotisme pur, afin d'obtenir pour leur pays de libres institutions politiques.

Voici la lettre du colonel Dundas, dont l'original anglais fait partie des Mémoires :

Mon cher Bouchette,

Je me reproche de ne pas vous avoir écrit, surtout à l'occasion du malheur qui vous a atteint au seuil même de votre nouvelle vie. Je vois d'autre part, par les journaux, que vous avez été mêlé à la révolte canadienne, que vous avez été blessé et fait prisonnier. Je vous écris pour vous exprimer l'intérêt que je prends à tout ce qui vous regarde et cet intérêt n'est aucunement diminué par la ligne de conduite que vous avez adoptée, bien que je la désapprouve aussi énergiquement que possible. Une partie de votre conduite me fait un sensible plaisir : vous n'êtes pas de ceux qui, ayant provoqué une révolte, ont bassement abandonné leurs camarades, mais vous avez bravement combattu pour la défense de votre drapeau et versé votre sang pour la cause que vous aviez épousée. J'aurais voulu vous voir mieux user de vos talents, mais une conduite conséquente est toujours respectable, et j'espère vous rencontrer en des temps plus heureux lorsque le tumulte sera apaisé. Vous avez, je crois, quelque confiance en mon intégrité. Je vous dirai donc que l'opinion de tous en Angleterre est que la révolte est absolument gratuite. Dans la chambre des Communes, quelques-uns des plus outrés (baser sort) prédirent, dès la première nouvelle, un soulèvement général et les conséquences les plus sinistres. Maintenant que leurs prédictions se sont trouvées fausses, ils voudraient faire oublier les mesures violentes qu'ils proposaient si prématurément. L'envoi de lord Durham doit indiquer les intentions pacifiques du gouvernement et j'ai la confiance qu'on fera disparaître tous les griefs réels.

Encore une fois, croyez à l'intérêt profond que nous prenons tous à votre bonheur. J'espère que vous m'écrirez. Madame Dundas est bien, ainsi que notre famille. Mon fils aîné est enseigne dans le $79^{\mathrm{e}}$ régiment. J'aurais voulu vous voir embrasser la même carrière. Le cadet étudie à Edimbourg, chez un $\mathrm{M}$. Terrot, un homme de grande érudition et qui, comme vous, est à moitié français. Il me reste à ajouter que si, comme je le crois, vous devez quitter le Canada pour quelque temps, j'espère que vous viendrez nous voir ici. Ma

aspirations, et dès le début ils ont compris que pour y atteindre ils devaient se servir de l'arme constitutionnelle seule. 
femme et ma famille vous feront l'accueil le plus cordial, et il en sera de même de votre très sincère ami,

THOMAS DUNDAS.

Carron Hall, 29 janvier 1838.

\section{(M. Bouchette, au colonel Dundas.)}

De ma prison, Montréal, 9 juin 1838.

Mon cher colonel,

Votre excellente lettre en date de Carron Hall, le 29 janvier, ne m'est parvenue que le 31 mai dernier. Elle me fut transmise par mon père qui la reçut le 26 ou le 27 de mai avec certaines dépêches de lord Glenelg, que lui envoyait le colonel Rowan, alors secrétaire du gouvernement. Je ne puis expliquer ce retard, mais il convient que j'en fasse mention, afin que vous ne m'accusiez pas d'une indifférence qui serait bien coupable après une lettre aussi généreuse que la vôtre. Vraiment votre démarche m'a causé une vive surprise, non pas que je vous crusse incapable de nobles sentiments. Loin de là. Mais les amitiés magnanimes sont rares dans la vie, vous en conviendrez; quelquefois elles nous surprennent. Vous m'avez donc surpris et causé aussi un bien grand plaisir.

Je ne puis vous dire ce que j'ai ressenti en vous lisant. Vous avez su réveiller mes souvenirs les plus chers. Vos reproches sont du présent, votre bonne et consolante amitié est un reflet des beaux jours disparus. Le malheur dont vous parlez a jeté un voile sur ma vie et a eu une influence incontestable sur ma carrière. Sans lui, je ne serais peut-être pas entré dans l'arène politique... En entrant dans le parti des libéraux ou des radicaux, j'agissais conformément à mes convictions, mais je faisais violence à mes goûts, car je m'aliénais un grand nombre d'amis personnels qui se trouvaient au nombre de mes adversaires politiques. Néanmoins, je m'y résignai et cela d'autant plus facilement que j'avais renoncé aux distractions sociales. Les devoirs de ma profession et les droits du peuple occupèrent désormais toute mon attention. Par droits du peuple, je n'entends nullement ces prétentions extravagantes qui sont incompatibles avec le bon fonctionnement de toute société organisée ; mais les droits fondamentaux de tout sujet britannique, et qu'on ne saurait avec justice lui refuser quelque éloigné qu'il puisse être du centre de l'empire.

Sachant qu'on refusait ces droits au peuple canadien, que nous avions l'ombre et non pas la substance de la constitution britannique; voyant le 
gouvernement embourbé dans la corruption, la partialité empoisonnant les sources de la confiance publique et du pouvoir, l'irresponsabilité dominant dans tous les départements du gouvernement local et la colonie devenue la pépinière du patronage de la métropole. Une connaissance intime, dis-je, de ces griefs me porta à combattre les odieux abus du système et je crus voir le remède dans une application plus générale du système représentatif.

Depuis 1834 l'horizon politique s'était graduellement obscurci. L'assemblée législative usa audacieusement de son privilège constitutionnel de refuser les subsides. En 1837, le Parlement adopta les trop fameuses résolutions canadiennes de lord John Russell, résolutions plus impolitiques encore qu'elles n'étaient despotiques. Sir Robert Peel, en discutant la question canadienne, avait bien raison d'accuser le gouvernement d'imprévoyance en n'envoyant pas en Canada une armée en même temps que les résolutions, car on devait présumer que de libres citoyens britanniques ne se soumettraient pas docilement à la dégradation politique qu'elles comportent.

La mesure de lord John Russell provoqua une indignation universelle. Dans des assemblées tenues sur tous les points de la province, le peuple déclara hautement que les résolutions étaient une violation flagrante de leurs droits constitutionnels. Leur langage était énergique, l'excitation était intense, et cette excitation s'accroissait encore par la virulence du parti opposé, lequel s'intitulait constitutionnel ou conservateur, c'est-à-dire conservateur des abus existants. Ces assemblées eurent lieu pendant l'été. En octobre dernier, la fameuse assemblée des cinq comtés fut convoquée à Saint-Charles. Les procédures de cette assemblée n'indiquaient pas autrement l'état de l'opinion publique que les résolutions adoptées aux assemblées précédentes ; cependant on en fit le prétexte d'une série d'arrestations comprenant tous les principaux hommes publics de la colonie, au nombre de quarante ou de cinquante. C'est cette violente mesure du gouvernement exécutif qui força le peuple à la résistance. Et ceci m'amène à vous dire un mot au sujet d'une expression dont vous vous êtes servi dans votre lettre, et que, j'en suis sûr, vous considérerez comme non avenue lorsque vous connaîtrez la vérité ; je veux dire les mots révolte gratuite. Je crois même en avoir dit assez pour vous convaincre que s'il y eut révolte elle n'était rien moins que gratuite. Croyez-vous que le peuple des Îles Britanniques eût vu sans s'émouvoir ses communes foulées aux pieds, ses amis et partisans les plus zélés et les plus capables emprisonnés, et ses libertés abolies ! Bolingbroke eût rougi du pays qui, en une telle conjoncture, ne se fût pas soulevé pour défendre sa liberté. Telle était absolument la position du BasCanada après les résolutions avilissantes de lord John Russell.

Les Canadiens s'étaient ralliés autour de leur Assemblée, ils avaient affirmé ses droits constitutionnels, et à cause de cela on les qualifiait de traîtres et de séditieux. Autant pourrait-on dire que les assemblées populaires de Londres ou de Birmingham visent le renversement du roi et de la constitution. Mais en 
vérité, en donnant à ce mot son sens véritable, il n'y eut pas de révolte ; le tout se résume en la résistance, à l'arrestation. Le peuple, spontanément et sans entente préalable, résolut de protéger ses chefs. De là des réunions d'hommes armés qui pouvaient produire l'illusion d'un mouvement de révolte préconçue. Mais il n'y eut rien de tel, et s'il en fallait une preuve, on la trouverait irréfutable dans le défaut absolu d'armement sérieux. Dans ces rassemblements on comptait généralement deux ou trois fourches et autant de faux et de fléaux contre un seul fusil de chasse, la plupart du temps de pauvre qualité. Eût-on médité une révolte, il eût été facile de se procurer dans les États voisins un armement suffisant pour toute la population canadienne. Mais le but immédiat du pays n'était pas de renverser la domination britannique; on voulait se protéger contre l'exercice arbitraire du pouvoir ministériel et judiciaire, et la résistance fut en certains cas d'autant plus désespérée qu'on croyait que le gouvernement avait déjà désigné plusieurs victimes.

Cette appréhension devint plus forte encore par suite des circonstances barbares qui accompagnèrent les premières arrestations effectuées à Saint-Jean par un détachement de la cavalerie volontaire de Montréal. Les deux messieurs arrêtés, le docteur Davignon et M. Démaray, N. P., furent arrachés de leurs demeures au milieu de la nuit, chargés de chaînes, jetés dans une charrette où ils furent solidement garrottés ; on leur passa des cordes autour du cou pour indiquer le sort qui les attendait. Ils furent délivrés par un parti de Canadiens sur le chemin de Longueuil pendant qu'on les transportait à la prison de Montréal. Le détachement de cavalerie fut mis en déroute, la charrette contenant les prisonniers renversée dans un fossé et les victimes délivrées sans grand mal, bien que la cavalerie eût tiré sur eux trois ou quatre coups de pistolet, trait de froide barbarie bien faite pour confirmer l'impression première et activer la résistance. C'est ainsi que commença la rencontre entre les deux partis.

Les limites d'une lettre (même de celle-ci, déjà beaucoup trop longue) ne me permettent pas de narrer les événements qui suivirent. Les journaux suppléeront en partie à cette lacune, bien que leurs comptes rendus soient sujets à caution, la presse étant présentement un monopole entre les mains de nos adversaires, dans ce district. On nous calomnie donc ad libitum. J'ai cru qu'il était de mon devoir tant pour la cause qu'en ce qui me regarde personnellement, d'entrer dans ces détails afin de me justifier de l'odieuse accusation d'avoir pris part à une révolte gratuite.

Quant à ma position individuelle, elle est la plus difficile et la plus pénible qui se puisse imaginer. Isolé jusqu'à un certain point de ma famille à cause de mes sentiments politiques, bien que nous soyons toujours unis par les liens de l'affection, m'ayant aliéné mes amis et rompu avec toutes mes relations sociales sacrifiant sur l'autel du patriotisme des perspectives certaines de promotion, combattant même contre mes prédilections et mes préjugés en faveur de ce qui 
est anglais, telle est la position anormale où je me trouve. Assurément, il doit être animé de fortes convictions celui que de telles considérations ne sauraient arrêter. Il me serait impossible de vous dire combien me répugne ce mot rebelle...

Comme vous, mon cher colonel, je crois que le choix de lord Durham pour gouverner la colonie est un gage des intentions pacifiques du gouvernement de la métropole, et de son désir de voir les idées politiques libérales et éclairées de cet homme d'État appliquées à notre pays. Sa tâche sera vraiment délicate et difficile. Notre position en ce moment est extrêmement humiliante. Nous sommes sans constitution, sans voix ni pouvoir et soumis à une dictature absolue. Cependant, il peut encore résulter du bien de cet état de choses exceptionnel, et si lord Durham sait mettre en pratique les théories politiques dont il fait parade, je crois pouvoir lui promettre la coopération du peuple canadien tout entier. Du fond du cœur je souhaite le succès de sa mission, qui devrait assurer pendant longtemps encore le maintien du lien entre ces colonies et la métropole.

Voilà près de quinze jours que le nouveau gouverneur général a pris le pouvoir. Il se tient éloigné de tous les partis. Il assume toutes les responsabilités et paraît vouloir cueillir seul tous les lauriers, s'il réussit. Il a démis les conseils existants à son arrivée et en a formés d'autres composés de ses secrétaires et du Commissary General (Routh). Nous, les prisonniers d'État, attendons patiemment qu'il décide de notre sort. Serons-nous jugés ou libérés sur amnistie générale ? C'est à lui d'en décider. La plupart d'entre nous sommes depuis six mois entre les murs d'une prison, privés du droit de voir nos familles et Dos amis et même de leur écrire. Depuis l'arrivée de lord Durham on a mitigé quelque peu cette sévérité. Nous pouvons maintenant écrire et recevoir des lettres.

Le dessin m'a été d'une grande ressource dans ma solitude... ${ }^{1}$

\footnotetext{
$1 \quad$ La fin de cette lettre traite d'affaires personnelles.
} 


\title{
CHAPITRE XIII
}

\author{
NÉGOCIATIONS ENTAMÉES PAR LORD DURHAM - ATTITUDE \\ DE 8 PRISONNIERS - ILS CONSENTENT À L'EXIL POUR PROCURER LA \\ LIBÉRATION DES AUTRES PRISONNIERS.
}

$\underline{\text { Retour à la table des matières }}$

Nous sommes au 28 juin 1838. Nous espérions que le couronnement de la reine serait signalé par une amnistie générale, mais il n'en est rien apparemment. La rumeur veut que lord Durham, gouverneur général et hautcommissaire, investi de pouvoirs très amples, soit favorable à nos prétentions. C'est ce que nous saurons bientôt, car le docteur Nelson et moi avons reçu il y a quelques jours une visite importante, celle de M. John Simpson. Nous avons eu avec lui une entrevue privée dans la chambre du geôlier. Il nous a laissé entendre que lord Durham était favorable à une amnistie générale, mais qu'il lui manquait quelque déclaration qui pourrait faire la base d'une proclamation officielle d'amnistie. Il nous a alors communiqué un projet de lettre au gouverneur général qu'il avait préparée et qu'il nous a invités à signer, ainsi que les autres chefs qui ont pris part au mouvement insurrectionnel. Nous avons rejeté ce projet qui était tout à fait inacceptable. Cependant, le but avoué de cette démarche nous parut recommandable. On nous représenta que de ce que nous déciderions dans cette occasion dépendrait le sort de trois ou quatre cents prisonniers politiques dans les deux Canadas. Nous proposâmes donc à M. Simpson de rédiger nous-mêmes un projet qui pourrait peut-être servir à lord Durham, s'il désirait donner un effet pratique à ses idées de clémence. $\mathrm{M}$. Simpson y consentit. Il laissa le projet qu'il avait préparé entre les mains du docteur Nelson, à titre de document confidentiel, et fixa une nouvelle entrevue pour le lendemain.

Ayant rédigé notre projet, nous le soumîmes à ceux de nos amis qui nous entouraient et qui se trouvaient en état de nous donner des conseils. Le lendemain, à l'heure convenue, nous vîmes de nouveau M. Simpson, et nous remîmes entre ses mains le projet que nous avions ainsi préparé. Je me 
souviens qu'en le lisant il secoua la tête en déclarant que notre lettre lui faisait bien plutôt l'effet d'un plaidoyer de justification et qu'elle n'était pas du tout une reconnaissance de notre culpabilité. Cependant, il finit par dire qu'il l'emporterait avec lui, qu'il y réfléchirait et qu'il reviendrait nous voir. Nous nous rencontrâmes de nouveau, le projet fut quelque peu modifié et finalement signé.

Cet incident ayant donné lieu à quelque discussion et même a de fausses représentations, je crois devoir transcrire ici une lettre que les exilés des Bermudes publièrent à ce sujet et qui contient outre notre lettre à lord Durham, une description des circonstances où elle fut écrite. Cette lettre a du reste été publiée au long dans l'histoire du Canada de M. Robert Christie.

Voici cette correspondance :

« Monsieur - Nous conformant à la règle que nous nous sommes imposée, nous avons jusqu'ici évité toute discussion relative aux questions politiques qui agitent notre pays. Nous n'avons rien relevé des nombreux articles publiés à notre sujet. Cependant, notre réputation exige que nous rompions, par exception, ce rigide silence, pour nous justifier des diffamations publiées contre nous par le London Sun du 20 août dernier et fidèlement reproduites par la Royal Gazette de ces îles (les Bermudes).

«Quelque calomnieux que soit cet article nous n'en aurions peut-être rien dit, s'il n'avait pas paru s'appuyer de la sanction de M. Charles Buller, premier secrétaire de lord Durham. Le nom et le caractère officiel de ce personnage donneraient un certain poids à cet écrit s'il restait sans réfutation.

« Pour établir la mauvaise foi et la fausseté de l'article du London Sun, nous n'avons qu’à citer les pièces sur lesquelles il prétend s'appuyer. Jamais nous n'avons pétitionné. Jamais nous n'avons sollicité notre " déportation », suivant l'expression du Sun. Jamais nous n’avons demandé grâce, clémence ou merci à lord Durham ou à qui que ce soit. Jamais nous n'avons imploré le gouverneur général de ne pas nous mettre en accusation. Il est faux que l'ordonnance nous exilant, et dont la nullité absolue a été récemment proclamée par le Parlement anglais, pourvoit à la mise en accusation des personnes ainsi expatriées, au cas de leur retour. Il est sans doute absurde de déclarer que les gens seront mis à mort sans forme de procès, mais nous ne pouvons être tenus responsables de cette absurdité.

Avant de mettre sous les yeux du public les lettres qui vont suivre, il convient de dire que la négociation fut entamée par M. John Simpson, percepteur des douanes de Sa Majesté au Coteau-du-Lac. Le principal secrétaire de lord Durham lui donna carte blanche pour communiquer avec les prisonniers d'État dans la prison de Montréal. 
Il se présenta sans être sollicité et inopinément. Il demanda et obtint de communiquer avec nous, et, avec beaucoup de précautions oratoires, il nous présenta un projet de lettre à lord Durham, et il nous invita, ainsi qu'une douzaine d'autres, à la signer. Toute cette conversation a été soigneusement notée et attestée, mais nous ne nous proposons pas d'en divulguer davantage maintenant. Qu'il suffise de dire que la lettre en question fut révisée, modifiée dans ses parties essentielles, revêtue de huit signatures et, dans la forme suivante, acceptée avec reconnaissance par M. Simpson.

MONTRÉAL, Nouvelle prison, 18 juin, 1838.

Monseigneur. - Vous venez parmi nous ne représentant ni une classe, ni une caste, mais avec un caractère qui vous est propre et qui vous donne droit à la confiance que nous vous accordons. Ne croyez pas que nous cherchions à capter votre faveur par de vains compliments. Nos âmes ne sont pas, comme nos personnes, prisonnières. Nous ne saurions jamais descendre jusqu'à invoquer la clémence pour nous-mêmes. Nous appartenons à notre pays et nous nous sacrifions volontiers sur l'autel de ses libertés.

Nous nous sommes révoltés, monseigneur, - que cet aveu ne vous étonne pas. Nous nous sommes révoltés ni contre la personne de Sa Majesté ni contre son gouvernement, mais contre une vicieuse administration coloniale ; et nous attendons l'événement, prêts à subir la peine qu'on voudra nous imposer.

Votre venue plus hâtive eût été un bienfait ; elle sera un bienfait même à cette heure tardive. Et si nos efforts y sont pour quelque chose, ils n'auront pas été inutiles au bonheur de notre patrie — et nous ne murmurons pas.

Votre venue plus hâtive eût mis fin à une administration vicieuse ; la justice eût triomphé ; la loi appliquée fidèlement et impartialement, eût fait disparaître les griefs et procuré au gouvernement la confiance et l'affection de tous les citoyens.

Nous protestâmes, on se moqua de nous ; on épuisa contre nous l'invective, la calomnie, l'outrage. Poussés à bout, nous eûmes soit à résister courageusement à l'injustice, ou bien, acceptant l'esclavage, à devenir un peuple dégradé et apostat. Nous nous mîmes en armes pour nous défendre, non pas pour attaquer. Le gouvernement nous en empêcha-t-il, essaya-t-il de nous en empêcher? Non! S'il n’encouragea pas, il toléra tout au moins notre tentative, et ce pour des motifs auxquels nous ne voulons pas penser. Pour calmer la fièvre d'un peuple que son malheur poussait aux mesures extrêmes, lord Gosford, par une proclamation, invita ceux qui avaient fui à rentrer dans leurs foyers. La magistrature tint-elle compte des intentions conciliantes que le gouverneur exprimait? Non! La trame était ourdie, les mandats lancés contre 
tous ceux qui, se réclamant de leurs droits inaliénables de sujets britanniques, osaient critiquer les hommes et les mesures publiques. Ainsi, monseigneur, les autorités elles-mêmes, non moins que la violence de cette classe qui nous était opposée en politique, nous poussait à la résistance. Nous voulons cependant oublier et même pardonner.

Revêtu d'un pouvoir dictatorial, sans injustes préventions et d'un honneur sans tache, vous êtes puissant dans les conseils de votre pays comme dans le nôtre, et votre voix pourra parvenir jusqu'au trône.

Ardent à réclamer la liberté civile, vous comprendrez ce qu'éprouve un peuple que ce principe anime, mais qu'on prive de cette liberté. Ressentant et déplorant la violation de notre constitution, nous luttâmes, non pas pour l'indépendance, mais pour le maintien du véritable esprit de la constitution et de la liberté britanniques.

Nous ne voulons pas vous distraire du grand et glorieux objet de votre haute mission, ni vous supplier pour nous-mêmes, ni tenter de nous soustraire au sort qui nous attend. Nous désirons éviter les formalités d'un procès, convaincus que nous ne saurions trouver un tribunal impartial et devant lequel nous pourrions comparaître sans crainte. Rétablir la tranquillité, la paix et l'ordre parmi un peuple confiant et généreux, voilà ce que nous vous prions de nous permettre d'accomplir. Et si, monseigneur, nous avons des liens qui nous rendent la vie aussi chère qu'à vous-même, nous ne pouvons néanmoins faire appel à votre sympathie par des supplications qui froisseraient la noblesse de vos sentiments et qui seraient d'ailleurs contraires à la dignité humaine.

Nous vous prions cependant de rendre à la liberté et à la société nos infortunés compagnons de prison et de rappeler ceux qui sont aujourd'hui fugitifs, convaincus que tous voudraient verser jusqu'à la dernière goutte de leur sang pour un gouvernement qui saurait comprendre et maintenir les droits de ses sujets, quelque éloignés qu'ils puissent être du siège de l'empire.

Nous prions Dieu pour le succès de votre mission pacifique, et pour que le peuple, adorant un même Dieu, puisse devenir un peuple uni ; répudiant, ainsi que nous l'avons toujours fait et comme vous-même en donnez l'exemple, tout ce qui différencie entre les origines, l'accomplissement de ce souhait sera le couronnement de nos efforts passés et la garantie de l'avenir.

Puissiez-vous, monseigneur, apporter le salut à ce pays si déchiré; puissiez-vous longtemps jouir du bonheur domestique que le sort nous refuse.

Nous prions Dieu de vous bénir, et si ces hautes aspirations sont coupables, nous reconnaissons notre culpabilité. 
Wolfred Nelson, R.-S.-M. Bouchette, Bonaventure Viger, S. Mareliessault, H.-A. Gauvin, T. Goddu, R. Des Rivières, L. Masson.

Au très Honorable le Comte de Durham, Gouverneur général, etc.

La lettre ci-dessus fut présentée à lord Durham, à Québec, par M. Simpson, le 23 juin. Le 26 il revint à Montréal, et ayant demandé à voir les messieurs qui avaient signé le document, il leur représenta qu'un document supplémentaire serait nécessaire pour compléter la négociation, et permettre à lord Durham, ainsi qu'il le laissait entendre, de montrer sa magnanimité par une amnistie générale. Il nous soumit une courte lettre qui était une reconnaissance pure et simple de culpabilité. À cela les signataires ne pouvaient souscrire. Nous étions cordialement disposés à faciliter les voies à lord Durham très désireux d'être les instruments de la libération de cent quarante de nos concitoyens alors prisonniers et du rappel d'un grand nombre d'autres, mais nous ne pouvions le faire en nous reconnaissant coupables, étant convaincus du contraire, et en contredisant par là notre déclaration du 18 juin. Nous défiant de notre propre opinion dans une question qui nous était si personnelle, nous refusâmes de rien faire sans l'assistance d'un aviseur légal. Jusqu'alors, on nous avait toujours refusé cet avantage, mais $\mathrm{M}$. Simpson, se croyant sans doute autorisé à cet effet, nous permit de consulter un des avocats les plus éminents du barreau de Montréal, lequel modifia la lettre et lui donna la forme où nous la transcrivons ci-après, affirmant sur sa réputation d'homme de loi qu'elle ne contenait rien de dérogatoire pour nous ni aucun aveu de culpabilité. Nous basant sur cette opinion nous signâmes la lettre suivante :

Prison de Montréal, 26 juin, 1838.

Monseigneur, - Nous avons raison de craindre que les expressions dont nous nous sommes servis dans notre lettre du 18 courant, adressée à Votre Seigneurie, peuvent paraître vagues et ambiguës.

Notre intention était d'avouer sans ambages qu'en poursuivant un but cher à la grande masse de notre population, nous avons pris part aux événements qui ont eu pour conséquence une accusation de haute trahison. 
Nous déclarions que nous voulions bien souscrire à une reconnaissance de culpabilité afin d'éviter la nécessité d'un procès et donner ainsi, en autant que cela dépendait de nous, la tranquillité à notre pays ; mais que tout en étant ainsi disposés à contribuer au bonheur des autres, nous ne pouvions condescendre à nous abriter derrière les clauses d'une ordonnance adoptée par l'ex-conseil spécial de la province.

Permettez-nous donc, monseigneur, d'accomplir ce grand devoir, de marquer notre entière confiance en vous, et de nous placer à votre disposition sans nous prévaloir de clauses qui nous dégraderaient à nos propres yeux en manifestant une indigne défiance de part et d'autre.

Avec cette courte explication de nos sentiments nous nous plaçons de nouveau à votre discrétion et nous prions que la paix du pays ne soit pas mise en danger par un procès.

Nous avons l'honneur d'être, avec un sincère respect, vos obéissants serviteurs,

(Mêmes signatures.)

C'est avec beaucoup de regret que nous donnons publicité en ces îles, aux documents ci-dessus. Nous aurions voulu aider lord Durham dans quelque projet sage et juste de politique coloniale. Nous lui souhaitions sincèrement succès dans la tâche herculéenne qu'il avait entreprise d'apaiser la tempête soulevée par ses prédécesseurs. Nous croyons cependant qu'il s'est trompé et lourdement, et nous en éprouvons un vif regret.

WOLFRED NELSON.

R.-S.-M.

Hamilton, Bermudes, 19 octobre 1838.

BOUCHETTE.

La lettre du 18 juin, puis celle du 26 furent placées entre les mains de M. Simpson qui les remit à lord Durham, et peu après une ordonnance du gouverneur condamnait les huit signataires à l'exil aux Bermudes, pour une période de temps indéterminée, en alléguant qu'ils s'étaient reconnus coupables de haute trahison ${ }^{1}$.

L'épisode dont parle la lettre des exilés aux Bermudes forme une page curieuse de l’histoire du règne de lord Durham au Canada. Arrivé à Québec en qualité de HautCommissionnaire, il était revêtu à ce titre d'une autorité très étendue qu'il outrepassa tout de 
Nous allons maintenant suivre les condamnés jusqu'au lieu de leur détention, en transcrivant cette partie des Mémoires que l'auteur intitule «le journal d'un exilé ».

même. On sait qu'après les affaires de Saint-Denis, de Saint-Charles et de Saint-Eustache, la prison de Montréal regorgeait de patriotes arrêtés un peu partout. Lord Durham se demanda ce qu'il allait en faire. Les livrer à un procès par jury, il n'y avait pas à y songer : leurs compatriotes les auraient acquittés comme leurs adversaires les auraient aveuglément condamnés. Il redoutait également, à bon droit, une cour martiale, dont les accusés seraient sortis sous le coup d'une condamnation à mort. C'est dans cette perplexité qu'il résolut de sortir des voies ordinaires de la légalité et d'agir en dictateur. Prenant occasion du couronnement de la reine Victoria, il proclama une amnistie dont tous les insurgés furent appelés à bénéficier, sauf les huit exilés aux Bermudes, dont Bouchette nous raconte ici les aventures. Cet acte général d'illégalité en renferme un second : la recherche des aveux chez les accusés Nelson et Bouchette, et leur procédure contraire au droit anglais qui présume innocent tout homme prévenu d'une infraction aux lois, tant que sa culpabilité n'a pas été établie devant un tribunal. On ne saurait trop blâmer Durham d'avoir mis Nelson et ses amis dans la pénible alternative de s'avouer coupables et de sauver à ce prix les patriotes tombés entre les mains de la police, ou bien de subir les peines de la loi dans toute leur rigueur. Se rendre au désir du gouverneur répugnait à leur conscience et à la haute idée qu'ils se faisaient du rôle qu'ils avaient joué. Mais s'ils persistaient dans leur refus, c'étaient des misères sans nombre pour une centaine d'accusés et leurs familles. C'est dans ce terrible dilemme qu'ils firent ce singulier aveu, portant une condition qui l'annule : «Si les hautes aspirations sont coupables, nous reconnaissons notre culpabilité ». Aussi lord Durham ne voulut s'en contenter, ce qui arracha aux exilés ce supplément de lettre dans laquelle ils retirent d'un côté ce qu'ils avouent de l'autre.

L'ordonnance de lord Durham fut désavouée en Angleterre comme entachée d'illégalité. Il avait agi sans consulter le conseil spécial qui existait à son arrivée au Canada, et dont il avait modifié la composition en réduisant le nombre des conseillers et en substituant à quelques-uns d'entre eux, ses secrétaires, des officiers et des fonctionnaires publics. Personnage hautain, plein de morgue et très emporté, Durham, en apprenant le désaveu, résigna sa charge et lança une proclamation qui était une réponse directe au gouvernement anglais dont il ne se gênait pas de critiquer la conduite à son égard. Cet acte de quasirévolte lui valut du Times de Londres l'épithète de « Lord High Seditioner ». Lorsqu'on lui reprochait l'illégalité de ses actes, il répondait : « Où est le respect de la constitution et de la loi dans un pays où l'on dépense l'argent du peuple sans le consentement de ses représentants ? » Cette réponse de Durham n'est-elle pas la justification de la conduite de l'Assemblée Législative avant 1837 ? 


\title{
Chapitre XIV
}

\author{
DÉPART POUR L'EXIL.
}

\section{Retour à la table des matières}

Lundi, 3 juillet, 1838. — À quatre heures cet après-midi, en compagnie du docteur Nelson et de nos six autres amis, j'ai dit adieu à ceux qui, pendant plus de six mois, furent nos compagnons de captivité dans la prison de Montréal.

Par ordonnance de lord Durham et de son conseil spécial, nous sommes condamnés à l'exil aux Bermudes pour une période de temps illimitée. L'ordonnance déclare que nous sommes ainsi condamnés parce que nous nous sommes reconnus coupables de haute trahison. Cela cependant n'est pas très exact, car nous n'avons jamais admis, nous n'aurions certes jamais voulu admettre qu'il y eut culpabilité, surtout culpabilité morale, dans nos actes politiques.

$\mathrm{Au}$ contraire, nous avons désavoué toute intention de changer notre allégeance ou de renverser le gouvernement de la reine, au Canada. Nous avons affirmé qu'en prenant les armes nous croyions avoir combattu pour la liberté dont se réclame tout sujet britannique et pour résister à des arrestations illégales qui mettaient cette liberté en danger.

La raison première de notre résistance, avons-nous déclaré, se trouve dans la loi naturelle même qui porte l'homme à défendre sa vie lorsqu'elle est menacée. La rumeur s'était accréditée, et cette rumeur était fondée, que quarante ou cinquante victimes devaient être arrêtées et qu'on devait faire un certain nombre d'exemples, afin, sans doute, d'inspirer au peuple un amour plus grand pour le gouvernement du jour. La vigueur spontanée des habitants du district de Montréal dans l'exécution de leur projet de protéger leurs chefs, pouvait, au premier aspect, et auprès de personnes ne connaissant pas les faits, passer pour une tentative de révolte. Mais si l'on examine le mouvement de plus près, l'on ne saurait y trouver autre chose qu'une de ces explosions d'indignation populaire qu'on a souvent vues se produire en des circonstances 
analogues et qui avaient pour cause la conviction que la liberté et la vie des chefs du parti radical étaient menacées par le parti au pouvoir, par les fonctionnaires et leurs enragés partisans du Doric-Club et autres organisations du même genre.

Voilà ce que contient notre déclaration, pas autre chose. Et pour ma part, je la crois rigoureusement exacte. Personne ici n'eut jamais, à ce que je crois, sérieusement dessein de renverser la domination britannique. Mais on espérait que l'énergie déployée par le peuple ferait voir combien il est sérieux dans sa revendication de réformes constitutionnelles et de réformes générales, et que le gouvernement comprendrait enfin que les Canadiens-Français conscients de leurs droits, n'hésiteraient pas à les faire valoir.

Cependant, nos actions nous avaient exposés à l'accusation de haute trahison. Un jury impartial nous eût sans doute acquittés. Mais où le trouver ce jury impartial ? Nous étions plus de cent quarante, pour la plupart des pères de famille, qui languissions depuis des mois dans les prisons de Montréal, sans qu'on nous permît de voir nos amis ni même de consulter des avocats, malgré la position difficile où nous nous trouvions.

C'est dans ces circonstances que $\mathrm{M}$. Simpson vint de la part de lord Durham nous soumettre certaines propositions. Après les avoir examinées et modifiées dans leurs parties essentielles, le docteur Nelson et nos autres compagnons d'exil consentirent à signer l'adresse à lord Durham que je viens d'analyser. J'ai en ma possession des documents qui expliquent toute la négociation ${ }^{1}$. Nous nous sentions fiers d'être les instruments de la délivrance de nos compatriotes prisonniers, et c'était là la condition fondamentale de notre négociation avec M. Simpson. Sans doute, M. Simpson nous avait dit que lord Durham ne se laisserait pas vaincre en générosité, il nous avait laissé entendre que le résultat de notre action serait une amnistie générale. Il s'y était même engagé sur l'honneur. Cependant, ce n'était pas là la partie essentielle de notre convention, et puisque nos amis qui languissaient dans les cachots sont libres, nous acceptons l'exil d'un cœur satisfait.

M. Simpson nous avait donné, samedi, l'assurance qu'on ne nous soumettrait à aucune indignité. Cependant, violant cette promesse, le shérif du district, après nous avoir perfidement serré la main à tous, donna l'ordre de nous enchaîner. Exerçant une haute fonction judiciaire et indépendant de tout contrôle militaire, il eut cependant la faiblesse, la pusillanimité de vouloir se justifier en invoquant les ordres du général Clithrow. C'était de sa part une grave erreur. Le shérif connaissait personnellement les huit prisonniers; quelques-uns d'entre eux se croyaient même ses amis personnels. Il aurait pu se

Beaucoup de ces documents sont malheureusement perdus. 
dispenser de leur infliger cette insulte et en laisser tout l'odieux à celui qui semblait croire que la chose était nécessaire ${ }^{1}$.

Clithrow lui-même arriva sur ces entrefaites et parut impressionné par la remontrance pleine de dignité que lui fit le docteur Nelson, mais il ne nous enleva pas nos chaînes.

En sortant de la prison pour gagner la voiture qui nous attendait, nous n'éprouvâmes aucune honte de nous voir ainsi. - Au contraire, nous élevâmes comme en triomphe nos bras chargés de chaînes, afin que nos amis qui se pressaient en foule aux fenêtres et aux soupiraux de la prison, pussent voir et tirer leurs propres conclusions quant au passé, au présent et à l'avenir.

L'escorte se composait d'un détachement du $7^{\mathrm{e}}$ de hussards. Le général Clithrow les accompagna jusqu'au quai. On nous embarqua au pied du courant Sainte-Marie, ce qui évita aux autorités les dangers d'une émeute et à nous les vociférations des furieux du Doric-Club. Sans l'insulte des chaînes, nos amis auraient eu lieu d'être satisfaits de cet itinéraire. Nous croyons que c'est lord Durham lui-même qui l'a prescrit.

À bord du vapeur Canada qui nous transporte en ce moment à Québec, on nous traite convenablement. M. Simpson était présent lors de notre embarquement et paraissait animé de dispositions amicales, bien que nous lui reprochâmes sa parole d'honneur violée. Sir Hugli Dalrymple commande l'escorte du $71^{\mathrm{e}}$ d'infanterie sur le bateau. Le patron, M. Douglas, un vieil ami, me serra cordialement la main, — la main gauche, la droite étant enchaînée à la main gauche de Nelson. Il avait les larmes aux yeux. Il nous combla d'attentions pendant le trajet. Avant notre départ, nous remerciâmes par écrit les hussards qui nous avaient témoigné des égards pendant le trajet de la prison au quai; nous adressâmes aussi à lord Durham une protestation contre l'indignité qu'on nous avait fait subir. Le forgeron qui nous enlevait nos fers, dit ironiquement au docteur Nelson qu'il espérait nous rencontrer au ciel.

— En enfer, alors, mon ami, en enfer, répondit Nelson, soyez sûr que nous ne vous retrouverons jamais ailleurs.

Nous croyons que Bouchette commet, sans le vouloir, faute de renseignements suffisants, une injustice à l'égard du shérif. Il nous a été donné de connaître un bon nombre de ses amis qui tous nous ont fait l'éloge de la bonté de cœur, des sentiments de pitié et de miséricorde dont débordaient le cœur de $\mathrm{M}$. de Saint-Ours, pris à partie par Bouchette, sentiments qui l'ont porté aussi loin que possible à ordonner le sort des prisonniers politiques de 1837-38. Comme tous les fonctionnaires de l'époque, les shérifs étaient sous la coupe de l'Exécutif, dont il fallait exécuter les ordres sans discuter (D.). 
Québec, mardi matin, 3 juillet. - À quatre heures et demie ce matin, on nous a embarqués sur la frégate Vestal qui doit nous transporter au lieu de notre exil. C'est notre qualité de prisonniers politiques qui nous procure l'avantage de faire le voyage sur un vaisseau de guerre ; les forçats n'y sont jamais admis.

On nous a assigné pour domicile une partie du pont, à l'arrière, près de la cabine du capitaine, et on y a transporté nos malles qui nous servent de sièges en attendant mieux. M. Simpson arrive. Il annonce que le vaisseau restera pendant deux jours à l'ancre à environ quatre milles en aval de la ville. Nous lui remettons tout ce que nous possédons en billets de banque et en argent français, et il nous rapporte une lettre de change payable aux Bermudes au montant de $£ 212,7,6$.

Vers midi, M. Charles Buller, premier secrétaire de lord Durham, vient à bord ; en se rendant à la chambre du capitaine il nous salue avec politesse. Un instant après, on vient prier le docteur Nelson et moi de nous rendre auprès de lui.

Le capitaine ainsi que M. Buller nous reçoivent convenablement. Celui-ci, au nom de lord Durham, exprime son regret qu'on nous ait mis aux fers, à Montréal. Il cherche à nous expliquer comment la chose est arrivée et désavoue de la part et au nom du gouverneur toute intention de nous faire cet affront, affirmant que si lord Durham eût soupçonné qu'on en agirait ainsi, il serait intervenu pour nous protéger. Cette explication nous fait plaisir et nous prions M. Buller de transmettre nos remerciements à qui de droit, ajoutant toutefois que nous regrettons l'effet probable de cette indignité sur l'opinion publique.

M. Buller nous demande ensuite de nous indiquer ce dont nous aurons besoin pour notre voyage. Nous lui soumettons une liste, il la sanctionne et y ajoute même une foule de choses que nous n'avions pas demandées. Évidemment, on a l'intention d'adoucir autant que possible l'amertume de notre départ pour l'exil.

Je laisse le docteur Nelson en conférence avec M. Buller pour aller rejoindre mon père et mes frères qui viennent d'arriver. Ah ! Mon pauvre père ! Absolu dans sa conception du devoir et de la loyauté, entièrement dévoué depuis plus de quarante ans au service de la science, de son pays et de son souverain, il ne comprenait guère ma conduite, et en m'embrassant il pleura sur mes péchés autant que sur mon infortune. Je lui présentai mes frères d'exil ; notre fermeté, notre calme et notre dignité l'impressionnèrent plus même que l'idée de notre séparation prochaine ne le chagrinait. Que mon cœur saigne pour ce bon père! En lui s'incarnent l'honneur sans tache, la tendresse, la générosité sans limites. Et moi, son fils, je l'ai blessé, j'ai peut-être contribué à l'affaiblissement de sa santé par ma trop grande ardeur d'esprit et de cœur. Que 
puis-je faire pour soulager le chagrin dont je suis cause ? À cette pensée mon cœur se gonfle. Cependant, j'ai pu me contenir, et il m'a vu comme je suis sûr qu'il désirait me voir, courageusement résigné à l'exil et, comme mes amis, du reste, supportant mon infortune de manière à imposer le respect. Il a dû se convaincre, à la manière qu'on nous traite en ce moment, que notre situation comporte bien plus de gloire que de honte. Enfin, il est parti, ainsi que mes frères. Ils étaient venus ces excellents frères le cœur plein d'une angoisse qu'ils ne parvenaient pas à dissimuler. Mais ils partent consolés, heureux même, car c'était surtout la détresse morale et physique dans laquelle ils me croyaient plongé qui les affligeait.

J'aurais bien voulu dire adieu à ma mère bien-aimée. Peut-être aurais-je réussi à sécher ses larmes, mais je ne suis pas assuré qu'en sa présence j'aurais su retenir les miennes. La tendresse d'une mère a quelque chose qui désarme. Comment résister à l'amour qui se traduit par ses regards, par ses accents ! Aussi, je crains bien que j'aurais succombé. Peut-être valait-il mieux qu'elle ne vienne pas. Mon père, mes frères calmeront sa douleur en dissipant ses craintes.

On m'envoie de Québec une foule de choses dont j'ai besoin, mon secrétaire, mes livres, ma guitare; ce dernier objet n'est pas le moins important. Vers quatre heures on apporte les approvisionnements commandés pour nous par M. Buller; des provisions de bouche, des services et du linge de table et de toilette.

Dans l'après-midi aussi, M. T. Bouthillier et M. Beaubien viennent prendre congé de Rodolphe des Rivières, leur parent. Pendant leur visite le commis aux vivres du bord nous envoie du vin et des biscuits. Ce soir nous dînons tous ensemble, et en organisant notre mess, le docteur Nelson est appelé à la présidence. On m'invite à siéger à l'autre bout de la table en qualité de viceprésident. Lord Durham et les officiers du bord, continuant à faire les choses très largement, n'ont rien oublié, pas même les vins dont on nous offre un excellent choix. Nous buvons à la santé de notre cher pays, à celle des officiers de la Vestal et aussi à celle du gouverneur. Je propose moi-même cette dernière santé dans un petit discours où je fais remarquer que nous pouvions sans inconvenance, dans la situation où nous étions, rendre hommage à l'élévation de son caractère et exprimer l'espoir qu'il saura réaliser l'intention dont il se réclame, celui d'administrer le pays de façon à procurer le bonheur du plus grand nombre.

J'allais oublier un incident. Nous étions sur la Vestal depuis quatre heures du matin ; il était neuf heures et les prisonniers n'avaient pas encore déjeuné, ce que voyant, un des matelots vint placer devant eux un grand seau de cocoa. J'étais en ce moment-là occupé à écrire, mais mes amis remercièrent cet homme et la plupart mangèrent sans façon, à la gamelle. Quelques instants 
après on nous servait à déjeuner dans la salle du mess des lieutenants où l'officier commandant l'infanterie de marine vint nous tenir compagnie.

Mercredi 4 juillet. - Ce matin, entre quatre et cinq heures, la Vestal leva l'ancre et se laissant descendre avec la marée, elle alla mouiller de nouveau à neuf milles en bas de Québec, à la hauteur du Trou-Saint-Patrice, île d'Orléans. Le vent souffle du nord-est et le ciel est sombre. On nous a donné pour serviteur un mousse nommé George Atkins. Nos hamacs étant descendus et la table dressée, nous déjeunons tous ensemble. Nos places à table pour le voyage seront comme suit : à tribord, MM. Masson, Goddu, Viger et Marchessault, à bâbord, les docteurs Nelson et Gauvin, Des Rivières et moi.

On nous avait promis qu'un vapeur nous amènerait nos amis qui désirent nous voir une dernière fois. Cependant, la matinée se passe dans une vaine attente ; il est midi et rien ne vient. On tire deux coups de canon pour avertir nos amis de se hâter ; encore une heure de répit, puis l'ordre est donné de lever l'ancre. Le sifilet du maître d'équipage retentit les marins se précipitent au virevaut ; chantant et marchant en cadence, ils font tourner le lourd cabestan. Spectacle intéressant, mais de triste augure pour nous. Nous ne reverrons pas nos amis. Déjà le vaisseau s'incline sous ses voiles déployées, lorsque nous apercevons une chaloupe qui s'approche à force de rames; elle nous atteint, elle accoste, M. Simpson monte sur le pont et la frégate reste en panne.

M. Simpson remet au docteur Nelson une traite au montant de $£ 172$. Il nous apporte aussi certaines provisions : de bouche et autres objets pour le voyage. Il nous expliquait par quel malentendu nos amis ne devaient pas pouvoir nous dire adieu et il était près de sept heures du soir, lorsque MM. Charles Drolet, député à l'Assemblée législative, et Hunter, accostent au navire et sont admis à bord. Ils nous annoncent qu'une réunion de plusieurs milliers de personnes a eu lieu à Québec aujourd'hui afin d'adopter une pétition à lord Durham au sujet de notre exil. Le texte des résolutions nous sera envoyé plus tard.

La visite de M.M. Drolet et Hunter est très opportune. Ils se trouveront par là en mesure de témoigner de notre attitude au moment où nous allons quitter la terre canadienne en de si pénibles circonstances et peut-être pour si longtemps. Ils pourront aussi se rendre compte de ce que fait lord Durham pour rendre moins pénible l'exécution de la sentence de bannissement qu'il a prononcée contre nous et pour réparer l'injure gratuite qu'on nous a faite lors de notre départ de Montréal.

Enfin, à huit heures, nos amis s'en vont chargés de nombreuses lettres d'adieu, le navire reprend sa route, et nous restons seuls, bien seuls, séparés de notre pays et de tout ce que nous aimons, voguant sous la garde d'étrangers vers la terre d'exil. Nous restâmes silencieux méditant ces choses et la soirée se passa ainsi jusqu'à ce que vint l'heure de nous retirer pour la nuit. C'était la 
première fois que nous tentions d'entrer dans nos hamacs, le vaisseau étant en mouvement, et ce n'est pas chose facile pour qui n'en a pas l'habitude. Les efforts inutiles de plusieurs d'entre nous pour y parvenir, dissipèrent notre tristesse. Nous rîmes de bon cœur les uns des autres, bien que les larmes ne fussent pas loin. Enfin, mes compagnons parurent s'endormir. Quant à moi, je restai longtemps sans sommeil, écoutant le bruit des vagues battant le flanc du navire et le chant monotone des matelots de quart. 


\title{
CHAPITRE XV
}

\author{
LE VOYAGE SUR LA VESTAL.
}

Retour à la table des matières

Jeudi, 5 juillet. - Le navire avait mouillé pendant la nuit à la hauteur de l'Île aux Grues. Ce matin, il continue sa route, en compagnie de l'Andromache, 28 canons, ayant à bord, sir William Harvey, gouverneur de l'Île du PrinceÉdouard. Du pont où nous nous trouvons nous ne voyons absolument rien de ce qui se passe, cependant on ne nous invite pas à monter sur le faux-pont. Craindrait-on de notre part quelque tentative d'évasion? Éprouve-t-on la nécessité de nous interdire quelque chose ? Il est certain que personne parmi nous ne songe à se jeter dans le Saint-Laurent.

Le commis aux vivres, libre par suite de l'absence du capitaine qui dîne à bord de l'Andromache, nous aide à ranger nos malles et nos provisions. Il nous assigne un second serviteur meilleur que le premier, qui sait faire le service de la table et qui surtout est cuisinier. Il devient notre Vatel attitré, et grâce à lui notre cuisine sera excellente.

Après dîner, deux officiers sont venus causer avec nous. La conversation, un peu gênée d'abord, s'anima bientôt grâce au sans-gêne d'un autre membre de l'équipage. Ce personnage se nomme Billy, c'est une chèvre, mais une chèvre d'une éducation soignée et qui aspire à l'élégance, malgré ses jambes cagneuses. Elle sait danser et boit son grog avec une satisfaction évidente. Elle sut rompre la glace bien mieux que la traditionnelle tabatière. Circonstance encore plus favorable, elle est née aux îles Bermudes ; c'était un prétexte pour parler de son pays, sujet d'un vif intérêt pour nous en ce moment.

Vendredi, 6 juillet. — La Vestal lève l'ancre au jour. L'Andromache a pris les devants, mais notre pilote, M. Saint-Amand, n'a pas voulu voyager de nuit par une brise très légère et dans le voisinage de la Traverse. Il hésite sans doute d'autant plus à encourir une trop lourde responsabilité que la rumeur s'est répandue, avant notre départ, qu'il était assez patriote pour mettre la Vestal à la 
côte et nous permettre ainsi de recouvrer notre liberté et fouler encore une fois le sol de notre pays. Inutile de dire que M. Saint-Amand ne médite rien de tel. Et même s'il en était autrement, il me semble que les exilés seraient assez généreux pour ne pas vouloir profiter d'un zèle inconsidéré. Se soumettre fièrement au destin, c'est grand. Une évasion, en général et si l'on en excepte l'émotion passagère de la fuite, c'est échanger un péril noble contre une aventure souvent ignominieuse. Il n'en saurait être autrement dans notre cas. Aussi ai-je toujours rejeté toute pensée d'évasion au moment où on nous indiquait l'échafaud comme la seule fin probable de notre aventure. La pensée que j'offrirais ma vie en sacrifice pour mon pays enlevait vraiment à l'échafaud presque toutes ses terreurs ; elle faisait du bois infâme un autel sacré.

Non, je n'aurais pas voulu m'enfuir. Un jour, dans la prison de Montréal, un homme condamné à la déportation pour divers crimes, travaillait dans ma chambre à un ouvrage quelconque de menuiserie. Il me proposa un projet d'évasion. Je me sentis aussitôt plein d'indignation et de colère et je menaçai cet homme de le dénoncer si jamais il osait encore me parler de la sorte.

La Vestal est une frégate nouveau type. Elle porte 180 hommes d'équipage et 28 canons. Le maître canonnier m'a fait voir aujourd'hui une nouvelle bouée de sauvetage dont on se sert lorsqu'un homme tombe à la mer. Elle se compose de deux pièces bois disposées en forme de croix et dont chaque extrémité est soutenue par un globe de cuivre d'un diamètre de douze pouces. Au centre se trouve un appareil phosphorique qui jette une faible lumière pendant quelques heures. Mardi dernier, un des marins de la Vestal tomba à la mer. La bouée lui fut inutile. Il fut entraîné sous le vaisseau et ne reparut plus. On ne put même retrouver son corps. Cet incident passa presque inaperçu à bord, non pas qu'on soit indifférent à la vie humaine, mais à cause de la familiarité de tous avec un péril toujours présent.

Notre pilote doit nous quitter à l'Île Verte. Nous lui confions donc par avance nos dernières lettres.

Samedi, 7 juillet. — Ce matin, nous sommes surpris de retrouver à bord $\mathrm{M}$. Saint-Amand. Il faisait, à l'heure où il devait partir, un calme plat dangereux en ces parages ; il est donc resté avec nous quelque temps encore et n'est débarqué qu'au Bic. En voyant sa chaloupe, nous comprenons que le dernier lien est maintenant rompu entre nous et la patrie et que nous ne sommes, plus désormais, que des exilés.

Un des officiers m'apporte Purdey's Memoir, un ouvrage descriptif des mers du globe. On y parle comme suit des Bermudes: «Dans ces parages, ainsi que nous le verrons plus tard on essuie de fréquentes tempêtes et des ouragans d'une extrême violence ; les vents du sud et de l'ouest qui règnent le plus souvent sont cependant des indices de beau temps. Un explorateur, 
écrivant en 1598, dit que la mer des Bermudes est, diabolique, que le tonnerre, les éclairs et la tempête s'y déchaînent sans cesse. Un autre voyageur, écrivant en 1615, décrit comme suit une visite à ces îles : " Sir Wm. Sommers se tenait sur la poupe et voyait le vaisseau en danger de donner sur les récifs de cette terrible côte des Bermudes. Chez toutes les nations on croyait autrefois que ces îles étaient enchantées et habitées par des sorciers et des démons. Cette croyance a pour source les terribles tempêtes et les effrayants coups de tonnerre qui se produisent dans ces parages, ainsi que l'extrême danger qu'offre la côte, à ce point qu'il est presque impossible d'en approcher sans faire naufrage ». Nous sourions aujourd'hui à la lecture de ces descriptions, sachant que le climat des Bermudes est plus doux et plus uniforme que celui de Madère même, que son atmosphère est plus pure et ses fruits et ses légumes de meilleure qualité.

Après le départ du pilote aujourd'hui, un aspirant est venu nous annoncer de la part du capitaine que nous étions libres de monter sur le faux-pont si nous le désirions. Gauvin, Des Rivières et Viger profitèrent aussitôt de cette permission, Nelson les suivit bientôt. Quant à moi, je préférai profiter de la tranquillité pour continuer ma lecture.

Le temps est toujours beau et la brise légère. Les officiers qui s'étaient d'abord tenus sur la réserve, commencent à causer plus librement avec nous et nous témoignent des dispositions amicales et beaucoup de courtoisie.

Dimanche, 8 juillet. - Nous nous réveillons ce matin au son de la cloche d'alarme. Nous sommes dans une brume épaisse et le vaisseau signale ainsi présence afin d'éviter les abordages. Le froid à cette heure matinale est intense.

La coutume de fauberter les ponts est excellente, elle est sans doute essentielle aussi à la propreté du navire. Mais vraiment nous ne serions pas fâchés qu'on l'omît par des matinées comme celle-ci. Suspendus dans ces nids aériens que nous appelons hamacs, le vent nous glace la tête; si nous en descendons, nos pieds se posent sur les planches humides et glacées du pont. Et cependant, malgré tout, si ce n'était de mon satané rhumatisme, je m'accommoderais assez bien de ce régime d'air salin et d'eau de mer.

Les officiers sont aujourd'hui en grande tenue, c'est le seul indice du dimanche. L'inspection des hommes et du navire se fait par le commandant aux heures ordinaires. Nous savons à peu près ce qui se passe, grâce aux roulements du tambour et aux mots de commandement, mais nous n'assistons pas aux manœuvres, ne désirant pas le faire à moins qu'on nous y invite. Notre position nous impose cette réserve. Après l'inspection, chaque homme retourne à son ouvrage spécial. Les uns font du bitord, d'autres le convertissent en fil de câble ou de lusin, celui-ci se rend à l'établi, celui-là à la forge, cet autre à la voilerie. Le tailleur, qui taille au couteau, jamais aux ciseaux, reprend sa 
coupe ; cuisiniers, marmitons, serviteurs, tous sont occupés et personne ne reste oisif. M. Viner, aspirant qui sera bientôt promu lieutenant, est un homme aimable et courtois. Il me prête avec beaucoup d'obligeance, un ouvrage contenant les règlements de la marine militaire.

Entre six et sept heures, une bourrasque soudaine atteint le vaisseau qui penche au point que ses sabords sous le vent affleurent l'eau. Aussitôt, au signal du maître d'équipage, les matelots du quart se précipitent pour diminuer de voiles. Les huniers sont amenés, les amures remontent, les voiles arrisées sont tendues de nouveau et la bourrasque est désarmée. C'est notre premier grain.

Pendant deux heures, après souper, j'ai fait la promenade sur le pont avec M. Gascoigne, l'officier qui commande l'infanterie de marine. Nous avons causé de l'Italie, de la Grèce, de dessin et de peinture, puis des choses du Canada. Les officiers de la Vestal avec lesquels j'ai pu causer jusqu'à présent, me paraissent d'opinions très libérales en matière de politique canadienne. Quelle différence entre ceux-ci et les soldats de terre, lesquels épousent toutes les injustifiables haines qui animent les étrangers contre la grande masse des gens du pays.

Lundi, 9 juillet. - Le froid et l'humidité ont fait leur œuvre, la nuit dernière j'ai été torturé par le rhumatisme articulaire. Ce matin, le temps est calme et la température moins froide, aussi je souffre moins. Je m'amuse à regarder les matelots qui tendent les voiles de poupe afin de profiter de quelques airs de vent qui nous viennent de l'arrière. M. Gascoigne me fait la politesse de m'envoyer ses cahiers de croquis. Ce sont principalement des paysages de la Méditerranée d'un dessin et d'un coloris admirables. Quel art aimable que celui-là ! Je voudrais le posséder au même degré que $M$. Gascoigne.

Cependant, le vent fraîchit, la Vestal dépasse tout ce qui vogue sur la mer, elle atteint même l'Andromache qui avait pris les devants pendant la nuit. Nous allons sortir du golfe Saint-Laurent par le détroit de Canso. Demain nous contemplerons, peut-être pour la dernière fois, la côte canadienne, qui s'effacera peu à peu devant nos yeux dans l'obscurité du soir.

C'est toujours un moment solennel que celui où l'on quitte son pays natal. La famille et le foyer, les amis et les souvenirs, tout cela surgit du cœur aux lèvres, et la tristesse profonde de la séparation s'empare de l'âme malgré l'espoir d'une réunion prochaine. Mais pour l'exilé, quel déchirement ! Pour lui l'espérance est si lointaine que son adieu est dans sa pensée un dernier adieu. Reverrai-je jamais les miens ? Pourrais-je jamais apporter à la tombe qui s'est creusée si cruellement sous mes pas, les fleurs emblèmes de la prière et du 
souvenir ? Ce souvenir au moins je le porterai dans mon cœur partout où l'on me conduira, il sera mon compagnon et mon soutien sur la terre d'exil.

Mardi, 10 juillet. - Temps magnifique et vent favorable. La Vestal file ses neuf nœuds, bonnettes déployées. L'itinéraire est changé, nous ne passerons pas par Canso, mais nous doublerons le cap Breton. Cela prolongera le voyage de trois cents milles. Nous ne connaissons pas le motif de ce changement. Je rends à $\mathrm{M}$. Gascoigne, son compliment d'hier en lui envoyant mes cartons. Si mes dessins ne valent pas les siens, il y trouvera au moins d'intéressants sujets d'étude et pourra en tirer quelques bonnes aquarelles.

Mercredi, 11 juillet. — Temps sombre et menaçant. La pluie commence vers midi. Nous passons en ce moment vis-à-vis l'Île Saint-Paul, une des rares terres canadiennes dont mon père n'a pas pu vérifier par lui-même le gisement exact. Il m'a demandé de le faire pour lui, mais cela m'est impossible, car je ne veux pas me rendre à l'habitacle pour consulter la boussole. Je suis peut-être trop scrupuleux en cette matière, mais notre position nous impose des réserves. Notre dignité exige que nous nous tenions à l'écart. Une certaine fierté est ici légitime. Notre expatriation est jusqu'à un certain point volontaire ; par notre acte nous avons obtenu la libération d'un grand nombre de nos compatriotes, et cette page de notre histoire ne restera pas sans éclat aux yeux de la postérité. En ce moment, bien des cœurs canadiens battent à l'unisson des nôtres ; notre exil, loin de nous séparer, resserre les liens de notre fraternité patriotique et qui peut dire quelle influence ces choses pourront avoir sur l'avenir?

J'espérais sincèrement que lord Durham allait s'appliquer à mettre fin aux griefs qui existaient depuis si longtemps dans notre gouvernement colonial. Cela eût certainement consolidé le lien entre les colonies et la GrandeBretagne, et dans ce cas il eût mieux valu pour lui de montrer noblement et hardiment son entière confiance dans le peuple en proclamant une amnistie générale. Je puis déclarer sans crainte qu'une telle politique eût entièrement réussi. Sans doute, la faction ultra-tory, sanguinaire et forcenée, eût poussé les hauts cris, mais elle eût bientôt été réduite au silence par ses chefs même, dès que ceux-ci auraient constaté leur impuissance à nuire davantage. Lord Durham a cru devoir en agir autrement, la responsabilité est la sienne.

Nous sommes à l'est de l'T̂le au Sable, ce fléau des marins. Ses récifs s'étendent, me dit-on, jusqu'à près de quarante milles dans toutes les directions. Trois ou quatre familles occupent de misérables huttes sur cette terre nue et sans arbres, si basse aussi que les grandes vagues du large la couvrent et la dévastent presque de toutes parts ${ }^{1}$. Malgré la brume qui nous entoure le vent

Tout a bien changé à lî̂le depuis le temps où Bouchette a passé dans ces parages. Le gouvernement y a établi des postes de sauvetage bien tenus. Nous est avis que la mer ne la couvre pas comme Bouchette le croit. On en était encore à la légende sur ce point. (D.) 
franchît et la Vestal tangue au point que Nelson et Marchessault, n’ayant pas le pied marin, sont forcés de prendre le lit. Les autres, et je suis du nombre, ne se sentent pas très à l'aise. Cependant, nous tenons bon. Les Canadiens en général sont bien constitués, ils endurent facilement le froid et le chaud, les longues marches, les jeûnes prolongés, sans parler du gros temps.

Jeudi, 12 juillet. - Un bruit infernal nous éveille ce matin ; on dirait d'un régiment d'artillerie passant au-dessus de nos têtes. Ce sont les marins qui blanchissent les ponts à la pierre ponce. Le temps est toujours couvert, mais le vent est favorable. J'assiste aujourd'hui à l'exercice du maniement du canon. Le service de chaque canon exige neuf hommes et un officier ou sous-officier. Au commandement prepare for action, quatre hommes se placent de chaque côté du canon et un en arrière. On soulève d'abord le canon pour atteindre le palan qu'on place toujours tout prêt en dessous, on l'attache à une cheville à boucle, ce qui permet de ramener la pièce ; on la charge, on la ramène au sabord, on pointe, puis on fait feu non plus en appliquant la mèche à la lumière, mais au moyen d'une nouvelle poudre fulminante. En chargeant la pièce, les hommes paraissent s'exposer beaucoup, mais dans la pratique il n'en est pas ainsi, car ils se trouvent, la plupart du temps, cachés par la fumée. Neuf hommes éprouvent quelque difficulté à manier une pièce de 32.

Vendredi, 13 juillet. — Nous sommes à 783 milles des Bermudes. Cette distance serait longue à parcourir si tous les jours ressemblaient là celui-ci. Il fait un calme plat, les voiles inutiles battent les mâts. Mes amis sont tous plus ou moins malades, le roulis par un temps calme étant plus difficile à supporter que le mouvement d'une forte brise. Quant à moi, après un excellent dîner, je passe l'après-midi à lire et ce n'est que vers le soir que la tristesse de mes compagnons commence à m'atteindre à mon tour. Chose terrible et menaçante que le calme plat en mer.

Samedi, 14 juillet. - Ce matin le ciel est sombre, mais la brise est favorable et la Vestal file ses dix nœuds, voiles arisées. Vers le soir la brise se maintient, mais le ciel devient clair. Nous nous réunissons sur le pont pour jouir de la soirée, car nous commençons à ressentir l'influence des latitudes méridionales. Pourtant, au ciel, les constellations sont toujours nos amies des latitudes canadiennes; leur position semble peu changée, sauf que l'étoile polaire est notamment plus basse que lorsqu'on l'observe de Québec. En ce moment je suis sur le gaillard d'arrière. Au couchant le ciel ressemble à une immense nappe d'or; de longs nuages bleus strient le ciel, la mer prend une couleur plus intense et les vagues apparaissent avec des teintes de turquoise sous le vaisseau qui bondit sur leurs crêtes écumeuses. Une chaleur très perceptible monte de la mer. Cela indique, dit M. Viner, que nous approchons du Gulf Stream, quoique nous n'y soyons pas encore. 
Pour moi, la mer n'est pas une chose nouvelle. Depuis mon enfance elle m'est familière. Mais ma situation actuelle est si nouvelle qu'elle me porte à observer mieux les choses que je croyais bien connaître. On me dirige vers une île de l'Océan que je ne connais pas et où je devrai vivre parmi des inconnus. On m'y soumettra peut-être à des restrictions dégradantes, et dans tous les cas les circonstances me condamneront jusqu'à un certain point à la solitude. Mais en revanche j'ai la satisfaction de penser que mes amis et moi nous nous sommes volontairement sacrifiés pour la délivrance d'un grand nombre de nos compatriotes prisonniers! Dulce est pro patria mori. Devons-nous compter les déchirements, les séparations, les souffrances que nous déposons sur l'autel de notre cher pays ? Le patriote en pleurant sur les maux de sa patrie, ne doit jamais désespérer de les voir un jour disparaître et son pays rendu au bonheur.

Dimanche, 15 juillet. — Le vent est moins fort, le temps beau, l'air chaud, sec et agréable. Si c'est là un avant-goût du climat des Bermudes, nous n'aurons pas à nous en plaindre. Shakespeare a célébré ces îles dans un de ses chefsd’œuvre, la Tempête ; Moore en fait, dans ses odes et épîtres, la résidence de la nymphe Néa. Cela nous fait espérer que nous trouverons au lieu de notre bannissement des lèvres roses, des yeux doux et des cœurs sensibles qui nous rappelleront les Canadiennes que nous avons dû quitter.

Le docteur Nelson et moi, dos à dos, et entre nous une barrique vide de bière, avons passé, cette matinée, trois grandes heures à lire. Nos goûts et nos pensées sont identiques sur une foule de questions. Ce matin notre lecture était plutôt sérieuse. Le docteur lisait la physiologie de Combe, et moi le traité de Combe sur la digestion.

Le calme se maintient, le temps est toujours beau. Nous dînons à quatre heures aujourd'hui et chaque dimanche, car ce jour-là le capitaine dîne à trois heures au mess des lieutenants et les exilés lui cèdent le pas. Le capitaine vient de descendre au carré des officiers (gun room), L'expression de sa figure est certainement plutôt bourrue qu'aimable. S'il attend que nous fassions les premières avances il attendra longtemps. Ce serait de notre part une démarche peu digne. Nous croyons d'autre part qu'il pourrait, sans nuire aux intérêts de son gouvernement, se montrer un peu moins désagréable dans ses rapports avec nous. Enfin, cela le regarde.

Le premier et le second lieutenant se montrent aujourd'hui un peu plus aimables que d'habitude. Après dîner, nous avions autour de nous un groupe de fumeurs et de causeurs qui écoutèrent avec attention nos explications sur les plaintes des Canadiens contre le gouvernement colonial. Le docteur Nelson a pris la principale part au débat et je l'ai secondé de mon mieux. Je dois dire que la plupart de nos auditeurs eurent la franchise d'admettre que ces plaintes paraissaient fondées. 
Lundi, 16 juillet. — La brise est forte et contraire, mais la pluie qui tombe par torrents empêche les vagues de se former. C'est un spectacle extraordinaire que cette lutte entre les eaux de la mer et celles du ciel. Celles-ci restent victorieuses, aussi est-ce sur une surface relativement unie que la Vestal file sous ses voiles arisées. Cette pluie est un bienfait pour l'équipage. On la recueille dans des vases de toutes espèces, de grandes voiles tendues deviennent des réservoirs. Sur l'ordre du maître d'équipage, chaque marin étale sur le pont son hamac qu'il se met aussitôt à savonner et à laver sous l'orage. Puis c'est le tour du linge et des vêtements, enfin une lessive générale qui offre dans ces circonstances un coup d'œil des plus réjouissant. Cependant l'intensité du vent augmente sans cesse et par trois fois les matelots risquent leur vie dans la mâture pour prendre de nouveaux ris. Vers le soir la tempête diminue puis se calme, les nuages se dissipent et le soleil se couche dans un ciel clair, ce qui présage du beau temps pour demain.

Mardi, 17 juillet. - Temps très beau, brise fraîche mais toujours adverse. Nous louvoyons dans une mer de plus en plus tumultueuse. Nous sommes maintenant à 420 milles des Bermudes et nous commençons à avoir hâte d'y arriver, car la vie à bord est monotone, surtout pour nous qui sommes inoccupés.

Ce matin chaque marin étale, pour l'inspection, son hamac sur le pont. Un des hommes se trouvait près de l'écoutille du gun room, c'est ainsi qu'on nomme la salle de réunion des officiers sur les vaisseaux de guerre anglais. Une vague plus grosse que les autres ayant frappé le vaisseau, cet homme perdit l'équilibre, tomba par l'écoutille sur une pièce de pin horizontale, donna de la tête contre un poteau de noyer et acheva sa chute, sur la table du mess, où il causa un dégât considérable, comme bien on se l'imagine. Heureusement pour les officiers, ils ne se trouvaient pas à table au moment où Jack Tar y descendait comme un bolide. Quant au marin, victime de l'accident, il se releva sans blessure. Il remonta sur le pont et reprit son rang au milieu des rires mal étouffés de ses camarades.

À dix heures ce soir le ciel est parfaitement pur, les étoiles apparaissent dans toute leur magnificence calme et majestueuse. La mer d'autre part s'élève en montagnes mugissantes sous le souffle d'une furieuse tempête. Toutes les voiles sont amenées sauf le grand hunier et le premier foc. Le vaisseau ballotté par des vagues énormes frémit jusqu'à sa quille, mais repousse bravement les assauts sans cesse renouvelés de la mer qui se retire furieuse et écumante. Chaque violente embardée cause dans le vaisseau un dégât quelconque, et dans le quartier des exilés les mésaventures se multiplient. Toute une boite de cigare est renversée dans mon hamac, nos livres sont déchirés et, disséminés par la place et nos bouteilles prises d'ivresse quittent leurs caisses défoncées et roulent et titubent sur le plancher parmi les mousquets et les coutelas tombés de leurs tablettes. Même les canons sont ébranlés, ce qui peut devenir 
dangereux. Et au-dessus de tout ce fracas on entend constamment le mugissement de la mer et le gréement vibrant sous le souffle du large comme les cordes d'une harpe éolienne.

Mercredi, 18 juillet. — Le temps est normal. Nous sommes à environ 400 milles des Bermudes. M. Jeffreys et M. Viner, deux des officiers, nous ont invités à prendre un grog à leur messe et nous avons passé une heure ou deux en très joyeuse compagnie. Il faut avouer que ces messieurs ne négligent rien pour rendre notre situation aussi agréable que possible. Leur cordialité forme un agréable contraste avec la roideur que le capitaine croit sans doute de son devoir d'observer et que les lieutenants imitent de leur mieux.

Jeudi, 19 juillet. - Aujourd'hui un concours de tir est venu varier la monotonie de la routine journalière. Une cible de vingt pouces de diamètre fut dressée à l'avant du navire et vingt-deux hommes placés à une distance de deux cent cinquante pieds brûlèrent dix cartouches chacun, soit deux cent vingt balles dont quarante atteignirent la cible. Ce résultat fut jugé excellent et ce jugement fit sourire les exilés, car nous sentions tous que nous aurions pu faire mieux. On ne nous donna pas l'occasion d'essayer.

Pendant qu'on tirait, un infortuné marin, qui, quelques jours auparavant, s'était fait écraser un doigt, subissait l'amputation. L'opération ne dura que quelques instants, mais aux cris et aux imprécations qu'il poussait, on pouvait juger qu'il souffrait les tortures les plus affreuses. Le chirurgien nous a dit que l'amputation d'un doigt est presque aussi douloureuse que celle d'un bras ou d'une jambe.

Le temps est merveilleusement beau, la mer d'un bleu si profond et si pur que si on en voyait la reproduction dans une peinture on crierait à l'exagération, tant il est juste de dire que le vrai peut quelquefois n'être pas vraisemblable. Plus invraisemblable encore sont les phénomènes, phosphorescents. Dans ces latitudes, la nuit transforme le sillage du navire en une trainée lumineuse d'une magnificence sans égale. Cette lumière est encore plus éclatante à la proue, contre laquelle les vagues viennent se briser en poussière d'argent. Malheureusement, les marins se servent de cette partie du vaisseau de façon à rendre ce voisinage très désagréable.

Vendredi, 20 juillet. - - Le vent est défavorable. Nous louvoyons sur une mer unie. Vers le soir quelques bourrasques nous atteignent, mais sans altérer la pureté du ciel. M. Harvey, l'assistant maître d'équipage, vient se placer à mes côtés au moment où je regarde le firmament en m'efforçant de reconnaître les constellations de ce ciel nouveau pour moi. Nous ne parlons pas et bientôt ma contemplation devient une rêverie. Les scènes de la patrie passent devant mes yeux. Je vous revois, mon père et ma mère, je te revois aussi 
Toi qui fus jadis ma vie et ma lumière,

Et qui plane aujourd'hui dans ces cieux éclatants.

Penche-toi, bien-aimée, écoute ma prière.

Il me semble te voir en de certains instants

Quitter ton trône d'or au sein des bienheureux.

Ta douce haleine assèche les pleurs de mes yeux.

Ta main cherche ma main, et tu redis tout bas :

Je t'aime ! Et pour qui aime, la mort n'existe pas. 


\title{
CHAPITRE XVI
}

\author{
L’ARRIVÉE
}

$\underline{\text { Retour à la table des matières }}$

Samedi, 21 juillet. - Le temps est toujours beau, mais le vent toujours contraire. Cependant, nous avançons et nous ne sommes plus qu'à 138 milles des Bermudes. Un seul incident est venu interrompre la monotonie de la journée. Après dîner, le chirurgien, M. Symes, le caissier, M. Fairweather, l'assistant-chirurgien, M. Acheson et M. Jeffreys sont entrés dans nos quartiers et plaçant sur la table une bouteille d'excellente fine champagne, ils nous ont invités à la vider avec eux. Ces messieurs se sont beaucoup excusés de ne pas nous inviter au gun room et nous ont expliqué les restrictions qui existaient à notre égard. Le chirurgien surtout nous fit part de son embarras et de celui de ses camarades, qui tous désiraient nous traiter avec cordialité, mais qui étaient forcés par les circonstances de se tenir sur la réserve. Je n'ai pas à dire que ces généreux sentiments touchèrent les exilés. Nous ajoutâmes à la fine champagne quelques bouteilles de bourgogne, et à la fin de la soirée si la réserve subsistait au dehors, je puis affirmer qu'autour de notre table elle avait disparu.

Dimanche, 22 juillet. — Le dimanche à bord ne se distingue des autres jours que par la parade en grande tenue et le dîner du capitaine avec les lieutenants. On ne récite pas de prières.

Le docteur Nelson et moi avons aujourd'hui mangé la soupe avec les aspirants. Ces messieurs dînent à midi et nous à quatre heures. Les seconds (mates), l'aide-chirurgien, l'assistant-maître d'équipage, le greffier, l'assistantgreffier, et les aspirants font table commune. Ce sont tous gens bien élevés et la gaieté ne manque pas. Leur menu n'est pas très recherché, mais excellent en son genre. Aujourd'hui, on nous a servi une purée de pois, du poisson, du bœuf et du lard salé et un pudding quelconque. On boit de l'eau-de-vie aux repas. Ces officiers dorment dans des hamacs, ils sont séparés du gun-room par un rideau, mais il n'y a aucune séparation entre eux et l'équipage. Cinq des seconds attendent leur promotion au grade de lieutenant, ils espèrent qu'à 
l'occasion de l'avènement de la reine Victoria ils obtiendront leurs parchemins. À l'heure qu'il est, ils n'ont pas de commission, quelques-uns ont affronté depuis douze ans les périls de la mer, loin de leur famille et de leurs amis, avec $£ 50$ par année pour tout salaire et sans un grade dans la marine qui leur ferait prendre patience en attendant l'avancement. Singulière organisation que celle de l'Angleterre qui donne tous les avantages à l'armée de terre et rien à la marine sur laquelle repose sa puissance. Si la Grande-Bretagne veut conserver son influence, il faudra des réformes ; advenant une guerre, elle sera forcée d'en faire.

Lundi, 23 juillet. - Vent toujours contraire. Nous avançons bien lentement vers "lîle de la beauté » chantée par Moore. Cependant nous sommes déjà dans les parages de l'île, chacun est sur le qui-vive. Enfin nous entendons le cri : Terre ! Ce mot-là cause toujours une certaine émotion après un voyage en mer, mais surtout au moment où l'on atteint une côte dangereuse où les récifs s'étendent au loin cachés sous les flots, dont on ne peut approcher que par un seul côté et cela en affrontant peut-être une de ces bourrasques fatales qui ont valu aux îles de la part d'un autre poète le titre « d'île des tempêtes ».

Mardi, 24 juillet. - Ce matin nous nous levons avant le jour, bien que le soleil paraisse dès quatre-heures. Nous avons hâte de voir notre terre d'exil. Mais pendant quelques heures il nous a semblé que ce désir ne se réalisera pas. Le temps était si épouvantable, la mer si menaçante que le maître d'équipage était très inquiet.

Vers sept heures du matin la tempête se calme et le ciel s'éclaircit. Nous voyons devant nous à une distance d'environ sept milles l'île Saint-David. Notre position est excellente, elle ne pourrait pas être meilleure. Il nous reste à attendre le pilote avant d'entrer au havre de Saint-Georges. Le voici qui arrive dans sa coquille de noix ballottée par les grosses vagues et mue par deux rames. Elle touche au navire et le pilote grimpe lestement à bord. C'est un nègre grand, droit, fort et intelligent. Il est vêtu d'un pantalon blanc, d'une vareuse bleue et d'un grand chapeau de paille autour duquel s'enroule un mouchoir rouge et qu'il touche fréquemment en parlant au capitaine. Il nous conduit habilement dans ces eaux difficiles et à cinq heures du soir nous mouillons devant la ville de Saint-George.

Nelson, Viger, Des Rivières et moi descendons dans nos quartiers et bientôt nous sommes entourés d'un groupe nombreux d'officiers du bord qui viennent nous dire adieu et nous serrer la main une dernière fois. Ce sont le docteur Symons, MM. Fairweather, Johnson, Vyner, Warren, le docteur Acheson, M. Hall, le maître d'équipage, M. Gascoigne, M. Jeffreys et d'autres encore. Ai-je besoin de dire combien cette démarche généreuse nous touche et nous fait plaisir ? Aussi est-ce avec notre meilleur bourgogne que nous buvons à la 
prospérité de ces véritables amis qui ont su comprendre et respecter notre malheureuse position.

Mercredi, 25 juillet. — La matinée se passe dans une vaine attente. Il n'est pas probable que nous débarquions aujourd'hui. Les chaloupes et les embarcations se succèdent, mais rien ne nous est communiqué de la part des autorités des îles. La plupart des embarcations qui approchent sont montées par des nègres qui offrent en vente des légumes, des fruits et des laitages. Ces produits sont en général inférieurs à ce qui se vend au Canada. Le pain est mal cuit, le beurre est liquide et a l'apparence d'une huile épaisse, le lait n'est que du lait de chèvre. Les fruits, en revanche, sont excellents.

Le temps est capricieux, le soleil et les orages se succèdent sans cesse. Ces orages, me dit-on, sont un bienfait pour le pays, car l'eau est rare; on la recueille pour l'usage domestique, en de vastes citernes. Aujourd'hui, sur la dunette, le thermomètre indiquait $94^{\circ}$ Fahrenheit au soleil, et $84^{\circ}$ à l'ombre. Vers le soir, le mercure est tombé à $78^{\circ}$.

Dans la soirée le capitaine Carter, qui s'était rendu chez le gouverneur, sir Stephen Chapman, revient à bord, mais apparemment, il n'a rien à nous communiquer. D'autres officiers reviennent aussi. Le bruit se répand que la Vestal doit repartir pour Québec demain.

Jeudi, 26 juillet. - Encore rien que des rumeurs. Je me trompe, il y a quelque chose de plus. MM. Symons et Fairweather me disent qu'ils ont rencontré le docteur Tasker, ancien assistant-chirurgien sur une frégate qui a visité Québec il y a deux ans. Il se souvient de moi, il m'envoie ses compliments et ses offres de service. Cette nouvelle me fait plaisir, car, moi aussi, j'ai conservé du docteur Tasker un excellent souvenir. On remet à Nelson et à Des Rivières, un paquet de journaux avec les compliments d'un M. Fozard. Ce sont des journaux d'Angleterre et quelques exemplaires de la Bermuda Royal Gazette, contenant la proclamation de lord Durham à notre sujet, accompagnée de quelques commentaires anodins ${ }^{1}$. Un carton rose est aussi

Extrait de la Royal Bermuda Gazette, 31 juillet 1839. - « Les personnes condamnées par lord Durham et par son conseil spécial à être déportées ici, pour la part qu'ils ont prises aux récentes menées séditieuses dans le Bas-Canada, sont arrivées mardi dernier sur le vaisseau de S. M. Vestal, capitaine Carter. La traversée, de Québec, a duré vingt et un jours.

« Les déportés se nomment:

Wolfred Nelson,

Bonaventure Viger,

Henri-Alphonse Gauvin,

Rodolphe Des Rivières,

« Ils ont débarqué samedi, et se sont fixés dans notre paroisse (Hamilton).

« Ces personnes, croyons-nous, ont lieu d'être reconnaissantes. Le bannissement Bermudes est une peine fort légère pour une offense aussi grave que la leur, et le conseil du 
remis aux exilés de la part de madame Judkins, leur annonçant qu'elle tient un restaurant à Saint-George.

Vers midi, regardant par un sabord je vois une goélette qui approche. J'aperçois du rouge sur le pont. Ce sont sans doute les soldats qui viennent nous chercher. Non. Le rouge n'est que la peinture du cabestan. C'est une bâche ou bateau-citerne apportant à la Vestal son approvisionnement d'eau douce, indice certain de son prochain départ.

M. Gascoigne me dit que le retard dans notre débarquement est dû aux craintes du gouverneur. Il prévoit, paraît-il, une guerre entre l'Angleterre et les États-Unis, et il croit que s'il nous laisse libres, nous sommes gens à livrer aux Américains la forteresse confiée à sa garde. Si huit bons garçons inoffensifs lui causent de pareils frissons, que serait-ce si nous étions quarante ? Nous avons ri de bon cœur de cette timidité. Tout rebelles que nous sommes, à son avis, nous ne songerions pas à livrer une place anglaise aux Américains; nous serions plutôt enclins à la défendre, surtout si l'on accordait à nos compatriotes les droits politiques que nous réclamons en notre qualité de sujets britanniques. Comme on se méprend ici comme en Angleterre sur nos sentiments et nos aspirations !

Vendredi, 27 juillet. — Le ciel est nuageux. De temps en temps une violente bourrasque soulève les eaux du port. Nous étions loin de nous attendre à un temps semblable au mois de juillet. La chaleur est intense. La nuit dernière nous avons à peine dormi. Nos malles sont fermées et notre mobilier prêt pour le débarquement et cependant nous ne débarquons pas. Le capitaine en est aussi contrarié que nous le sommes. Cela se voit. Toute une journée sur le qui-vive. Est-il rien de plus agaçant?

Samedi, 28 juillet. - M. Julius Wood est un homme célèbre aux Bermudes. Il dispose d'une flottille considérable d'embarcations au moyen desquelles il vend aux équipages des navires en rade des légumes et des fruits. Il nous fait aujourd'hui l'honneur d'une visite. Sa face noire et luisante rayonne d'hospitalité. Sa femme, nous dit-il, est la blanchisseuse du gouverneur et il espère bientôt nous compter parmi ses clients, quoique des moins illustres. Vous débarquerez bientôt, nous dit-il. Vous demeurerez à Hamilton où l'on prépare un hôtel pour vous recevoir.

gouvernement a mis peu d'entraves à leur liberté en acceptant simplement leur parole d'honneur qu'ils ne quitteront pas l'île principale.

« D'après l'ordonnance de lord Durham et de son conseil spécial, que nous avons publiée il y a quinze jours, Ils seront mis à mort pour crime de haute trahison ceux qui s'aviseront de retourner en Canada sans permission spéciale ». 
Cette nouvelle est véritable. L'instant d'après, le capitaine nous mande tous et nous présente à $\mathrm{M}$. Papillon, aide de camp et secrétaire du gouverneur, sir Stephen Chapman. On nous demande de signer un document par lequel nous nous engageons, sur parole, à ne pas quitter l'île sur laquelle on va nous débarquer ? Nous signons. Nous serrons une dernière fois la main à nos bons amis de la Vestal et nous nous embarquons pour Hamilton dans une grande chaloupe pontée. M. Papillon nous accompagne et se tient à l'arrière avec Des Rivières et moi, tandis que nos six compagnons se pressent dans l'étroite cabine. Le vent est violent et contraire. Pendant le trajet de quatorze milles qui nous sépare de Hamilton, la mer nous couvre de son écume. Mais cela nous est bien égal. Nous allons enfin fouler la terre, et quelle terre enchantée ! C'est l'île de Calypso ; nous pensons à Ulysse et à Télémaque.

Le soleil baissait déjà à l'horizon lorsque nous sortîmes du dédale d'îlots et de récifs qui défend les approches de Hamilton, pour entrer dans la baie du même nom. La petite ville aux maisonnettes blanches repose à l'ombre des cèdres qui couvrent également les coteaux et descendent jusqu'à la mer. À l'arrière-plan une rangée de collines roses. C'est féerique.

Nous débarquons dans une anse tranquille et nous gagnons la ville par un chemin étroit bordé de murs bas en pierres et ombragé de cèdres, de tilleuls, de bananiers et de citronniers. La ville nous paraît d'un singulier aspect avec ses toits concaves pour recueillir l'eau. Nelson et moi nous installons dans une vallée tranquille formée par le mont Langton et à quelque distance de la ville. Nos amis demeurent dans la ville même, à l'hôtel Hamilton, tenu par un brave homme du nom de Vaughan. C'est là que nous passons la soirée tous ensemble après avoir confié nos dernières lettres à l'illustre Julius Wood et à son fils Richard, lesquels se chargent de les remettre au capitaine de la Vestal, qui dès demain matin lèvera l'ancre pour Québec. 


\title{
CHAPITRE XVII
}

\author{
DOCUMENT RÉDIGÉ À BORD DE LA « VESTAL ».
}

$\underline{\text { Retour à la table des matières }}$

Avant de quitter la Vestal, j'avais rédigé, à la demande de plusieurs des officiers de ce vaisseau, un exposé des griefs des Canadiens. Ce document était signé par le docteur Nelson et moi ; j'ai appris plus tard qu'on l'avait transmis au ministère des colonies et qu'il y avait donné lieu à quelque correspondance.

Ces trois documents : la lettre au colonel Dundas, le récit de la Vestal, et la protestation publiée aux Bermudes même par les exilés, forment le résumé des événements qui ont précédé, accompagné et suivi immédiatement le mouvement de 1837. Il faut bien remarquer que le soulèvement de 1838 eut un caractère bien différent. 1837 nous offre le spectacle de tout un peuple qui proteste ; 1838 celui de quelques hommes n'écoutant que les conseils du désespoir. À la distance où nous sommes, nous pouvons comprendre que ces deux faits sont distincts et n'ont pas la même portée historique.

Voici la version française de cet exposé :

Pour bien faire comprendre les griefs dont le peuple du Canada se plaint depuis longtemps, il faudrait écrire un volume qui embrasserait l'histoire de la colonie depuis au moins trente ans. Il est possible cependant de résumer les causes des récents soulèvements dans les deux Canadas et de démontrer combien il est faux de dire que les hommes publics du Bas-Canada visaient au renversement du gouvernement de la reine Victoria.

Disons d'abord que l'Assemblée législative se compose de quatre-vingtquatre députés. L'immense majorité de ce corps, - soit de soixante-cinq à soixante-quinze députés - est libérale et représente l'opinion de la masse du peuple. La minorité appuie l'administration. 
L'Assemblée, ainsi composée, s'est montrée la gardienne fidèle de nos droits constitutionnels et l'ennemie des abus coloniaux, contre lesquels elle n'a jamais manqué de protester tant auprès de l'exécutif que du gouvernement de la métropole.

Parmi les nombreux abus incessamment dénoncés par l'Assemblée, nous signalerons :

$1^{\circ}$ Le gaspillage et la mauvaise administration des terres inoccupées de la Couronne ;

$2^{\circ}$ La situation des fonctionnaires, qui échappent au contrôle des représentants du peuple, ce qui donne lieu aux fraudes les plus audacieuses. Nous ne citerons que le cas du Receveur-général, concussionnaire au montant de £100,000, sans parler des malversations de deux des shérifs de Québec, du Commissaire des Terres et de plusieurs autres ;

$3^{\circ}$ La mauvaise administration de la justice, attribuable non seulement à l'ignorance des juges, mais à leur dépendance de l'exécutif, qui peut les démettre à plaisir. La même chose peut se dire des shérifs ;

$4^{\circ}$ La constitution absurde de la cour d'Appel, d'après laquelle les décisions des premiers jurisconsultes du pays peuvent être infirmées par des gens qui n'ont jamais étudié la jurisprudence et qui souvent sont d'une ignorance grossière ;

$5^{\circ}$ Le cumul des fonctions; on a vu la même personne occuper à la fois jusqu’à quatre charges importantes ;

$6^{\circ}$ L'injuste répartition des revenus publics entre les deux provinces ;

$7^{\circ}$ L'esprit injuste et injudicieux qui préside aux nominations à toutes les charges et particulièrement à la magistrature ;

$8^{\circ} \mathrm{La}$ composition du Conseil exécutif et du Conseil législatif, celle-ci n'étant que la succursale de celui-là. Le public ayant perdu toute confiance au Conseil législatif, l'Assemblée et le peuple ont constamment demandé sa réorganisation, soit en le rendant électif, ou autrement ;

$9^{\circ}$ La multitude de mesures utiles adoptées par l'Assemblée et rejetées par le Conseil, entre autres la loi de l'instruction publique, la loi des municipalités, l'envoi d'un agent canadien à Londres. 
Tout cela peut donner une idée générale des griefs du Bas-Canada. Mais, pour les bien comprendre, il faut consulter les documents publics, surtout les 92 résolutions adoptées par l'Assemblée, en 1832.

Telle étant la situation du Bas-Canada, l'Assemblée, afin d'obtenir les réformes que réclamait le peuple, affirma son droit de refuser les subsides jusqu'à ce qu'on eût mis fin aux abus. Ce droit, qui est de l'essence même de la constitution britannique, le bouclier de la liberté civile et dont le peuple par ses représentants a le droit et le devoir de se servir dans les cas extrêmes, on osa la refuser à l'Assemblée, laquelle n'en insista qu'avec plus de fermeté.

Quel fut le remède appliqué par la couronne ? Comment les remontrances des Canadiens furent-ils accueillies par le parlement britannique ? Par les Résolutions anticonstitutionnelles de lord John Russell, lesquelles privaient toute la population canadienne de ses droits politiques et la réduisait à l'état dégradé des ilotes. Le pays tout entier fut rempli d'indignation. Le peuple alarmé à la pensée qu'il allait perdre ses droits de sujets britanniques, se réunit dans toutes les parties de la province pour se consulter sur les affaires politiques. Dans de nombreuses assemblées tenues partout, on rédigea des protestations énergiques et qui indiquaient la conviction ancrée dans l'esprit populaire que les autorités avaient résolu de profiter de la faiblesse des Canadiens pour les écraser sous la tyrannie et l’injustice.

Le gouvernement vit bien, par le ton de ces assemblées, que de même que le peuple avait été sérieux dans ses demandes de réformes, de même aussi il n'hésitait pas à exprimer son sentiment sur l'odieuse injustice des résolutions de lord John Russell. Néanmoins, nous le croyons fermement, aucune des résolutions adoptées, aucun des discours prononcés dans les assemblées publiques du Bas-Canada n'outrepassa les limites de la discussion légitime sanctionnée par la constitution britannique. Il est bien certain, dans tous les cas, qu'on s'est souvent servi, en Angleterre, d'un langage qui surpasse en violence ce que tout ce qui a été dit au Canada, sans que personne n'ait crié à la révolte. Cependant, on affecta de regarder les assemblées publiques tenues dans la province et les discours qu'on y prononçait comme des actes de sédition et de trahison. Deux mois s'écoulèrent néanmoins avant que les officiers en loi exprimassent une opinion officielle en ce sens ; et alors on crut avoir imaginé un coup de maître en décrétant l'arrestation des présidents et des secrétaires de ces assemblées, ainsi que de tous ceux qui avaient proposé ou appuyé des résolutions. Cette classe de personnes comprenait tous les hommes marquants de la province ; la plupart étaient magistrats, officiers de milice, commissaires, etc. Ils furent tous sur-le-champ privés de leurs charges; et ceux de leurs partisans qui occupaient des charges semblables s'en démirent spontanément sans en n'être priés. On vit ainsi remettre jusqu'à cinquante commissions dans une seule paroisse. 
En même temps, les adversaires de l'Assemblée s’armaient et s'exerçaient publiquement ; ils insultaient et molestaient les patriotes dans les villes. Ceuxci, pour se protéger, durent s'organiser à leur tour, et une association de jeunes gens se forma à Montréal sous le nom Fils de la liberté. Les choses en étaient là, lorsque en novembre dernier, des mandats d'arrestation furent lancés contre tous les hommes les plus considérables et les plus populaires du pays, et, chose à peine croyable, un grand nombre de ces mandats étaient signés en blanc !

On disait et on croyait généralement que le gouvernement se proposait d'intimider la population en faisant subir à quelques-uns de ses chefs la peine capitale. Cette conviction poussait davantage le peuple à résister à l'arrestation de ses chefs. On savait en effet que grâce à l'influence du gouvernement sur les shérifs, ses créatures, il était très peu probable que les chefs populaires pourraient obtenir un procès impartial. On accusait les shérifs de choisir des jurés corrompus lorsqu'il s'agissait de faire le procès des adversaires de leurs maîtres. Les chefs populaires, de leur côté, sachant aussi ces choses, acceptèrent la protection que leur offraient leurs adhérents. C'est ainsi qu'il arriva qu'on résista à leur capture, laquelle du reste, fut dans la plupart des cas, tentée par les militaires et non pas par le pouvoir civil.

Voilà ce qu'on a appelé rébellion et révolte. Telle fut la conspiration. Cette action fut qualifiée de haute trahison, de tentative de renverser le gouvernement de la reine d'Angleterre dans ses colonies canadiennes.

La faction hostile aux droits populaires affirme insidieusement, que cette lutte politique est imputable au préjugé français, que la population voulait établir la domination française et que ce n'était pas une lutte de principes. Mais s'il en était ainsi, à quoi pourrait-on attribuer l'action audacieuse des réformateurs du Haut-Canada, où la population se compose d'Anglais, d'Écossais, d’Irlandais et d'Américains ? Le Bas-Canada est allé bien moins loin que le Haut-Canada dans la manifestation de son mécontentement, et cependant elle a des sujets de plainte beaucoup plus graves assurément. Les résolutions de lord John Russell ne s'appliquaient pas au Haut-Canada, et le peuple de cette province ne maintenait pas ouvertement, comme on le faisait dans la province inférieure, les droits constitutionnels de sa Chambre d'Assemblée.

Dans le Bas-Canada, la rencontre fut virtuellement entre l'Assemblée d'une part, les Conseils exécutif et législatif et le ministère des colonies d'autre part. L'Assemblée qui avait si fermement revendiqué les droits du peuple n'était-elle pas en droit de lui demander son appui ? Telle fut la lutte. Était-ce une trahison ? Cependant des centaines de citoyens furent enchaînés, cruellement liés avec des cordes et des courroies et jetés dans les cachots pour y languir pendant plus de six mois. La propriété privée fut mise au pillage, des villages entiers totalement dévastés et brûlés, non pas dans la chaleur du combat, mais 
de sang-froid et par pure malice, lorsqu'on n'offrait pas une ombre de résistance. Tels furent les exploits de sir John Colborne ${ }^{1}$.

À l'appui de l'exactitude de ce résumé, ses auteurs n'auront qu'à s'en rapporter aux écrits publiés par les ennemis de la réforme. Leur langage trahit la haine la plus invétérée contre tout ce qui est Canadien, et une soif de persécution qui fait le déshonneur d'un siècle de civilisation et de progrès.

R.-S.-M. BOUCHETTE, WOLFRED NELSON.

Signé à bord du vaisseau de S. M., Vestal.

18 juillet 1838.

J'ai raison de croire que ce vandalisme, qui s'est exercé particulièrement à Saint-Eustache, et à Saint-Benoît, fut perpétré par les volontaires, malgré les ordres de sir John Colborne J'ai pu vérifier ce fait dans les documents publics longtemps après avoir écrit ce mémoire à bord de la Vestal. (Note de l'auteur en 1859.) 


\title{
CHAPITRE XVIII
}

\author{
SÉJOUR AUX BERMUDES - RETOUR.
}

$\underline{\text { Retour à la table des matières }}$

Je ne m'attarderai pas à faire la description des Bermudes. Ces îles sont maintenant beaucoup mieux connues au Canada qu'au moment où j'écrivais mon journal du bord en 1898.

Saint-George était alors le quartier général militaire. Il s’y trouvait des docks considérables pour l'époque mais qui seraient inutiles aujourd'hui à moins d'être modifiés et agrandis. Hamilton et ses environs étaient paisibles. On trouvait partout de frais ombrages, une flore magnifique, une société agréable, aimant la musique et la poésie, puisqu'elle se souvenait de Moore dont la Néa y vivait encore toujours charmante et digne d'être l'inspiratrice d'un poète, même d'un poète qui comme Moore a chanté le Canada et les «voyageurs canadiens". Cela contribuait sans doute à la popularité des refrains du pays que nous aimions à chanter. Nous trouvions partout une franche et cordiale hospitalité, un sincère désir de la part de tous de rendre notre séjour agréable.

Cette attitude amicale était tout à fait désintéressée, car les exilés n'étaient pas très bien partagés quant au temporel. Le gouvernement ne faisait rien pour notre maintien. Nous ne nous y attendions pas et nous ne demandions aucune faveur.

Cependant, trois des exilés étant des médecins, ils sollicitèrent du gouverneur la permission d'exercer leur art dans les îles, en offrant de subir, si on le jugeait convenable, un examen de compétence. On leur répondit que cette permission ne pouvait leur être accordée. Heureusement pour nous, les ressources dont nous disposions, quoique limitées, se trouvèrent suffisantes et il nous en restait encore quelque chose au moment de notre départ. 
Un jour, une dame de nos amis vint nous trouver dans notre retraite du mont Langton. Elle m'annonça une nouvelle qui fit battre mon cœur bien vite. Mon père était aux Bermudes ! Il venait de débarquer d'un vaisseau arrivant de Québec.

On conçoit mon émotion. Madame X... m'offre une place dans sa voiture. Nous nous rendons en toute hâte à Hamilton. À peine y sommes-nous entrés que j'aperçois celui que je cherche. Oui, le voilà mon bon, mon excellent père. Je reconnais au loin sa démarche, puis son beau et noble visage où se lit en ce moment une certaine pénible incertitude. Dans quel état trouvera-t-il son fils ?

Mes amis bermudiens l'ont entouré. Ils le conduisent vers la demeure de mes frères en exil. Je m'élance de la voiture et je me jette dans ses bras. Nous pleurions tous les deux, et nous n'étions pas les seuls à pleurer.

Mon père me donna les nouvelles les plus rassurantes sur ma mère et sur toute la famille. Il ne put séjourner que quelques jours aux Bermudes, mais il en partit le cœur allégé d'un grand poids, car il ne me trouva pas malheureux, si ce n'est à cause de ma séparation de tous les miens. Mes compagnons, qu'il traita comme s'ils eussent été ses propres enfants, l'entourèrent d'attentions et de soins incessants et cela resserra les liens qui nous unissaient déjà. Le gouverneur et les autorités le comblèrent de politesses. Il se rembarque pour le pays emportant des lettres et des souvenirs pour les familles de tous les exilés.

Notre tristesse à son départ eût été moins grande si nous avions su alors que notre exil était sur le point de prendre fin. Quelques jours après, nous recevions du gouverneur une lettre officielle nous rendant notre parole et nous annonçant que nous étions libres de gagner la côte de l'Amérique et même de retourner au Canada. En même temps, tous les journaux publièrent la proclamation du Parlement anglais abrogeant l'ordonnance nous condamnant à l'exil et le Bill of Indemnity relevant lord Durham et son conseil spécial des pénalités dont leur acte illégal les rendit passibles. C'était pour la population des Bermudes tout un événement et pour nous un véritable triomphe. Nos nombreux amis nous entourèrent et nous prodiguèrent leurs félicitations. Plusieurs personnages, que notre état d'exilés avaient tenus à distance vinrent noue faire visite.

Malgré toutes ces démonstrations qui nous touchèrent vivement, nous n'avions qu'une pensée, partir. Une goélette se trouvait en ce moment à l'ancre dans le port, en partance pour la Virginie. Nous nous abouchâmes avec le patron, M. Davis, lequel consentit à nous donner passage sur son navire. Nous nous embarquâmes le surlendemain, 3 novembre 1838, jour à jamais mémorable pour nous. Nous trouvâmes le pont encombré de colis de toutes espèces, de cadeaux de fruits et autres objets adressés aux exilés par nos amis des îles. 
Voici l'instant du départ. Une foule compacte se presse sur le quai. Blancs et noirs sont là réunis pour nous souhaiter bon voyage. Nous soulevons nos chapeaux, la foule lance des hourras formidables. La goélette hisse sa voile. Le docteur Masson s’avance et entonne ce qui est pour nous le chant du départ.

Nous reprenons tous le refrain, « nos amis sur la rive faisant de même, nous nous éloignons de cette terre hospitalière en y laissant l'écho de la douce chanson canadienne :

Lève ton pied, légère bergère, Lève ton pied légèrement. 


\section{CHAPITRE XIX ${ }^{1}$}

\section{QUELQUES DÉTAILS SUR LA CARRIÈRE SUBSÉQUENTE DE L'AUTEUR.}

\section{$\underline{\text { Retour à la table des matières }}$}

Le voyage de retour fut orageux. Les exilés débarquèrent pourtant sans accident sur les rives de la baie Chesapeake. Ils se rendirent à Washington, puis à New York, où la nouvelle leur parvint que le docteur Robert Nelson s'était mis à la tête d'un nouveau mouvement insurrectionnel au Canada.

Prévoyant les perturbations regrettables, les malheurs et l'effusion de sang qui devaient être les résultats inévitables d'une pareille tentative, ils en éprouvaient beaucoup de chagrin. La conduite de M. Robert Nelson était, du reste, absolument contraire à leur idée de revendication constitutionnelle ; elle allait mettre toute la population canadienne dans une position fausse et embarrassante, dont ses adversaires ne manqueraient pas de tirer parti. On pourrait désormais révoquer en doute leur sincérité lorsqu'ils déclareraient qu'en prenant les armes en 1837 ils n'avaient voulu que résister à une arrestation illégale et à la violation de la constitution. Le fait est que sans ce malheureux incident, on eût compris bien mieux et bien plus tôt, en Angleterre, la véritable situation au Canada.

Cette échauffourée leur interdisant pour le moment l'entrée dans leur pays, ils écrivirent à leurs amis pour les mettre en garde. Ils ne rentrèrent eux-mêmes que plus tard, et alors Bouchette se rangea sous la bannière de La Fontaine et de Baldwin qui avaient su continuer et mener à bien l'œuvre de l'émancipation constitutionnelle du Canada.

\footnotetext{
Rédaction de M. Errol Bouchette.
} 
Aussi est-ce ici que s'arrêtent, à proprement parler, les Mémoires. Les cahiers qui suivent offrent sans doute beaucoup d'intérêt pour la famille de leur auteur. Quelques-uns, surtout ceux qui traitent de l'organisation du ministère des Douanes et de la représentation du Canada à l'exposition universelle de Paris, en 1867, sont des pièces que pourrait consulter avec profit l'auteur d'une histoire générale du Canada. Cependant, il a semblé à l'éditeur qu'il valait mieux dans le présent ouvrage, s'en tenir à l'important événement qui le remplit presque tout entier, sur lequel on a tant écrit et qui néanmoins, semble encore mal connu.

On a voulu offrir au lecteur une page d'histoire, non pas un registre de famille. Ceux qui s'intéressent aux deux ancêtres de l'auteur, en Canada, JeanBaptiste, le marin, et Joseph, le géographe, pourraient consulter, entre autres ouvrages, ceux des regrettés Douglas Brymner et Joseph Marmette, archivistes du Canada. Ces écrivains ont, pièces en mains, rendu hommage à la science, aux services, à la modestie et au désintéressement de ces deux illustres Canadiens. Les amateurs de généalogie trouveront dans l'ouvrage de M. PierreGeorges Roy, de Lévis, la famille Taschereau, des détails sur les alliances de famille de M. Bouchette. Mais ses enfants, bien que fortement attachés à la famille de leur excellente et bien-aimée mère, famille qu'ils ont toujours, et avec raison, regardée comme leur seule famille, leurs parents du côté paternel étant dispersés, aux quatre coins du monde, estiment que ce sont là des choses d'intérêt privé qu'il ne faut pas infliger au public.

Bouchette, au physique, ressemblait à sa mère, Adélaïde Chaboillez, dont il nous a tracé le portrait dans les Mémoires. Il était de taille élevée et dans sa jeunesse, il excellait dans les exercices qui requièrent la force ou d'adresse. D'un caractère très vif et très sensible, charitable et généreux à l'excès il était aimé de tous ceux qui le connaissaient. Au ministère des Douanes, il a laissé le souvenir non seulement d'un administrateur hors ligne, mais parmi ses subordonnés, d'un ami et d'un père, ainsi que pourront l'attester tous les fonctionnaires de son temps qui vivent encore. Jusqu'à la fin, il fut un travailleur infatigable, aimant et servant son pays, apprenant à ses enfants à l'aimer et à le servir, à son exemple. Il a laissé, outre les Mémoires, une foule d'écrits en vers et en prose, qui n'ont pas encore été recueillis, et une œuvre administrative, l'organisation du ministère dont notre pays tire encore aujourd'hui le plus clair de ses revenus. Une telle organisation n'était pas facile à créer dans un pays aussi vaste et aussi peu peuplé que le nôtre.

Comme Ruskin, et avant lui, il s'était voué au culte du beau. Il fut très malheureux dans sa prison de Montréal jusqu'à ce qu'il l'eût embellie au moyen de son pinceau. La politesse, disait-il, n'est que la charité dans les petites choses. Aussi a-t-il laissé le souvenir d'un homme du monde aimable et courtois. Savoir dégager la joie et la gaieté des moindres incidents de la vie ! 
Pour faire cela il faut être bon et il faut une âme d'artiste. Soulignons d'un petit incident ce trait saillant de son caractère.

C'était en 1870, par un beau soir d'été. Plusieurs personnes étaient réunies sur la véranda de la maison de Bouchette, rue Daly, à Ottawa. Cette véranda donnait sur une pelouse qui s'étendait en arrière de la maison jusqu'à la rue suivante. Bouchette, s'accompagnant sur la guitare, chantait la romance napolitaine Santa Lucia alors peu connue au Canada. Madame Bouchette, madame Lemoine et plusieurs autres dames unissaient leurs voix à la sienne. Tout à coup, on entend au dehors comme un écho de la mélodie. Chacun prête l'oreille, mais Bouchette continue son chant et la musique invisible le suit et l'accompagne. La romance terminée, dames et messieurs s'élancent vers l'endroit d'où était venu ce mystérieux accompagnement. Ils trouvent trois musiciens ambulants qui se sont arrêtés pour écouter ces accents qui leur rappellent leur beau pays. Bouchette leur parle dans leur langue, les ramène avec lui et organise sur-le-champ un concert inoubliable. C'est ce soir-là que celui qui écrit ces lignes entendit pour la première fois l'opéra du Trouvère rendu impromptu par Bouchette, par madame Robert Lemoine et par ces trois pauvres Italiens. Jamais depuis les accents des plus grands maîtres ne lui ont causé une pareille impression.

Bouchette aimait à rappeler les grandes choses accomplies par nos compatriotes et il devenait enthousiaste en démontrant l'importance des résultats obtenus. Ses idées sur ce point n'étant pas sans intérêt, nous y consacrerons notre dernier chapitre. 


\section{CHAPITRE XX}

\section{LE GOUVERNEMENT RESPONSABLE EST L'EUVRE DES CANADIENS.}

$\underline{\text { Retour à la table des matières }}$

Pour bien comprendre, pensait-il, l'œuvre accomplie par nos compatriotes, il faut tout d'abord se pénétrer des problèmes sociaux qui attendaient ou qui attendent encore leur solution au nouveau monde. Au XVIII ${ }^{\mathrm{e}}$ siècle, un souffle irrésistible de liberté semblait passer sur le vaste continent américain, et chaque peuple civilisé qui s'y était implanté, pour en prendre sa part, n'avait qu'à respirer l'air ambiant, Un seul peuple, le peuple canadien, eut à surmonter de très grandes difficultés.

Le problème, relativement simple pour les Anglo-Saxons des États-Unis et pour les Espagnols et les Portugais du sud, devenait complexe pour les Français du nord. Ceux-ci en effet, au même titre que leurs nouveaux compatriotes; de langue anglaise, voulaient ardemment la liberté sociale et politique, mais sans abdiquer le génie national. Une centaine de mille cultivateurs, sans chefs et sans ressources, s'étaient posés en face des millions d'hommes de race étrangère qui les entouraient et avaient dit: Nous conserverons notre individualité française et nous deviendrons libres, et cela sans renoncer à l'allégeance britannique que nous avons franchement acceptée. C'est à cette pensée, qui semblerait utopique si nous n'en voyions pas la réalisation, que l'Angleterre doit d'être encore la suzeraine de la moitié du sol d'Amérique; c'est d'elle que naquit l'admirable système d'administration impériale qui fait présentement la gloire et la puissance de la Grande-Bretagne comme celle du Canada.

Sans doute, l'on ne voit au début que l'instinct de conservation d'un peuple désorganisé et décapité. Mais de ses résistances il se dégage bientôt une pensée plus distincte et plus grande, lorsqu'il surgit de la masse populaire des chefs capables de se faire ses interprètes. 
Cet admirable système de l'autonomie coloniale est peut-être la conception la plus grande qu'un peuple ainsi situé ait jamais imposée. Elle n'est pas l'œuvre d'un chef isolé, ni d'un parti. En lisant l'histoire de nos cinquante premières années de luttes constitutionnelles, on est frappé du calme plein de puissance de l'électorat canadien, qui, de parlement en parlement, change ses représentants chaque fois que ceux-ci s'écartent de la voie à suivre. Intelligence remarquable du devoir public, où l'on peut voir la synthèse de la pensée de tout un peuple résolu à vivre sans abdiquer et trouvant dans l'excès de son patriotisme un remède à ses maux.

La plupart des peuples conquis se sont docilement pliés sous le joug et ont fini par s'assimiler à leurs vainqueurs. D'autres se sont usés en colères inutiles et désintégrantes. Chez nous, rien de semblable. Très peu de haines, de préjugés ou de tristesses. Les Canadiens n'ont pas de Jérémie. Gais et confiants, comme tous les peuples sains, ils respectent les lois et l'ordre établi, tout en continuant la revendication constante, calculée, irrésistible : donneznous la liberté et cette liberté deviendra la base de la grandeur de votre empire. Jamais la Grèce conquise ne sut tenir un pareil langage à son vainqueur.

Ce langage nouveau causait à la Grande-Bretagne un étonnement dont on peut aujourd'hui difficilement se faire une idée. Elle ne comprenait pas du tout. La conservatrice Angleterre concevait à la vérité qu'un peuple pût se révolter, mais nullement que ce peuple osât lui indiquer sa règle de conduite. Encore moins pouvait-elle croire qu'au lendemain de Waterloo, on pût songer à mettre de côté la vieille idée de gouvernement par la caste. Pendant vingt ans, la lutte entre la caste et la révolution avait ensanglanté l'Europe. La caste semblait triomphante. Ce triomphe, une certaine partie du public anglais le regardait comme le sien. C'était pour elle la consécration du principe aristocratique; aussi s'était-on hâté d'établir partout, dans les domaines coloniaux de la Grande-Bretagne, de petites aristocraties à l'image de la grande.

Et voilà que la démocratie qu'on croyait morte montrait de nouveau sa tête. Comment expliquer, cela ? On avait oublié ce mot d'un des grands hommes d'Angleterre : «L'esprit libre d'un peuple libre ne peut jamais périr et ne saurait être conquis ».

Même de nos jours, chose singulière, il est des historiens qui semblent ne pas encore comprendre cette époque sur laquelle on à pourtant tant écrit. Ils relatent tant bien que mal les batailles et les changements de ministère, qui sont souvent la moindre partie de l'histoire, en les accompagnant de commentaires qui n'expliquent nullement la corrélation entre les événements et les idées. C'est ainsi que M. Castell Hopkins, un écrivain de bonne foi, sans doute, écrit comme suit sur cette période : «L'exclusivisme de la minorité anglaise, avait bien sa contrepartie dans celle de la majorité française, et toute la généreuse hospitalité et la bonne volonté évidente des gouverneurs successifs ne purent 
amener les deux races ensemble. À maintes reprises le gouvernement proposa que les juges fussent rendus indépendants de la politique et exclus des sièges du Conseil, mais la mesure se brisa toujours sur le roc de la demande rivale de l'Assemblée, qui voulait contrôler le paiement et le montant de leurs traitements, et, par conséquent, contrôler réellement les nominations à la magistrature... À partir de ce moment que pouvait faire le malheureux gouverneur? Il ne pouvait donner le contrôle de toutes les finances à l'Assemblée sans établir un ministère responsable à ce corps, et le gouvernement anglais ne pouvait concéder cela, vu que par là même il aurait livré le pouvoir absolu dans la province à une majorité française qui se montrait de jour en jour plus agressive et plus anti-britannique. Et pour expliquer que cette attitude qu'il qualifie d'anti-britannique, bien qu'elle fût de l'essence même de toute constitution britannique, était le fait des politiciens et non pas du peuple, il affirme que le Canadien-Français fut pendant plusieurs années réellement incapable de comprendre, la signification d'une assemblée élective. Lorsqu'il la comprit, ajoute-t-il, les résultats ne furent pas précisément bienfaisants.

Voilà tout ce que lui dit à lui, ainsi qu'à un assez grand nombre d'écrivains, cette grande revendication politique qui, croyons-nous sincèrement, est sans exemple dans l'histoire. Il est vrai que les Canadiens étaient bien coupables. Ils ne tenaient pas compte de la bonne volonté évidente de nos gouverneurs, laquelle se traduisait en défiance ouverte, ni de leur généreuse hospitalité qui conviait les représentants du peuple à des repas et à des bals. Ne rien accepter de tout cela, ne vouloir que le gouvernement responsable dans sa plénitude et le vouloir si résolument qu'on finit par l'obtenir, quelle ingratitude ! Que cela était peu digne d'un peuple gentilhomme !

Au temps dont nous parlons, on n'avait pas écrit les lignes qu'on vient de lire, mais c'était alors comme aujourd'hui la thèse favorite de beaucoup de gens que les anciens Canadiens ne comprenaient pas les institutions représentatives et qu'ils ignoraient ce que pouvait être le gouvernement responsable. Leur agitation était vague et sans but, répétait-on volontiers. Le gouvernement responsable colonial n'est qu'un accident. Le hasard voulut que l'idée en fût exprimée dans un rapport officiel.

Ce n'est pas ainsi que les grandes idées prennent naissance. Elles sont une œuvre lente. Elles se dégagent d'une succession d'événements. Elles sont une résultante dont la philosophie de l'histoire sait trouver la genèse au sein même du groupe humain qui en doit profiter. Aussi des faits incontestés parleront-ils plus haut que toutes les théories contraires.

Analysons ces faits. 
Que voulaient les Canadiens? La liberté politique d'abord; puis la conservation de leur langue, de leurs institutions et de leurs lois.

Pour maintenir celles-ci, ils refusèrent l'union avec les États-Unis. Mais ils voulurent conquérir, sur ce sol qui était leur unique patrie, une indépendance relative et suffisante pour permettre à la nation de se développer. C'est à quoi ils s'appliquèrent résolument durant cinquante années. Il y eut au début certains tâtonnements, nous l'avons vu, mais le peuple tenait le fil de ce labyrinthe et il ne l'abandonna pas. Il comprit que pour ce qu'il voulait faire il ne s'agissait pas de bouder, mais d'accepter franchement la situation, non pas avec feintes protestations et une humiliante sentimentalité, mais en s'affirmant dans l'esprit pratique de gens qui se sont associés pour mener à bien une importante affaire, non pas par la force mais par la persuasion. Ainsi guidés ils s'avancèrent avec de plus en plus d'assurance jusqu'à ce qu'enfin ils réussirent à créer une impasse où le gouvernement responsable s'offrait comme la seule issue. De ce long effort, dont 1837 n'est que l'explosion d'impatience finale, se dégage ce principe actif: gouvernement responsable colonial, système dont les Canadiens, nous le répétons, sont les inventeurs ${ }^{1}$.

Ces mots, "gouvernement responsable colonial » étaient nouveaux; la chose qu'ils représentent était inconnue dans l'empire britannique. Celui qui à cette époque eût parlé d'un empire formé du groupement de grandes nations autonomes, eût passé pour ridicule. On ne soupçonnait pas même la possibilité de donner une telle extension au système constitutionnel anglais. Ce qui advint dans les treize colonies le prouve au delà de tout doute. Si on avait connu ce remède si simple et si efficace, on l'aurait appliqué. Ces colonies n'étaient pas ennemies de la métropole. Elles avaient jadis déployé un zèle extraordinaire contre la Nouvelle-France, elles comptaient dans leur sein des loyalistes tellement ardents qu'un grand nombre préférèrent abandonner leur pays et leurs biens plutôt que de vivre sous un nouveau drapeau. On trouve la trace de ce regret même chez les chefs de l'insurrection américaine ${ }^{2}$. Ils auraient accueilli avec enthousiasme le don du gouvernement responsable. Cela eût rendu la révolution américaine impossible. Mais ce remède, n'était pas inventé encore, et le ministre des colonies, tâtonnant dans la cécité des vieilles idées, laissa perdre par impuissance un vaste empire à son pays.

Ici un nom se trouvera sur toutes les lèvres, celui de Robert Baldwin, surnommé le père du gouvernement responsable dans le Haut-Canada. Il soutint dans sa province et avec le plus noble courage l'idée mère qui depuis longtemps animait la lutte politique dans le BasCanada.

2 Il est remarquable que les résolutions adoptées par les législatures des treize colonies furent souvent presque la contre-partie de celles de la législature canadienne. On se serait contenté là aussi du self-government. "Nous avons pétitionné, s'écrie Patrick Henry, protesté et supplié, nous nous sommes prosternée au pied du trône pour que le roi mette fin aux mesures tyranniques de son ministère ». 
Ce ne fut qu'en 1839 qu'on commença de songer à gouverner les colonies suivant le système autonome. Voici comment cela advint. Lord John Russell, revenant à la vérité après avoir donné dans les plus graves égarements, en inaugura le principe par une loi à laquelle il donna plus de force au moyen d'instructions spéciales envoyées à ses gouverneurs ; il avait puisé ce principe dans le rapport de lord Durham. Lord Durham l'avait recueilli de la bouche des hommes d'État canadiens. Un instant de réflexion prouvera qu'il n'aurait pu le prendre ailleurs. Lord Durham était un homme aux théories libérales, mais son rapport pèche sur presque tous les points, hors celui qui nous occupe. Ou donc aurait-il puisé une idée si hardie, et qui cadre si peu avec les autres parties de son travail, si ce n'est dans le seul pays auquel cette idée pouvait alors vraiment profiter? Nous verrons tout à l'heure une preuve frappante de ce dernier avancé. Les individus, même les plus grands, et lord Durham, malgré les qualités qu'on doit lui reconnaître, n'était pas de ces derniers, n’ont pas de ces intuitions-là. Ce sont des semences qui germent au sein des peuples qu'une pensée forte et fixe pousse irrésistiblement de l'avant.

En niant à lord Durham la gloire d'avoir imaginé le système du gouvernement responsable colonial, nous devons lui, concéder une part importante de mérite. Il transcrivit dans un document officiel la revendication de nos compatriotes. Malheureusement pour lui, il gâta sa solution. Il conseilla à son gouvernement d'admettre le principe politique réclamé par les hommes publics canadiens, mais il voulut qu'on s'en servît pour annuler ceux qui l'avaient inventé.

«C'est en Canada, dit Todd que cette grande mesure de réforme administrative coloniale fut d'abord introduite... L'insurrection, en Canada, ayant été reprimée par la force,... le comte Durham fut nommé gouverneur général et haut-commissaire pour s'enquérir des affaires de l'Amérique Britannique du Nord. En 1839, l'année d'après sa nomination, lord Durham présenta à la reine un rapport élaboré sur le résultat de ses recherches. Dans ce rapport, Sa Seigneurie indiquait comme panacée aux plaintes politiques existantes, l'introduction dans les colonies britanniques nord-américaines du principe de self-government local... M. Poulett Thompson (lord Sydenham) fut envoyé au Canada en l'automne de 1839 en qualité de gouverneur général ; il avait instruction de mettre en pratique les recommandations de lord Durham ».

Ces recommandations de lord Durham, que pouvaient-elles être sinon l'écho des aspirations du pays qu'il venait de quitter ? Il y avait trouvé, il le dit lui-même, une lutte de races. Il ne paraît pas s’être aperçu que si une telle lutte existait, elle se compliquait d'une lutte de castes. Il crut comprendre que les colonistes de race anglaise demandaient qu'on dénationalisât les CanadiensFrançais. Il crut se rendre à leur vœu en proposant l'union législative des provinces. Les Canadiens-Français demandaient pour l'Assemblée législative le contrôle des fonds publics, des fonctionnaires et la direction de la politique 
générale du pays, c'est-à-dire le self-government. Il recommanda donc le selfgovernment. Seulement, un point important lui avait échappé. Ce n'était pas la population de langue anglaise qui demandait la disparition des CanadiensFrançais, mais bien la caste dirigeante qui s'était cantonnée au Conseil législatif, qui s'opposait à toutes les mesures libérales, sous prétexte qu'on ne devait pas se fier aux gens du Bas-Canada. De sorte que lors de l'établissement du nouvel ordre de choses, le peuple des deux provinces se servit de la recommandation juste de lord Durham, c'est-à-dire du gouvernement responsable, pour neutraliser l'effet de la recommandation inconsidérée qui y était annexée ${ }^{1}$.

Le peuple des deux Canadas, dès la promulgation de la nouvelle loi, voulut affirmer sa victoire, en déclarant officiellement que le représentant du souverain ne pourrait désormais gouverner qu'avec l'assistance et d'après l'avis de ceux qui formeraient l'administration provinciale, laquelle devrait posséder la confiance de la majorité des représentants du peuple.

Cette proposition que le gouvernement responsable colonial tel qu'il existe maintenant dans presque toute l'étendue de l'empire est l'œuvre des Canadiens ne saurait donc être mise en doute, à la lumière des faits incontestés de l'histoire.

Si nous voulions citer des faits à l'appui, en dehors de ceux qui ont été signalés par les historiens et qui constituent déjà des preuves irrécusables, ces faits ne nous manqueraient pas. Songeons seulement que le système autonome fonctionnait déjà depuis seize ans au Canada avant qu'on songeât à l'appliquer aux autres colonies! Les provinces maritimes, qui ne faisaient pas alors partie du Canada, ne l'obtinrent qu'en 1848, l'Australie qu'en 1855, le Cap qu'en 1872. Les autorités le décrétèrent d'abord avec un regret qui se conçoit, car elles abandonnaient par là beaucoup d'autorité immédiate, surtout le droit de percevoir des impôts. Les gouverneurs s'y soumirent avec plus de regrets encore, car leur rôle leur parut fort réduit. Faisons remarquer, cependant, qu'il n'en est pas réellement ainsi et que la position de premier magistrat d'un pays constitutionnel n'a rien de pénible. Bien au contraire, si ce magistrat est un homme considérable et s'il comprend bien sa position et son rôle, son influence sera très importante sans qu'il outrepasse en quoi que ce soit ses attributions.

Circonstance plus remarquable encore, les colonies britanniques auxquelles l'on donna le gouvernement responsable ne surent pas toujours s'en servir. L'instabilité sinon la mauvaise administration fut la règle presque partout. De 1856 à 1877, la Tasmanie eut douze ministères, la Nouvelle-Galles-du-Sud

1 Dans cette analyse des recommandations de lord Durham, il n'est question, bien entendu, que du politique. L'homme était courtois et humain. Il était personnellement respecté en Canada. 
dix-sept, Victoria dix-huit, l'Australie Méridionale vingt-neuf, un par neuf mois. On sait le fiasco du Cap. Quant aux Antilles, on leur avait d'abord donné le gouvernement responsable, mais les peuples ne surent pas s'en servir, et l'on dut le leur retirer à leur propre demande. L'on sait aussi que tout récemment il a été question de faire retourner Terre-Neuve à l'état de crown colony ; peu s'en est fallu que le même sort n’atteignît le Cap.

Enfin c'est au Canada seulement que le système a fonctionné dans des conditions satisfaisantes. Les ministères s’y sont succédé à des intervalles réguliers. Chaque chef de cabinet a eu le temps d'élaborer son programme et de développer ses idées de réforme devant un peuple sage, probe, qui connaît ses besoins et qui est décidé à faire respecter ses droits. L'autonomie coloniale est un système excellent qui nous a donné la liberté. Mais pour s'en servir utilement, il faut aimer sa patrie et aimer la liberté ; ne pas regarder la terre qui nous nourrit comme une mine à exploiter, et qu'on abandonnera ensuite, fortune faite.

Ainsi l'idée du gouvernement autonome ne pouvait venir des Antilles qui n'en voulurent pas, ni de l'Australie ni du Cap qui ne surent pas tout d'abord s'en servir, ni des gouverneurs, ni du ministère des colonies qui l'appliquaient avec l'hésitation que comporte une expérience en matière de gouvernement, mais des seuls Canadiens qui en avaient un besoin urgent, qui en firent la base de leur système et qui en usèrent avec une sagesse rare et qu'on admire en tout lieu.

Et c'est ainsi que 60,000 cultivateurs, entourés d'une innombrable population différente, conquirent la liberté constitutionnelle et le respect de leurs voisins. Ils firent plus. Les hommes d'État de la Grande-Bretagne puisèrent, à leur contact des idées qui font aujourd'hui la stabilité et la gloire d'un empire plus vaste que l'empire romain et qui se maintiendra aussi longtemps que ce principe fondamental sera respecté. 